\title{
CREATING A GUIDE AND CONTROLLED VOCABULARY FOR CATALOGUING PHOTOGRAPHIC JEWELLERY
}

\author{
by \\ Andrea Beiko \\ B.A. (Honours), University of Toronto, 2010 \\ OCAD, Sheridan College Institute of Technology and Advanced Learning, 2010 \\ A thesis presented to \\ Ryerson University and George Eastman House, \\ International Museum of Photography and Film \\ in partial fulfillment of the \\ requirements for the degree of \\ Master of Arts \\ in the program of \\ Photographic Preservation and Collections Management
}

Toronto, Ontario, Canada, 2013

(C) Andrea Beiko 2013 
I hereby declare that I am the sole author of this thesis. This is a true copy of the thesis, including any required final revisions, as accepted by my examiners.

\title{
Andrea Beiko
}

I authorize Ryerson University to lend this thesis to other institutions or individuals for the purpose of scholarly research.

\section{Andrea Beiko}

I further authorize Ryerson University to reproduce this thesis by photocopying or by other means, in total or in part, at the request of other institutions or individuals for the purpose of scholarly research.

\section{Andrea Beiko}

I understand that my thesis may be made electronically available to the public.

\author{
Andrea Beiko
}




\section{CREATING A GUIDE AND CONTROLLED VOCABULARY FOR CATALOGUING PHOTOGRAPHIC JEWELLERY}

Master of Arts, 2013

Andrea Julie Beiko

Photographic Preservation and Collections Management

Ryerson University in conjunction with the Art Gallery of Ontario, and George Eastman House, International Museum of Photography and Film.

This thesis is a practical project which consists of a guide and controlled vocabulary for cataloguing photographic jewellery. Although photographic jewellery has been around for over a century, there currently is no standard guide or controlled vocabulary with which to catalogue such items.

Twenty-one institutions and private collectors were contacted in regards to their current cataloguing structure. Using their information, alongside museum registration methods and pre-existing regulations, a guide and vocabulary list has been created and can be implemented on current and future photographic jewellery collections.

The accompanying essay takes into account the history, uses, and preservation concerns of photographic jewellery. The research, observations, and conclusions are derived from the collection within the Art Gallery of Ontario, the publications listed within the Literature Survey, and from numerous research sources in order to provide a resource for those interested in the subject of photographic jewellery, and the necessity of cataloguing them. 


\section{ACKNOWLEDGEMENTS}

I am grateful to the faculty and staff of Ryerson University, Art Gallery of Ontario, and the other institutions and collectors referenced within this thesis, for their help and support. I offer my sincerest thanks to my first reader, Maia-Mari Sutnik, who patiently and meticulously read many drafts of this paper and for her invaluable knowledge on photographic jewellery she shared throughout the process. I would also like to thank David Harris who helped guide all the students in the right direction regarding their theses. Liana Radvak and Alison Skyrme who both graciously guided me through the creation of the cataloguing guide, and to Larry West whose book Antique Photographic Jewellery: Tokens of Appreciation and Regard was an invaluable source of information for my thesis process and research.

I am ever so lucky to be surrounded with a wonderful group of classmates who brought any and all related material to my attention, and for their endless suggestions and input. 
This thesis is dedicated to Alison Beiko who taught the importance of jewellery to me at a very young age. Without her continued love and support, I would have never been able to complete this thesis project. 


\section{CONTENTS}

INTRODUCTION ........................................................ 1 - 3

LITERATURE SURVEY ............................................. 4 - 8

BRIEF HISTORY OF PHOTOGRAPHIC JEWELLERY ................. 9 - 14

PHOTOGRAPHIC JEWELLERY PROCESSES \& MATERIALS ......... 15 - 19

METHODOLOGY .................................................... 20 - 26

CURRENT ART GALLERY OF ONTARIO PHOTOGRAPHIC

JEWELLERY COLLECTION ............................................ 27 - 36

INTRODUCTION TO CATALOGUING GUIDE \& CONTROLLED VOCABULARY ..................................... 37 - 38

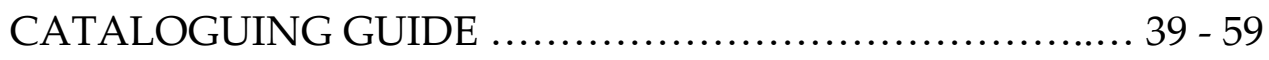

CONTROLLED VOCABULARY ............................... 60 - 63

DEFINITONS .......................................... 64 - 72

FULL ART GALLERY OF ONTARIO PHOTOGRAPHIC

JEWELLERY CATALOGUE .......................................... 73 - 82

CONCLUSION .................................................. 83 - 84

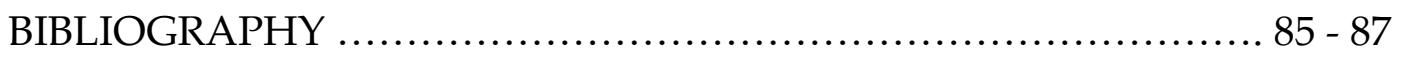

ILLUSTRATION CREDITS .......................................... 88 


\section{LIST OF ILLUSTRATIONS}

FIGURE 1 ..................................Page 3

One-of-a-kind pin of woven hair, with a daguerreotype of a female Grecian statue

Unknown Photographer; c. 1850

Double-oval pin back; $1^{3 / 8}$ by $1^{7 / 8}$ inches

Larry West Collection

Courtesy of Larry West

FIGURE 2 Page 11

Pin of soldier wearing military sash, rank stripes, and belt buckle, large curly locks, and reverse with basket weave hair. Twisted wire border of pinchbeck, with grape leaves.

Unknown Photographer; late 1860s

Tintype; 3 by $2 \frac{1 / 2}{2}$ inches

Larry West Collection

Courtesy of Larry West

FIGURE 3 ...............................Page 12

Dorrett \& Martin, Electric Photo Works, Advertisement

The British Journal: Photographic Almanac (1910): 393

FIGURE 4 .Page 13

Brady's Gallery of Daguerreotype

Circa 1849; original size $8 \frac{1}{2}$ by 5 inches

Source: From Larry West's Antique Photographic Jewelry: Tokens of Affection and Regard

FIGURE 5 Page 14

Keywind, with gold chain and one image of a baby girl with curls in a plaid dress and chair, another of a young boy, with curls, engraved exteriors.

Unknown Photographer; c. 1852

Daguerreotypes; each $1^{7 / 8}$ by ${ }^{13 / 16}$ inches

Larry West Collection

Courtesy of Larry West

FIGURE 6 Page 16

Rare double portraits of two young children, watch locket, one daguerreotype of them, fully tinted, and one albumen print of them a few years later (wearing necklaces), engraved on reverse with figure and grapes in vintage case. 
Unknown Photographer; c. 1865

Daguerreotype and albumen print; 2 inches in diameter

Larry West Collection

Courtesy of Larry West

FIGURE 7 ................................Page 17

Watch case locket with two images, disassembled.

Watch case; $1845-55$

Photograph taken by Grant Romer

Courtesy of Grant Romer and Larry West

FIGURE 8 .Page 18

Man's fob with engraved oval mounting and triple wire twist, agate cover.

Unknown Photographer; c. 1850

Daguerreotype; $1 \frac{1}{4}$ by $3 / 4$ inches

Larry West Collection

Courtesy of Larry West

FIGURE 9 Page 21

List of Institutions Contacted with Institution Inquiry Letter (Figure 11)

Chart assembled March 2013

FIGURE 10 Page 23

Metropolitan Museum of Art, New York; Online catalogue ;

Accession number 2005.100.78

Retrieved online on February 22 2013

FIGURE 11 Page 24

Heinch Exhibition Guide; Provided by Historic New England Collections and Conservation Center.

Retrieved via email on February 20 2013

FIGURE 12 .Page 26

Institution Inquiry Letter sent to institutions listed in Figure 8 Letter written and delivered January $29^{\text {th }} 2013$

FIGURE 13 Page 27

Screen capture of TMS object record 2004/154 as of March 2013 (prior to recataloguing) Art Gallery of Ontario Collection 
Screen capture taken March $10^{\text {th }} 2013$

FIGURE 14a

FIGURE $14 b$

FIGURE 14c Page 28

Locket: Portrait of a Woman; Portrait of a Woman with Collar; c. 1860

Silver Locket with Daguerreotype (left), Ambrotype (right); $4.5 \mathrm{~cm}$ by $4.5 \mathrm{~cm}$

Art Gallery of Ontario Collection

2001/170

FIGURE 15a

FIGURE $15 b$

FIGURE 15c .............................Page 29

Locket: Portrait of an Elderly Man; Portrait of an Elderly Woman; c. 1860

Silver plated locket with two daguerreotypes; $4.5 \mathrm{~cm}$ by $4.5 \mathrm{~cm}$

Art Gallery of Ontario Collection

2001/171

FIGURE 16a

FIGURE $16 b$

FIGURE 16c .............................Page 30

Locket: Portrait of Man with Mustache; c. 1900

Round metal case with bromide toned print and encased hair; $4.7 \mathrm{~cm}$ by $4.7 \mathrm{~cm}$ Art Gallery of Ontario Collection

2001/172

FIGURE 17a

FIGURE $17 \mathrm{~b}$

FIGURE 17c Page 31

Locket: Woman wearing white bonnet; c. 1850

Gold plated locket with daguerreotype with applied colour; $3.6 \mathrm{~cm}$ by $3.6 \mathrm{~cm}$ Art Gallery of Ontario Collection

2002/9421

FIGURE 18a

FIGURE $18 b$.............................Page 32

Portrait; Young man (top), Portrait: Boy wearing a ribbon (bottom); c. 1870

Gold plated locket with tintype; $3.3 \mathrm{~cm}$ by $3.3 \mathrm{~cm}$

Art Gallery of Ontario Collection 
$2002 / 9422$

FIGURE 19a

FIGURE $19 b$

FIGURE 19c

Page 33

Pocket watch with portrait of baby; on clock face; Portrait of Woman wearing glasses (interior of clock); c. 1892

Photographic transfer on enamel, gold electroplated; $6 \mathrm{~cm}$ by $5 \mathrm{~cm}$

Art Gallery of Ontario Collection

2004/146

FIGURE 20a

FIGURE 20b

FIGURE 20c Page 34

Pocket watch with portrait of young man on clock face; c. 1910

Photographic image on enamel; $4.5 \mathrm{~cm}$ by $3.4 \mathrm{~cm}$

Art Gallery of Ontario Collection

2004/147

FIGURE 21a

FIGURE $21 b$ Page 35

Pin; Portrait of a man with muttonchops; c. 1900

Brass setting with red stones with carbon celluloid on metal; $2.4 \mathrm{~cm}$ by $2.4 \mathrm{~cm}$

Art Gallery of Ontario Collection

2004/154

FIGURE 22a

FIGURE 22b .............................Page 36

Pin; Double portrait of man and woman; c. 1890

Gold plated pin with clover-leaf motif and bromide prints; $2.5 \mathrm{~cm}$ by $3.5 \mathrm{~cm}$

Art Gallery of Ontario Collection

2006/189

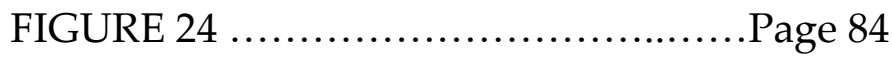

Bar pin, with two pendants containing albumen prints of a young girl with her doll, one with basket-weave hair and a cross on the back.

Unknown Photographer; c. 1865

Albumen Prints; $1^{3 / 8}$ by $1^{7 / 8}$ inches 


\section{INTRODUCTION}

This thesis is a practical project to create a cataloguing guide for photographic jewellery. Currently there is no standard guide or controlled vocabulary with which to catalogue such items. Descriptions of photographic jewellery appear without consistency and would deeply benefit from being catalogued in a standard form. Few publications have focused on these objects, thus making my research into the subject more challenging, but also essential. This essay discusses and analyzes the process of creating the cataloguing template guide and controlled vocabulary in relation to such challenges. Photographic jewellery ${ }^{1}$ is defined as a piece of jewellery containing elements of a photograph2. For the sake of this project, I am defining an object as photographic jewellery if it contains a photograph of any process affixed on or within the object, it can be worn decoratively or with purpose on the costume or body, and can be classified into the following categories: worn on or around the neck, arms and hands, legs and feet, head, or costume.

Although photographic jewellery can be made to acknowledge many different purposes - love, marriage, death, birth, or other personal milestones all pieces can typically fall into three larger categories: decorative, commemorative, and functional accessory.

The opportunity to work on this project came about while beginning my graduate internship at the Art Gallery of Ontario (AGO). I saw the Photographic Objects section within the vault and was immediately intrigued by the range of

\footnotetext{
${ }^{1}$ Throughout my research I noticed there is a wide range of spelling possibilities for the word 'jewellery'. For the sake of this essay, cataloguing guide and vocabulary list, I have chosen to use the Canadian spelling - jewellery.
} 
different one-of-a-kind, three-dimensional objects that lay within the meticulously organized boxes. After delving into this collection of objects, I was instantly drawn to the pieces of photographic jewellery. I made my interest in the material known, and after a discussion with curators Maia-Mari Sutnik and Sophie Hackett, both agreed that a standard way of cataloguing these items did not exist, but should. It was then that I proposed to create a guide for this thesis.

Although these objects have been around for over a century, their origins often uncertain, by observation one can determine they were mainly very personal and private items. They are often very beautiful pieces of jewellery or functional accessories, which had sentimental value and some, invested in monetary value as well. It is because of this that they have remained as heirlooms, remaining within the family for generations. It is only within the past decade or so that museums and galleries have acquired such objects and are now facing the dilemma of cataloguing and describing them.

Photographic jewellery collections within institutions appear to be few in numbers; thus not receiving priority attention to cataloguing completion. Many institutions include them within the Photography or Jewellery departments, and the cataloguing is executed similarly as other acquisitions within the department. These objects are treated by the departmental standards for cataloguing since no guidelines exist, specifically for photographic jewellery.

In my research I have found that very little has been written about photographic jewellery in publications and very few academic research papers devoted solely to the subject. With what has been written, the emphasis has been on their larger social aspects, functionality, and the photographic processes in terms of the manufacturing of photographic jewellery. The topic that did not 
surface within any publication was how to catalogue photographic jewellery; only reinforcing the need for standards within the cataloguing process.

While conducting research on the subject of photographic jewellery and working closely with the cataloguing system, The Museum System (TMS) at the AGO, I have created a cataloguing template guide and compiled a list of controlled vocabulary in order to rectify the absence of standards. The guide and vocabulary can be implemented to fully catalogue existing collections and serve future photographic jewellery acquisitions. Because the idea for this project originated while interning at the AGO, this paper also includes complete cataloguing records for the nine pieces within the institutions' collection implementing the complete guide and vocabulary.

This essay takes into account the history, uses, and preservation concerns of photographic jewellery in order to address cataloguing them within an institution. The research, observations, and conclusions are derived from the collection within the AGO, the publications listed within the Literature Survey, and from primary research sources from the nineteenth-century.
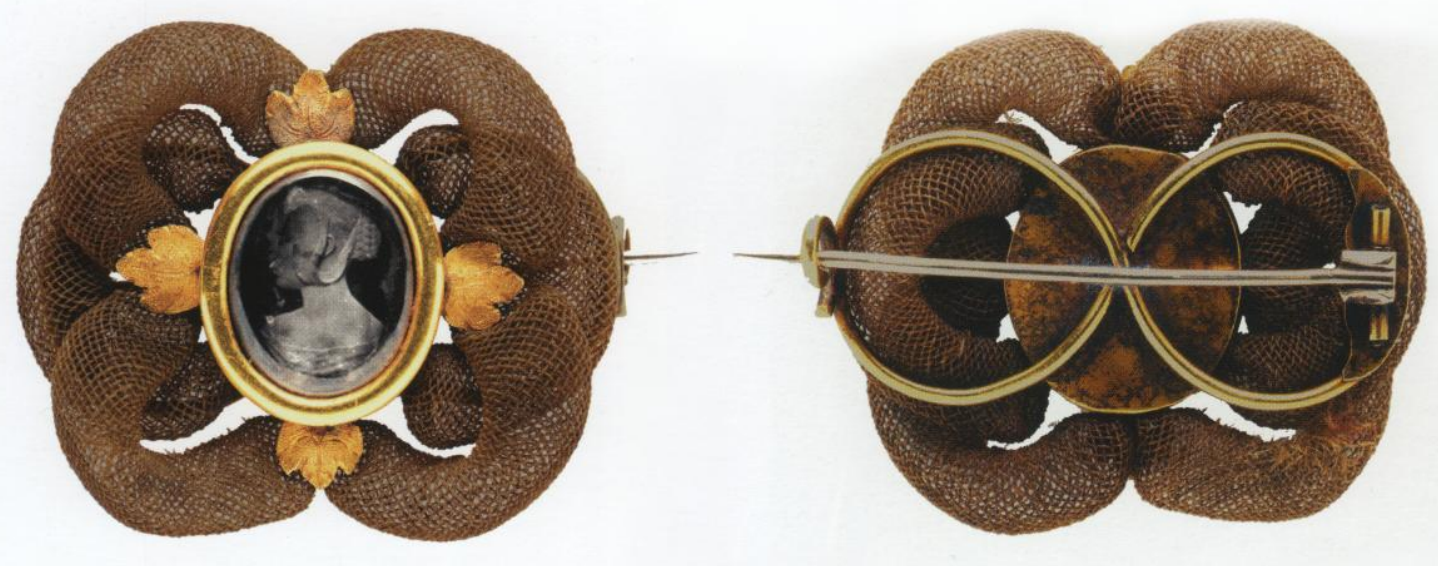

Figure 1 Source: Larry J. West's Antique Photographic Jewelry: Tokens of Affection and Regard, 2005 


\section{LITERATURE SURVEY}

Photographic jewellery has been overlooked in photographic literature and histories, especially when addressing ways with which to catalogue such items. The reason for their absence is that the histories of photography are typically fine art focused and photographic jewellery usually falls within a "collectable" or vernacular-based objects category. Elizabeth Edwards and Janice Hart's Photographs Objects Histories: On the Materiality of Images and Larry West and Patricia Abbot's Tokens of Affection and Regard are both valuable publications that discuss photographic jewellery as well as their place within the vernacular ${ }^{3}$ photography idiom.

Histories of photography are not the only historical surveys to neglect the topic; histories of jewellery similarly lack inclusions on photographic jewellery. Mention is only made in very short paragraphs, referencing the subject and providing a brief definition of the era and processes used. It becomes evident through research that photographic jewellery is a specialty field and not enough sufficient in-depth research has been conducted to be included in general history surveys. Therefore it is from authors such as Larry West and Geoffrey Batchen that we must look to for historical information.

Larry West has collected photographic jewellery since 1975. Since then he has dedicated his time to researching and writing about the topic. His book Antique Photographic Jewelry: Tokens of Appreciation and Regard was released in

\footnotetext{
${ }^{3}$ Vernacular photography refers to the creation of photographs, typically taken by unknown or amateur photographers who take studio portraits and everyday images that are common and familiar; vernacular photographs are usually seen as a cultural specialty.
} 
2005. This publication is the first known book devoted purely to photographic jewellery. Discussed in seven chapters, headings such as American and European Pieces and The Photo-Jewelry Industry provide the reader with detailed descriptions and captions of each piece reviewed. Along with providing a neverseen-before look at photographic jewellery, West's descriptive text proves very helpful for learning the purposes for such unique pieces of the nineteenth century.

Laura Curran's essay entitled Photographic Portrait Jewelry: Object, Memory, and Mourning focuses on the historical background and widens the discussion of photographic jewellery with its purpose made for mourning. Curran begins discussing, at great length, the effects the death of Prince Albert had on Queen Victoria in $1861^{4}$. The British not only wore jewellery to commemorate the late Prince, but for their loved ones as well. The demand for mourning jewellery accelerated in Britain due to the rising death rates in the nineteenth century.

Academic, Geoffrey Batchen, is one of the most well known authors on photographic jewellery. He has significantly contributed to the topic with an emphasis on the aspects of mourning photography, vernacular photography, and photographic objects. Batchen explores a wide range of photographic subjects in his publication entitled Each Wild Idea: Writing, Photography, History. Within the third chapter, "Vernacular Photographies", he discusses the idea of photographs as memories that differentiates it from fine art. Photographic jewellery is discussed in a paragraph and provides a fine introduction to those not familiar with the process or history. His other writings such as Ere the Substance Fade: Photography and Hair Jewellery go much more in depth and provide a more

4 Curran, Laura. Photographic Portrait Jewelry: Object, Memory, and Mourning. 2010 
detailed analysis of photographic jewellery.

Batchen wrote a book in 2006 dedicated to the use of photography for remembrance and mourning purposes. Batchen's book Forget Me Not:

Photography and Remembrance explores the unification of photography in context with paint, frames, text, embroidery, fabric, string, hair, flowers, bullets, cigar wrappers, butterfly wings, and jewellery to create often one-of-a-kind hybrid objects meant for the purpose of remembrance..$^{5}$ In the chapter "A Form of Perpetual Caress" he discusses the more unusual, uncommon forms of jewellery. For example, a locket that holds eight portraits - each pair of photographs in the locket expands outwards like the pages of an album ${ }^{6}$. His ideas are not exclusive to this chapter; he explores the topic in other writings. ${ }^{7}$

Batchen's essay “Ere the Substance Fade: Photography and Hair Jewellery" is the essay that should be read closely, found in Elizabeth Edwards and Janice Hart's book Photograph Object Histories: On the Materiality of Images. Here, Batchen provides a strong case that vernacular objects such as a photographic locket deserve attention in the larger history of photography. Batchen brings a larger understanding to added elements of jewellery, such as hair, and the ideas of double indexicality. Eleven other essays written by a diverse group of individuals in Edwards and Hart's book each explore the idea that while photographs are images, they are also objects, and this materiality is

\footnotetext{
5 Batchen, Geoffrey. Forget Me Not: Photography and Remembrance. New York: Princeton Architectural Press, 2006.

6 Batchen, Geoffrey. Forget Me Not: Photography and Remembrance. New York: Princeton Architectural Press, 2006.

7 Each Wild Idea: Writing, Photography, History and "Ere the substance Fade: Photography and Hair Jewellery".
} 
integral to their meaning and use. ${ }^{8}$

A handful of essays, research papers, and short chapters that mention photographic jewellery exist ${ }^{9}$; although brief, they are helpful in giving the reader a historical understanding. These writings typically address the rise in popularity in photographic and artistic jewellery and their different purposes. In the chapter "Like a Bird Before a Snake: The Miniature and the Photograph" in Robin Frank's Love and Loss: American Portrait and Mourning Miniatures, Frank discusses miniature art and photographic jewellery. This chapter illustrates how a few Daguerreotypists of the time introduced photography to memorial jewellery.

While photographic jewellery has not been fully explored in scholarly works in the past, their recent inclusion in some publications demonstrates that they are objects relating to photography and visual culture that scholars are perhaps, finally beginning to consider in depth. Although more is being written on social and cultural meaning, it still remains that there is no attention to description elements or cataloguing. The only useful publications in regards to cataloguing are textbooks and registration method guides. Often referred to as "the bible of the museum registrar", Museum Registration Methods $5^{\text {th }}$ Edition edited by Rebecca A. Buck includes extremely detailed information on museum accessioning, measuring, marking, and displaying and storing objects of all kinds. Although not directly dealing with photographic jewellery pieces, Jean Allman Gilmore and Patricia Falk's Cataloguing outside the box: a practical guide to

\footnotetext{
8 Edwards, Elizabeth, and Janice Hart. Photographs Objects Histories: On the Materiality of Images. 2004.

9 "Like a Bird Before a Snake: The Miniature and the Photograph" in Robin Frank's Love and Loss: American Portrait and Mourning Miniatures
} 
cataloguing special collections materials is a practical guide to cataloguing and processing unique items. Along with other cataloguing reference books, these publications are necessary when one is confronted with an unfamiliar cataloguing field that needs to be addressed.

The publications discussed in this Literature Survey highlight descriptive and enlightening information that has been most useful during my research. Batchen's insight on added elements to photographic jewellery and West's plethora of visual examples from within his own collection has been most valuable while developing my cataloguing guide. 


\section{BRIEF HISTORY OF PHOTOGRAPHIC JEWELLERY}

The history of photographic jewellery and the history of photography are closely linked. Jewellery design and production was shaped as photographic processes evolved. The first known pieces of photographic jewellery were from the 1840 s and incorporated daguerreotype ${ }^{10}$ portraits. As the daguerreotype process reigned for the following two decades, other processes were introduced to photographic jewellery as their popularity peaked in the nineteenth century: tintypes, ambrotypes, and paper prints.

The idea of carrying a unique, wearable object that housed a mirror image of a loved one made photographic jewellery alluring and embraced by consumers. As personal objects they were now treasured in private or proudly shown off in public. Some of these objects also fulfilled a duel-purpose; not only were they wearable, they often served a function as well - they could be decorative and also posses' practical function or an emotional and commemorative function. A practical object, such as a pocket watch, was a very popular item belonging to the upper class due to its higher price. Along with hairpins and stickpins, these objects could be used in everyday life with purpose and decorative qualities. A commemorative item such as a mourning brooch would have been worn like a badge of honour ${ }^{11}$, indicating that a woman had lost a husband or son in battle. ${ }^{12}$

\footnotetext{
${ }^{10}$ For a description of the daguerreotype process please reference following section, PHOTOGRAPHIC JEWELLERY PROCESSES \& MATERIALS.

${ }^{11}$ Kaplan, Daile. Pop Photographica: photography's objects in everyday life, 1842-1969. Toronto: Art Gallery of Ontario, 2003.

${ }^{12}$ So many lives were lost during The Civil War (1860-1870s) photographic jewellery became a popular way to indicate mourning.
} 
Although worn by men, women, and children, it was women who wore the greatest variety of jewellery. Items such as bracelets, charms, earrings, hair ornaments, pendants, necklaces, and pins were marketed exclusively for women. ${ }^{13}$ While women did wear watches, they were traditionally marketed more towards men; pocket watches in the nineteenth century, with wrist watches following in the twentieth century. Children of high society families would have been given the privilege to wear photographic jewellery, such as charms, bracelets, and necklaces. Today, we are able to surmise it was a children's piece of jewellery due to the drastically smaller size these pieces possess; both the photographs and the piece of jewellery are much tinier than that of an adult piece.

It was Queen Victoria who successfully increased the acceptance of wearing photographic jewellery by wearing, collecting, and exhibiting a variety of jewellery incorporating photographs of her late husband, Prince Albert ${ }^{14}$. The Queen was instrumental in making it a fashion statement that many embraced, first in the United Kingdom, with Europe and North America following thereafter. ${ }^{15}$

Up until the invention of photography, painted miniatures were worn solely by upper class society due to their expensive price ${ }^{16}$. But with the new technology of photography on the horizon, it was a photographic portrait that

\footnotetext{
${ }^{13}$ Abbott, Patricia, and Larry J. West. Antique Photographic Jewelry: Tokens of Affection and Regard. New York: West Companies, 2005: 35.

${ }^{14}$ Prince Albert died in 1861

${ }^{15}$ Abbott, Patricia, and Larry J. West. Antique Photographic Jewelry: Tokens of Affection and Regard. New York: West Companies, 2005:19.

16 Painted miniatures were a wearable art form beginning in the sixteenth-century; they were portable and also possessed realistic colour. A great deal of time and effort went into the creation of these objects, thus making the cost very high.
} 
was preferred over a painted miniature. It had become the new fashion, new process and new medium that finally enabled lower and middle-class citizens to participate in owning wearable art. To enhance and enrich the photograph, hand-tinting was often used to offset the photograph's toneless form, thereby bridging the gap between photography and painted miniatures. As such, this process could be considered the best of both worlds.
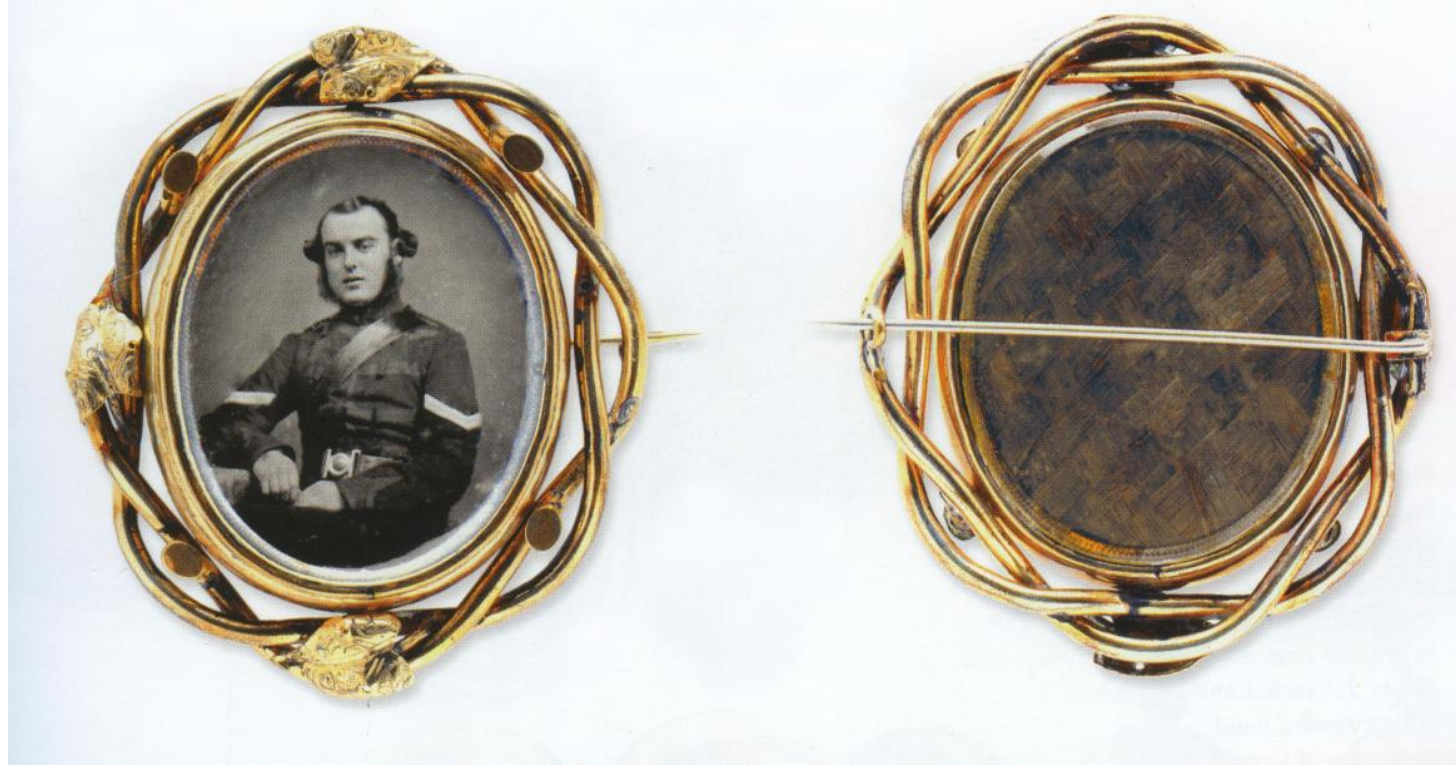

Figure 2 Source: Larry J. West's Antique Photographic Jewelry: Tokens of Affection and Regard, 2005

Due to their size and readily availability and access, it is uncertain as to how many pieces of such jewellery were created. One way to comprehend the quantity created during its peak, is to view the sizeable range of advertisements. Advertisements were typically shown in brochures, newspapers, photographic billboards, and catalogues. Most photographic studios would advertise for such specialty items on the back of more common products like their carte-de-visite's to alert customers of their other available processes/products. Another way to 
grasp the vast scale of pieces created during the 1840-1860's peak of

photographic jewellery, is viewing the survival of what appears to be hundreds

of different mounting options - indicating that demand was substantial. ${ }^{17}$

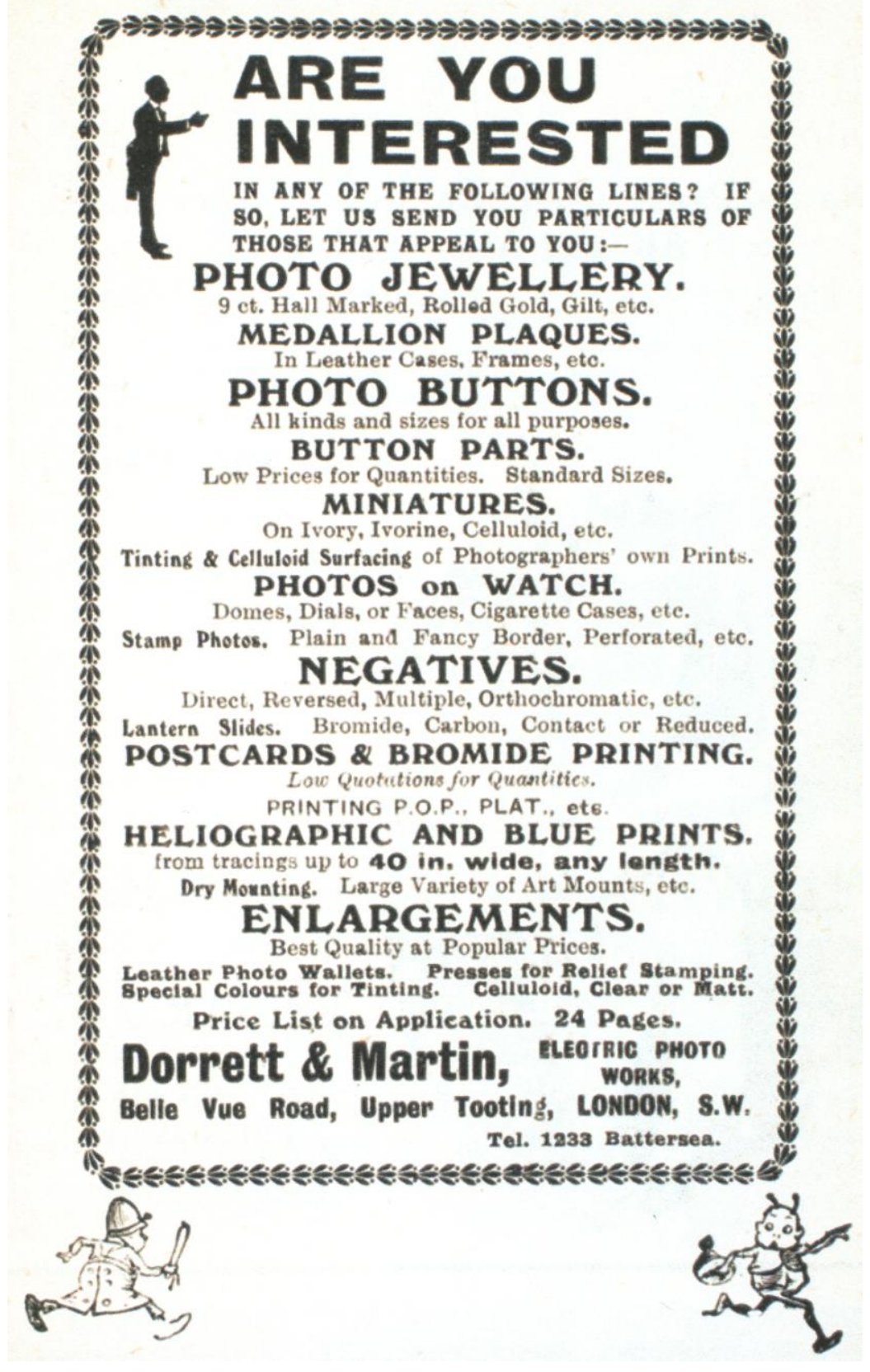

Figure 3

${ }^{17}$ Abbott, Patricia, and Larry J. West. Antique Photographic Jewelry: Tokens of Affection and Regard. New York: West Companies, 2005: 20. 


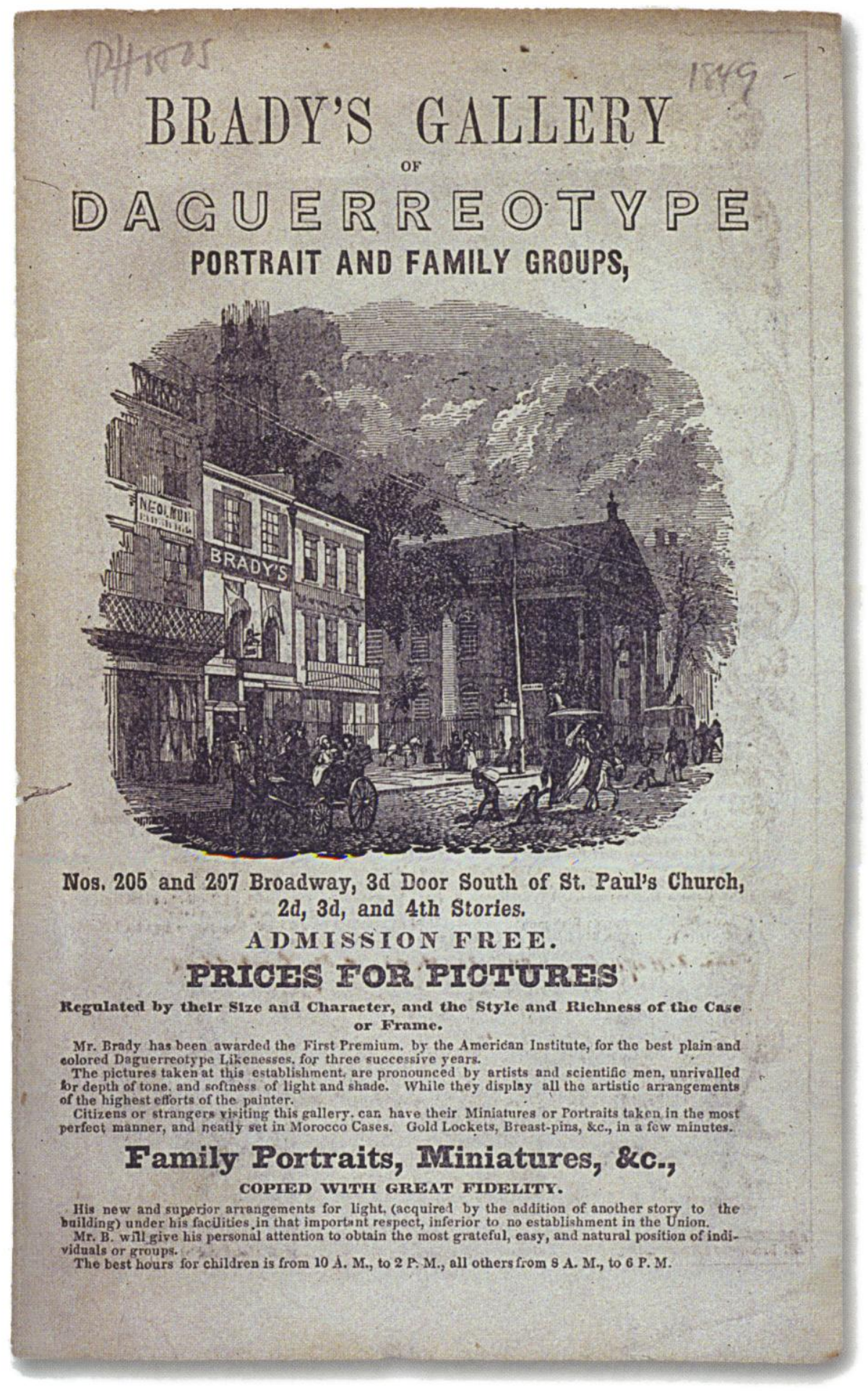

Figure 4

Source: Larry J. West's Antique Photographic Jewelry: Tokens of Affection and Regard, 2005 
Although photographic jewellery can still be made in the twenty-first century, the processes and jewellery included would differ greatly from that used in the nineteenth and twentieth centuries. The popularity of photographic jewellery began to be phased out with the rise of vernacular photography and the snapshot. Cameras such as the Kodak Brownie ${ }^{18}$ provided an affordable way to take photographs that were later included in frames, wallets, and other objects which could be assembled and created at home; photography studios were not as essential as they had been in the past. Other processes evolved and technology advanced in a way that has allowed one to carry photographs of loved ones in a much more accessible way.

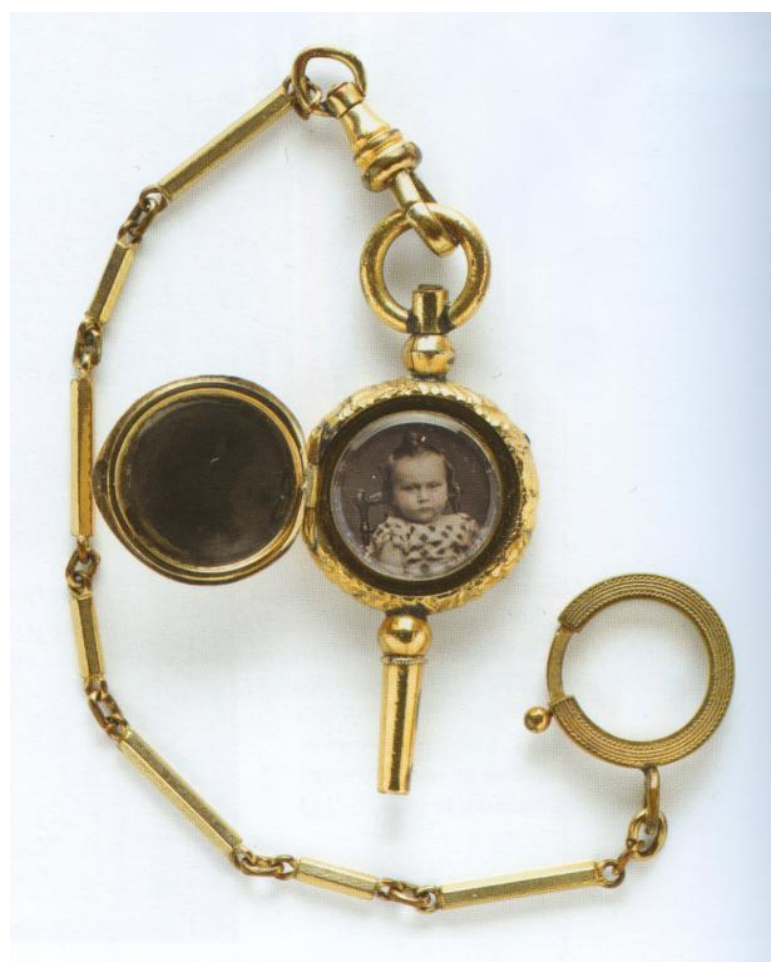

Figure 5

Source: Larry J. West's Antique Photographic Jewelry: Tokens of Affection and Regard, 2005

18 The Brownie was introduced in 1900 and is responsible for the rise of low-cost photography and introduced the concept of the snapshot and vernacular photography. 


\section{PHOTOGRAPHIC JEWELLERY PROCESSES \& MATERIALS}

The popularity peak of photographic jewellery was arguably from the mid-nineteenth to the early-twentieth century. In this time there were many photographic processes created and incorporated in countless objects. The most common for photographic jewellery included daguerreotypes, ambrotypes, tintypes, and paper prints. ${ }^{19}$ At the time, these were extremely common and some processes were inexpensive to manufacture; each process provided a different look and feel to the object.

Invented in 1839, the daguerreotype was the first commercially successful photographic process. The daguerreotype is a direct positive made inside the camera on a silvered copper plate. The surface of the daguerreotype is similar to that of a mirror, with the image made directly on the silver; the reflective exterior can appear as a positive at some angles, and as a negative at another. It must be viewed at close proximity and turned to a specific position to view the image properly. Typically found in lockets, a daguerreotype jewellery piece is not uncommon to come across, but condition usually suffers due to a lack of care or from advancing oxidation. ${ }^{20}$

The ambrotype (collodion positive) is a process that creates a negative image on a sheet of glass, which when backed with an opaque black lacquer coating will appear as a positive image. The image is not reflective, as with a daguerreotype; however it was far less expensive to reproduce. Ambrotype's

\footnotetext{
${ }^{19}$ Abbott, Patricia, and Larry J. West. Antique Photographic Jewelry: Tokens of Affection and Regard. New York: West Companies, 2005: 201.

${ }^{20}$ Oxidation occurs when the silver plate has been exposed to oxygen; this process creates an unwanted affect around the edges or on the entire surface of the plate, sometimes affecting the overall image.
} 
within photographic jewellery were often hand tinted to give colour to the sitter's cheeks and clothing; this was very common and successful due to the ambrotypes' greyish-white complexion. Ambrotype's were frequently found in an assortment of photographic jewellery pieces such as lockets, charms, buttons, and hairpins, due to its durability. Even when cared for, sometimes the glass surface would break and the emulsion would flake off the glass, but nevertheless its inexpensiveness made it popular.

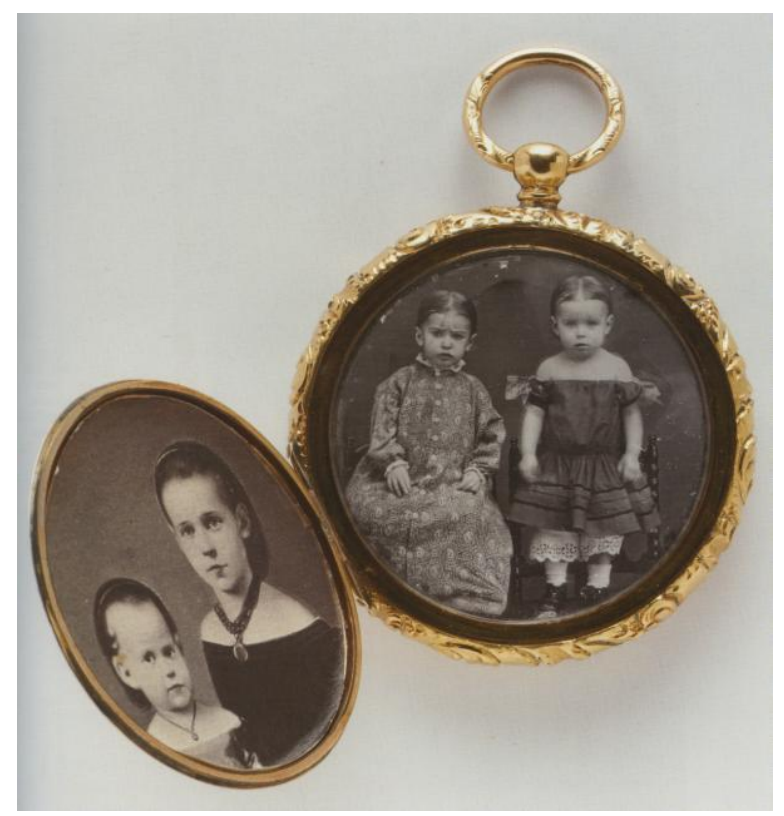

Figure 6

Source: Larry J. West's Antique Photographic Jewelry: Tokens of Affection and Regard, 2005

Unlike daguerreotypes, but similar to the ambrotype, the tintype (ferrotype) is a variation on the collodion process, whereby a negative image takes on an appearance of a positive. Used well into the twentieth century, the tintype is created on a thin metal sheet of iron coated with an opaque black paint, lacquer, or enamel. The image is directly exposed in the camera, and while actually a negative, the collodion containing silver salts produces a positive 
when developed. A tintype does not have the reflection that a daguerreotype provides, and viewing the image is easier, nor does it require to be protected behind glass. Compared to the daguerreotype, the tintype provides a certain freedom and allowed for an array of photographic jewellery to contain tintypes without the fear of inflicting damage to the image. The processes daguerreotype, ambrotype, tintype - are unique image processes and would have to be re-photographed to create a duplicate image.

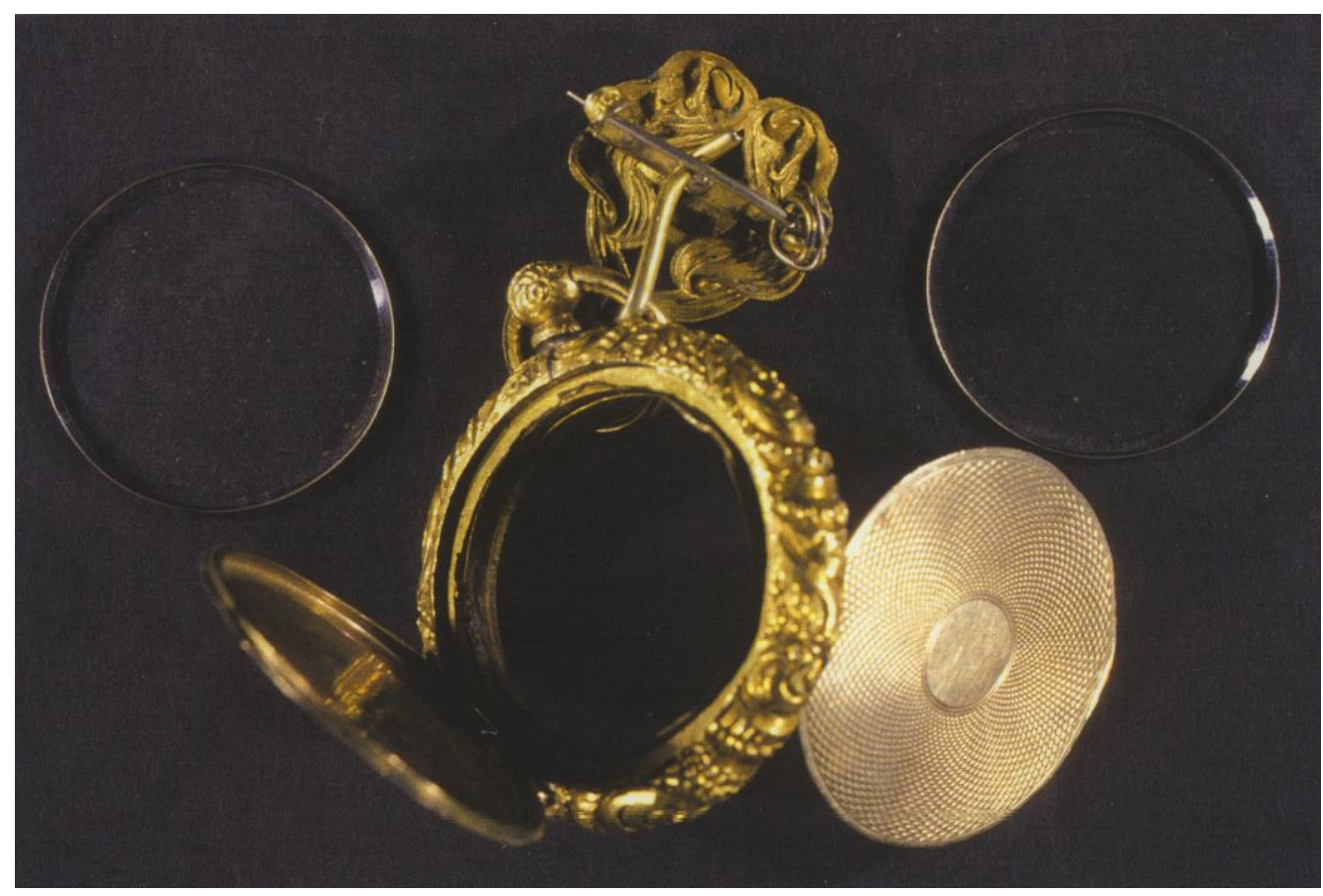

Figure 7

Source: Larry J. West's Antique Photographic Jewelry: Tokens of Affection and Regard, 2005

The process that remains the most common form of photography is paper prints. Although the majority of photographic jewellery pieces contain a metal based photographic process, paper prints exist within lockets and other enclosed objects to ensure the image was properly protected. Different photographic processes for paper prints were possible, including salted paper, collodion, and albumen prints. Sometimes an object containing more than one photograph 
would consist of more than one process. For example, figure 6 shows a watch locket that includes one daguerreotype, and one albumen print; both portraits are of the same two children but taken some years apart. This was not uncommon due to the rapid progress of photographic technology which led owners to select the most current process for their latest portrait. The factor of time is not only visible in the change in subject matter, but also in the change of process.

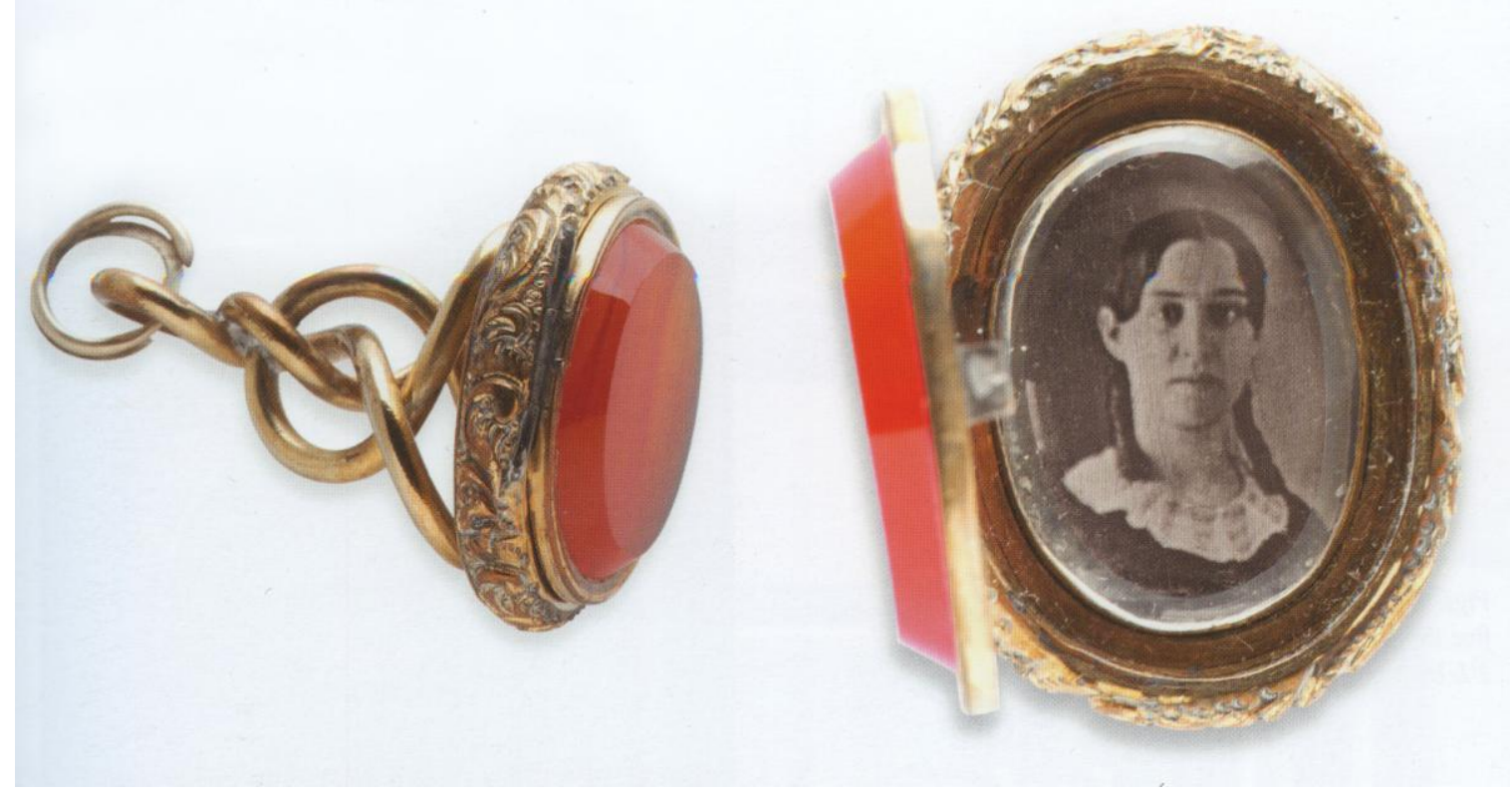

Figure 8

Source: Larry J. West's Antique Photographic Jewelry: Tokens of Affection and Regard, 2005

Although photographic jewellery is not limited to the above processes, they do generate the majority of pieces within collections. Most objects are composed of a photograph and a piece of material creating the final jewellery piece. The sub-components depend on the type of jewellery; at the minimum, the majority consists of the photograph(s), the main jewellery setting, and a backing. 
Other common materials and components for photographic jewellery are Bakelite (plastic), bronze, gems, glass, gold, hair, ivory, pearl, porcelain, and silver. While some are the jewellery setting, others are added components such as hair or gems. These components are reflective on the time period, and typically contain an added purpose to the jewellery suggesting the idea of a double indexicality. ${ }^{21}$

\footnotetext{
${ }^{21}$ Batchen discusses this idea in his writings; please refer to LITERATURE SURVEY.
} 


\section{METHODOLOGY}

This project was divided into two sections: the practical component and the written component. The written component existed throughout the entire process of this thesis project and began very early in the process while researching; books, articles, journals, primary advertisements, and online sources were very important in finding historical and cataloguing information on photographic jewellery. The second section, the practical component, involved the creation of the cataloguing guide and controlled vocabulary. It began by contacting twenty-one institutions to inquire on their photographic jewellery collection and how they catalogue such objects. This information helped confirm that this guide did need to be created, and also helped decide which components were necessary.

In order to gain an understanding of how other institutions and private collectors dealt with their photographic jewellery acquisitions in the past, I created a letter (figure 12) that addressed different institutions. This institution inquiry letter described to them what I had set out to create, and asked whether or not they would be able to share any information or suggestions with me. Choosing which institutions to contact was based off of the Illustration Credits in Larry J. West's Antique Photographic Jewellery, Tokens of Affection and Regard.22 This index provides names of the jewellery collectors whose items were illustrated in the book. I then completed research online by searching websites of institutions I thought might contain photographic jewellery. Letters were sent to a contact within these institutions, or to the general inquiry email address, where I would

${ }^{22}$ Details of this publication can be found within the LITERATURE REVIEW. 
later be referred to the proper person.

Out of the twenty-one letters sent out, there were a total of fourteen responses received. Figure 9 lists the institutions contacted, where they are located, and indicates whether or not there was a reply. What the responses essentially did was provide examples of how the institution catalogued their photographic jewellery and whether they had any special treatments or elements that stood out as necessary.

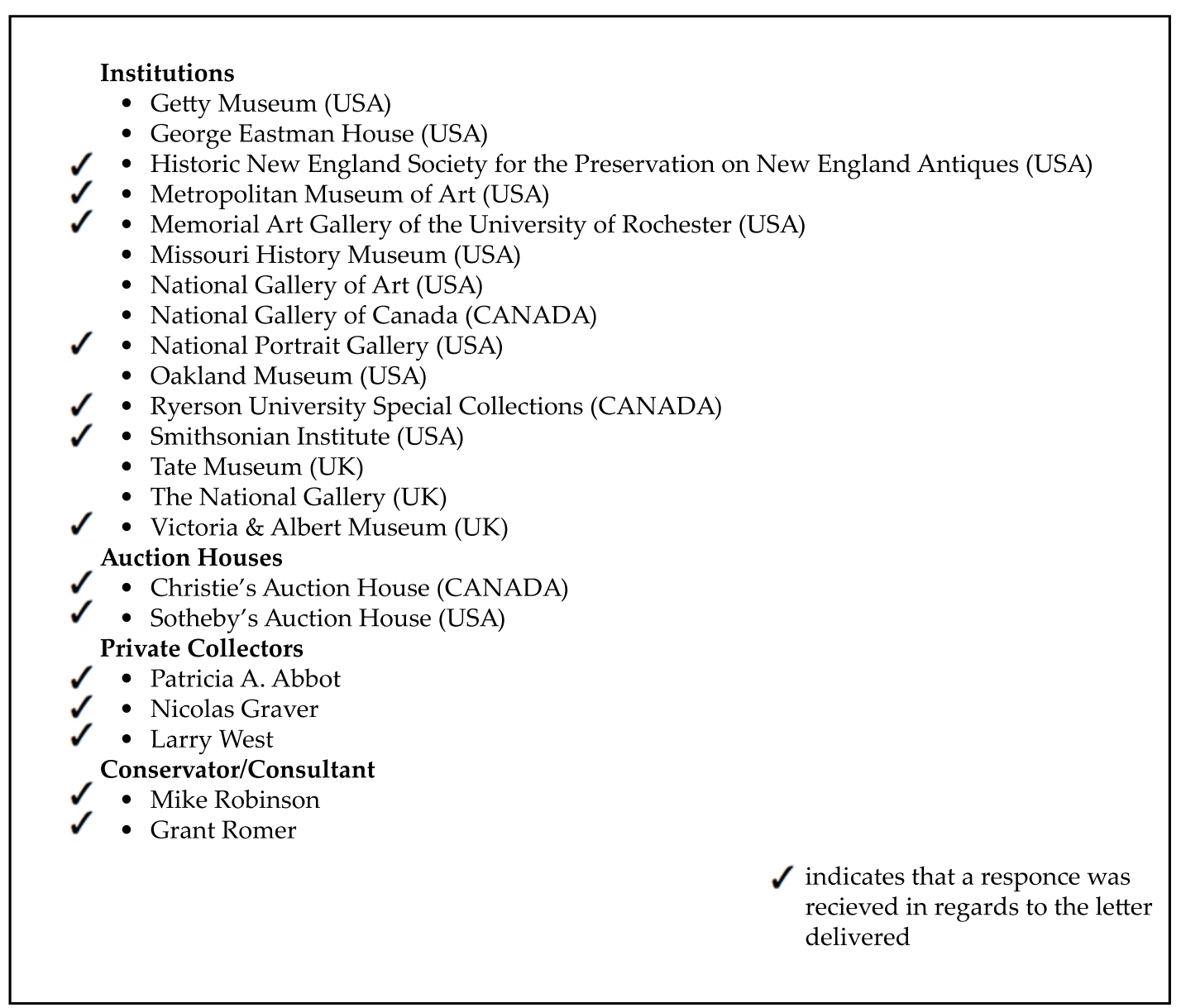

Figure 9

Unfortunately this process was not overly helpful to my research, in the sense that none of the institutions I contacted had a guide or controlled vocabulary for their photographic jewellery. Collections Manager, Meredith 
Friedman, at the Metropolitan Museum of Art (Met) in New York stated, “...we only have a handful of photographic jewelry objects in the collection (a few pins), and it's entirely likely they haven't been cataloged in a consistent manner." ${ }^{23}$ Collection Manager, Nicole Chalfant, from Historic New England Collections and Conservation Center specified, "We received a grant to catalogue our jewelry collection in 2007. We did not have specific parameters for the describing of photographic jewelry, but simply made it fit with the other cataloguing records." ${ }^{24}$ The above responses just further prove that institutions do not have specific instructions when dealing with, or cataloguing photographic jewellery.

Other responses advised me to view their catalogue online to see how cataloguing the photographic jewellery was executed. As illustrated in Figure 10 - Figure 11, it is evident that some records are detailed, while others have limited cataloguing information and are sometimes missing a corresponding image. Regardless, each one has suitable components that were taken into consideration when creating the completed guide. For instance the Heinch Exhibition Guide (Figure 11) contains a recto and verso image of the object; not all institutions photographed both views, but this procedure seems logical in order to view the entire casing and any inscriptions that might appear on the back of the object. The New York Historical Society Online Catalogue did not provide a complete visible measurement record. Despite being an important element, they have chosen to have only an overall object dimension, and exclude any measurements of the included photograph.

${ }^{23}$ Personal email dated February $10^{\text {th }} 2013$ from Meredith Friedman.

24 Personal email dated January 30 2013 from Nicole Chalfant. 


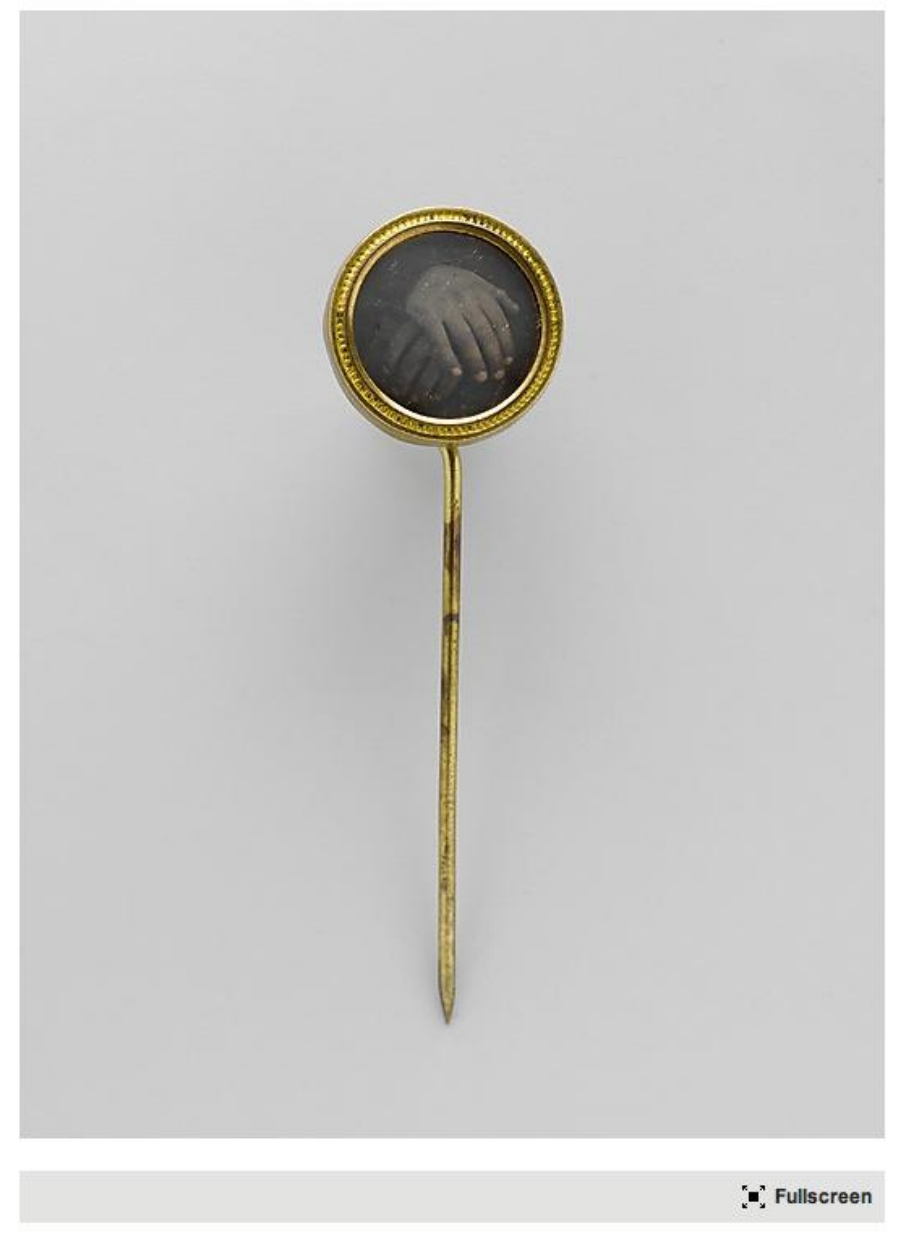

\author{
[Abolitionist Button] \\ Unknown

\begin{tabular}{|c|c|}
\hline Date: & $1840 \mathrm{~s}-50 \mathrm{~s}$ \\
\hline Medium: & Daguerreotype \\
\hline Dimensions: & Image: Diameter $1.6 \mathrm{~cm}$ (5/8 in.) \\
\hline Classification: & Photographs \\
\hline Credit Line: & $\begin{array}{l}\text { Gilman Collection, Purchase, Joyce } \\
\text { F. Menschel Gift, } 2005\end{array}$ \\
\hline Accession Number: & 2005.100 .78 \\
\hline \multicolumn{2}{|c|}{ This artwork is not on display } \\
\hline$\&$ Share & MyMet \\
\hline
\end{tabular}
- Description
This daguerreotype with an abolitionist motif may be one of the first political buttons made in America to incorporate a photograph. Believed to be unique, the miniature daguerreotype shows two hands held together, one black, one white resting on a book assumed to be the Bible. The photograph is set into a two-piece gold-washed brass frame with a loop on the reverse for sewing to a garment. The case design with its simple, raised ornamental border is typical of the gilt- metal buttons mass-produced from 1830 to 1850 in several New England factories such as the Scovill Manufacturing Company in Waterbury, Connecticut, which also manufactured daguerreotype plates. The button was discovered in the early 1980 s in a flea market in Massachusetts.
Like the piecework quilts made by women's antislavery societies, this button may have been produced to raise money for the abolitionist cause and sold at one of the popular antislavery fairs organized by women. The first such fair took place in 1834 in Boston, the center of the abolitionist movement. Although the fairs accepted "all well-made, useful, and ornamental nroducts." the nroanizers nreferred textiles and

Figure 10

Source: Metropolitan Museum of Art, New York; Online catalogue ; Accession number 2005.100.78 


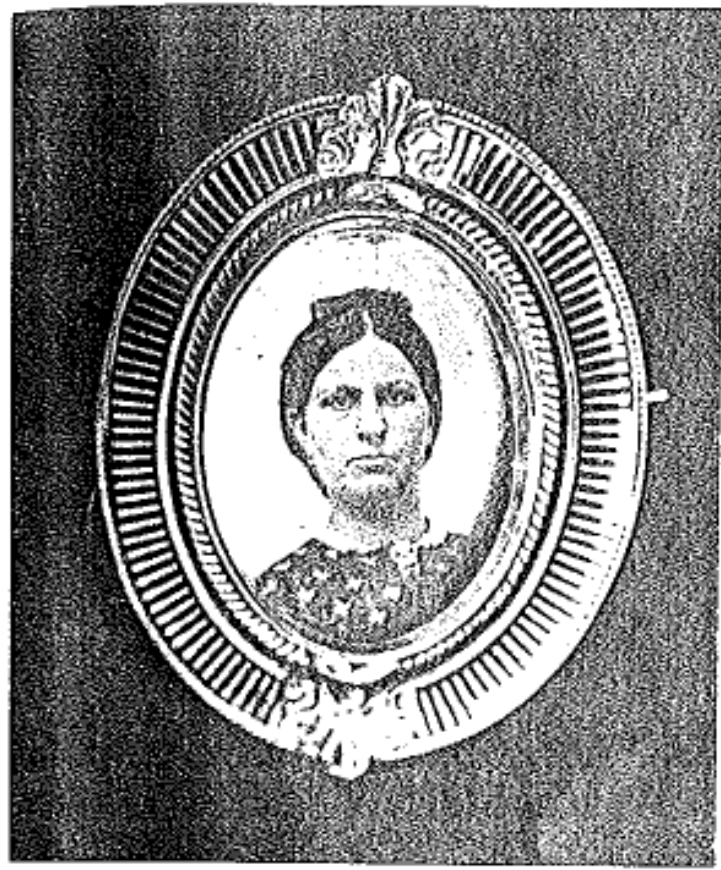

PJ 04

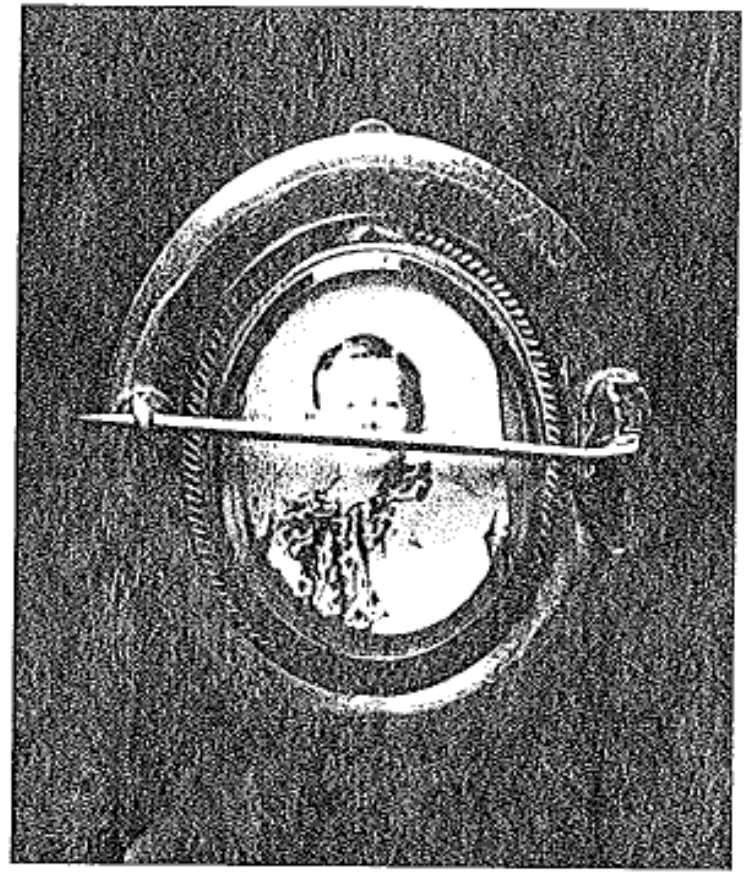

PJ 04 Reverse side

PJ 04

Two-Sided Swing Brooch

Unknown, c. 1860

American

Tintype and albumen print

$1^{\prime \prime} \times 3 / 4^{\prime \prime}$, oval

Brooch containing two photographs, giving the wearer the choice of which to display.

Figure 11

Source: Heinch Exhibition Guide; Provided by Historic New England Collections and Conservation Center. 
The practical component occurred in two parts. The first was from January $29^{\text {th }}-$ February $28^{\text {th }}$ in which the institution inquiry letter was written, sent out, and responses were received. Also at this time, the guide was outlined and roughly half completed; I needed to ensure that I had a substantial amount completed prior to the oral presentation in early April 2013, to make certain proper feedback could be received. The second part was from June $30^{\text {th }}-$ July $15^{\text {th }} 2013$ in which the guide was completed and revised.

In mid-March 2013, I compiled a list of terms which, with revision, would become the final controlled vocabulary list. With the current lack of a controlled vocabulary for photographic jewellery, I felt that some institutions and collectors might not be familiar with some of the terms present on the list. In order to ensure cataloguers would know precisely which terms were applicable to their collection, I collected definitions and images to accompany as many of the listed terms as possible. Getty's Art \& Architecture Thesaurus (AAT) and Anita Mason and Diane Packers publication, An Illustrated Dictionary of Jewellery was extremely helpful throughout this process, along with images from the Internet and glossary definitions from jewellery and photography publications. ${ }^{25}$

${ }^{25}$ All sources for definitions and images are made note of in the controlled vocabulary list. 
January $29^{\text {th }} 2013$

\section{To Whom it May Concern,}

My name is Andrea Beiko and I am currently a student in Ryerson University's (Toronto, Ontario) Photographic Preservation and Collections Management program. This is the final semester in my Masters degree, therefore my thesis is well underway. At the moment, the working title for my thesis is Creating a Cataloguing Template for Photographic Jewellery at the Art Gallery of Ontario (AGO). I am working with photographic jewellery (i.e. personal objects that incorporate photographic images, such as pins, brooches, lockets, watches) at the AGO with the goal to create the ideal cataloguing template for their photographic jewellery holdings. AGO's collections management system for cataloguing is The Museum System - TMS.

One of the main collection management concerns with photographic jewellery is that there does not appear to be a standard cataloguing template or a common terminology with which to catalogue such items. The majority of jewellery descriptions are inconsistent and would benefit from being catalogued in a standard form. I am proposing to rectify this issue at the AGO by proposing a template and controlled terminology that can be implemented to fully catalogue the existing collection and serve future photographic jewellery acquisition.

In order to achieve this goal and complete my thesis, I am beginning by contacting institutions, galleries, museums, private collectors, and auction houses to inquire about formats and whether or not a standard template for cataloguing photographic jewellery is in place.

If you and your institution would be kind enough as to provide me with any information on how you have dealt with photographic jewellery in the past, it would be a great help. If you are able to provide me with such information, please advise if you would be willing to respond to a brief questionnaire I will send by email. Your participation would be most helpful to me. Should you not have any information specifically related to my research, regardless I would appreciate hearing from you if there are others in your institution I should consider to contact regarding my thesis project.

If you have any questions whatsoever, please do not hesitate to contact me via email, and I will respond ASAP.

Thank you in advance for your time and your help.

Sincerely,

Andrea Beiko

andrea.beiko@ryerson.ca

Figure 12 


\section{CURRENT ART GALLERY OF ONTARIO PHOTOGRAPHIC JEWELLERY COLLECTION}

To conclude the practical component of this thesis, I applied the guide and controlled vocabulary to complete the existing cataloguing entries of the photographic jewellery at the AGO; by doing so, it validates that the guide can be properly followed ${ }^{26}$.

The current photographic jewellery collection at the AGO consists of two pins, two pocket watches, and five lockets; one piece is from the twentieth century, while the remaining eight pieces are from the nineteenth century. An anonymous donor between 2001 and 2007 gave the objects to the AGO. Although a specific provenance is unknown, the donor would have acquired them over a period of time prior to the donation to the museum.

A detailed view of all nine objects are visible on pages 28 to 36; a full catalogue of these items are available within the section, FULL AGO

PHOTOGRAPHIC JEWELLERY CATALOGUE (pages 73 to 82).

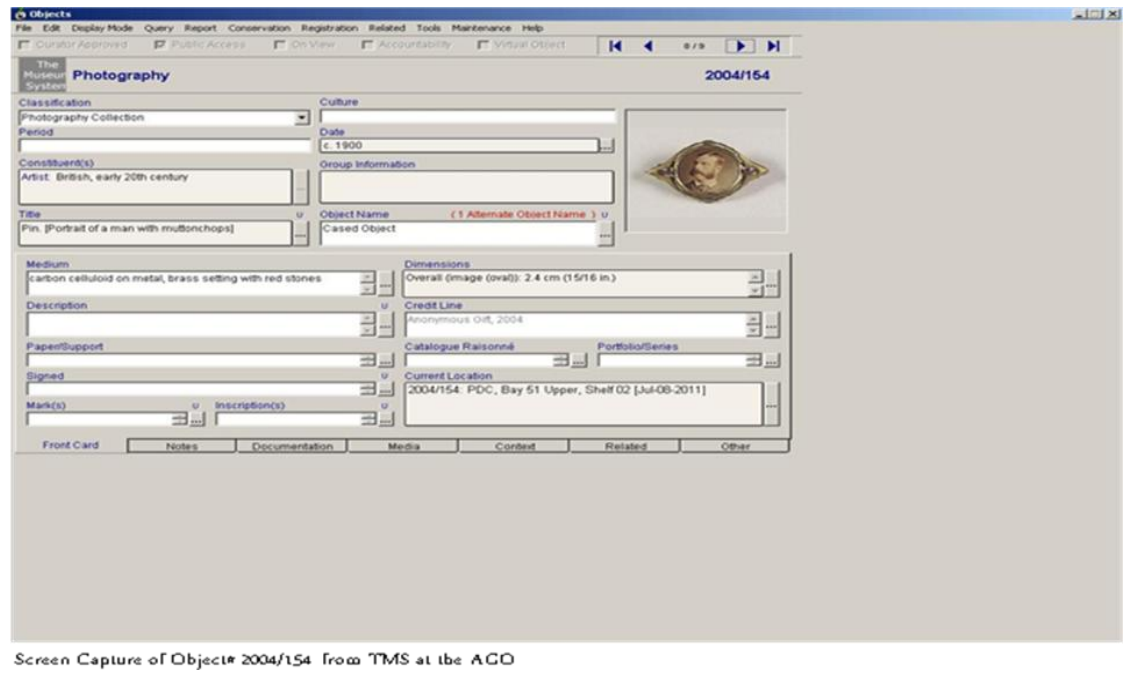

Figure 13

${ }^{26}$ Cataloguing completed August 2013. 


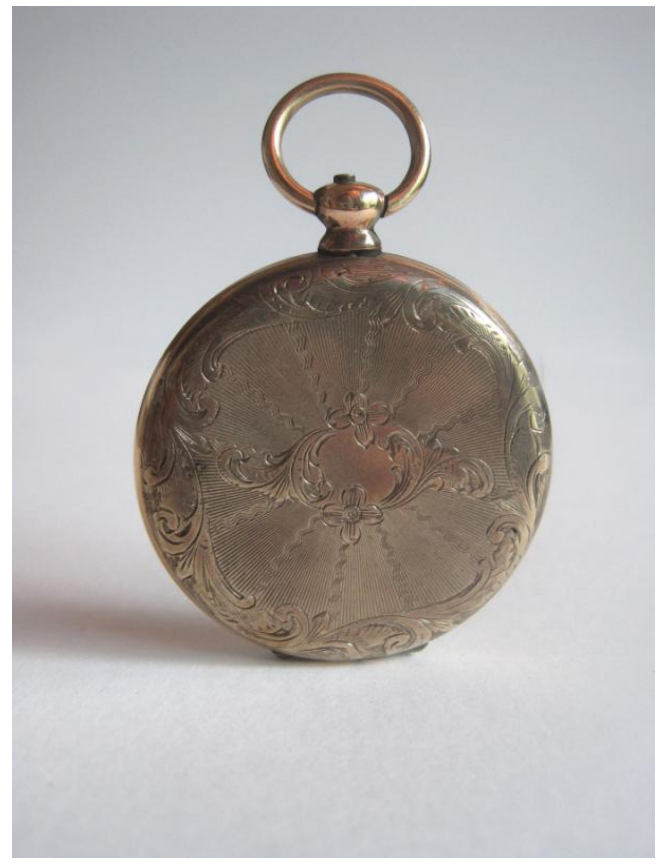

Figure 14a

2001/170; recto

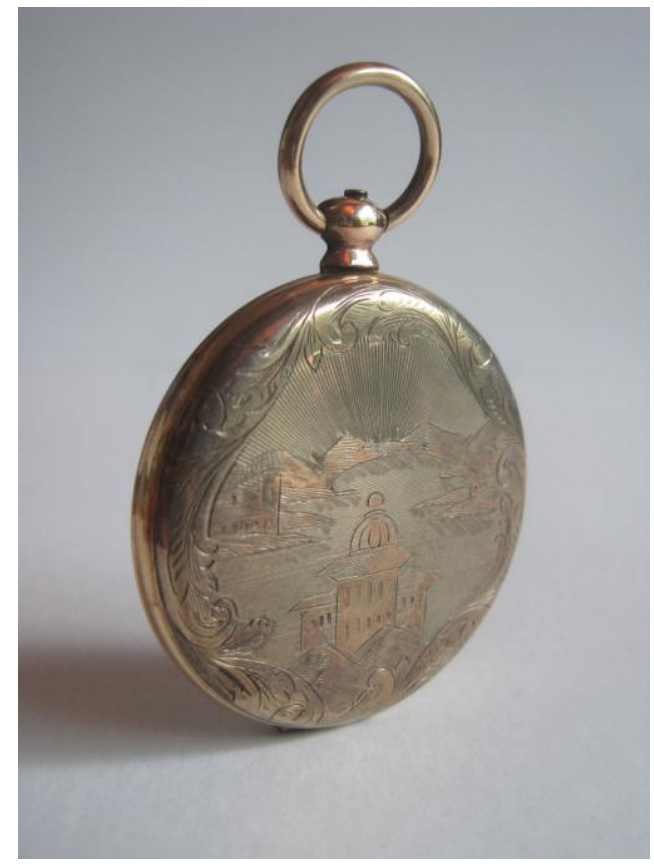

Figure 14b

2001/170; verso

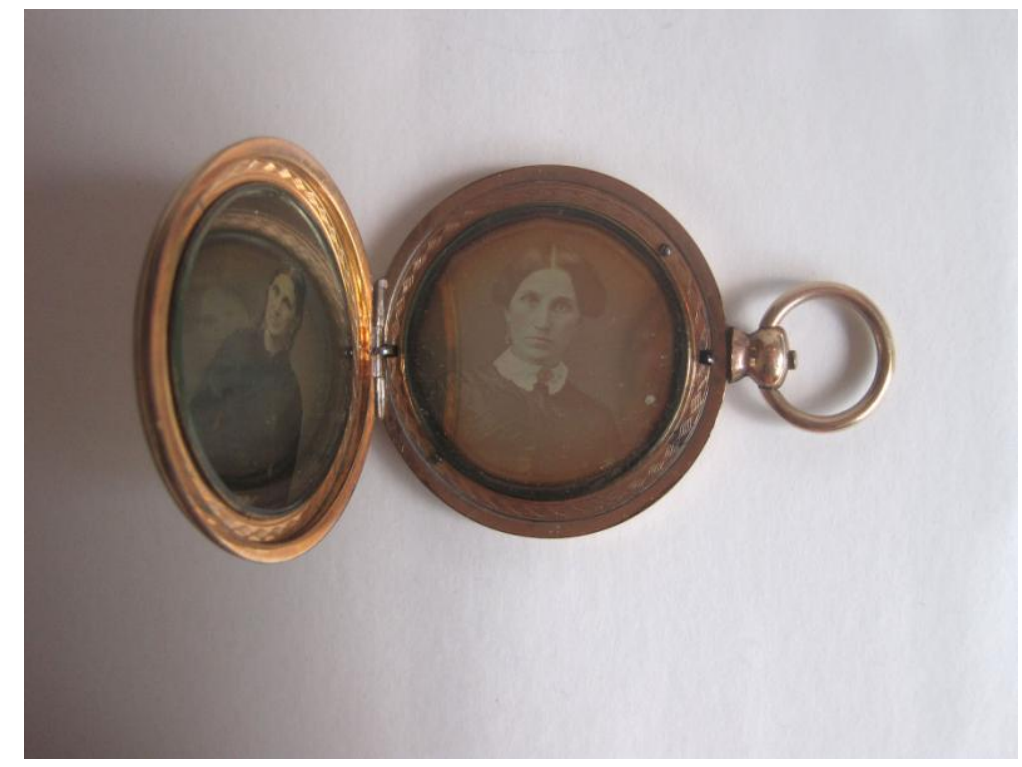

Figure 14c

2001/170; interior 


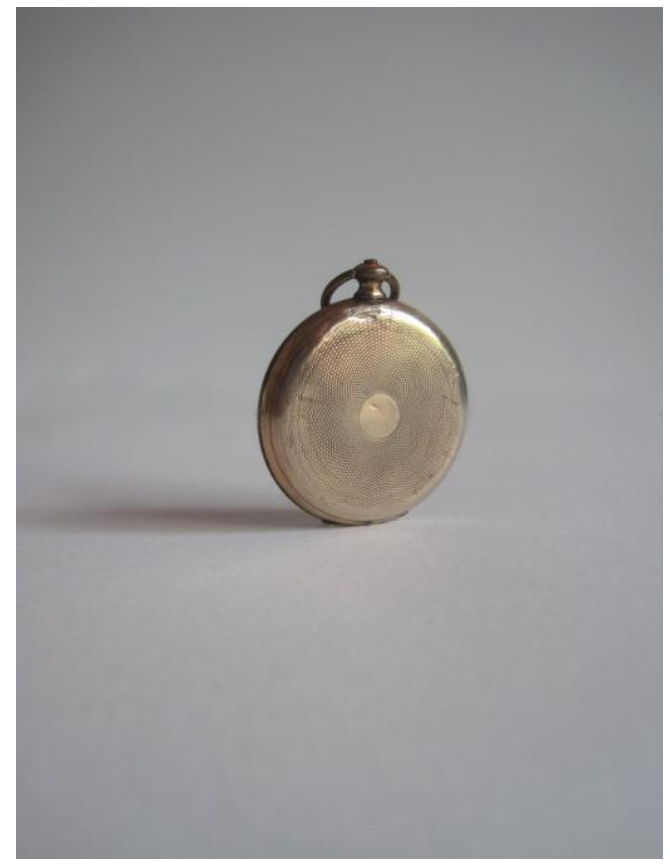

Figure 15a

2001/171; recto

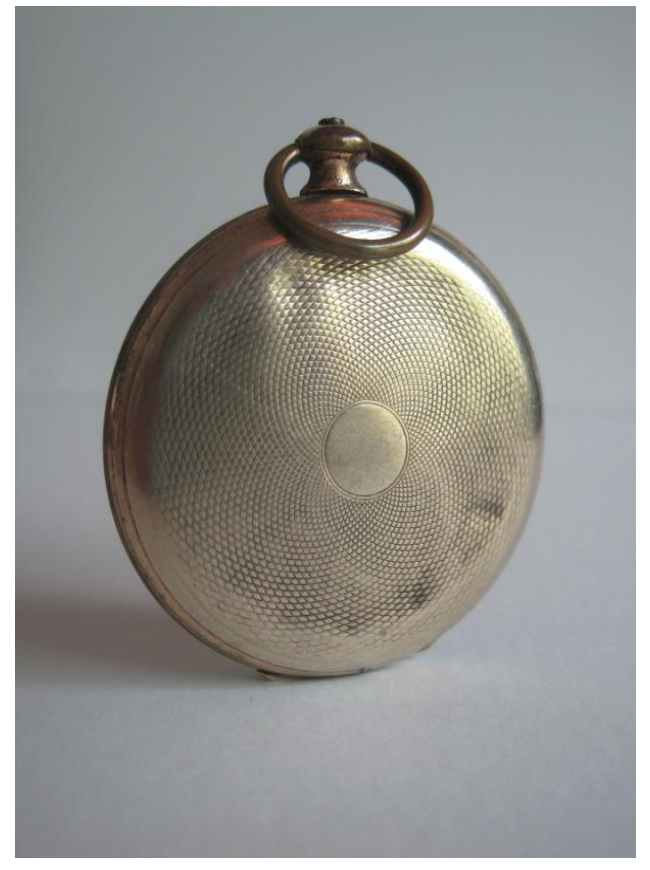

Figure 15b

2001/171; verso

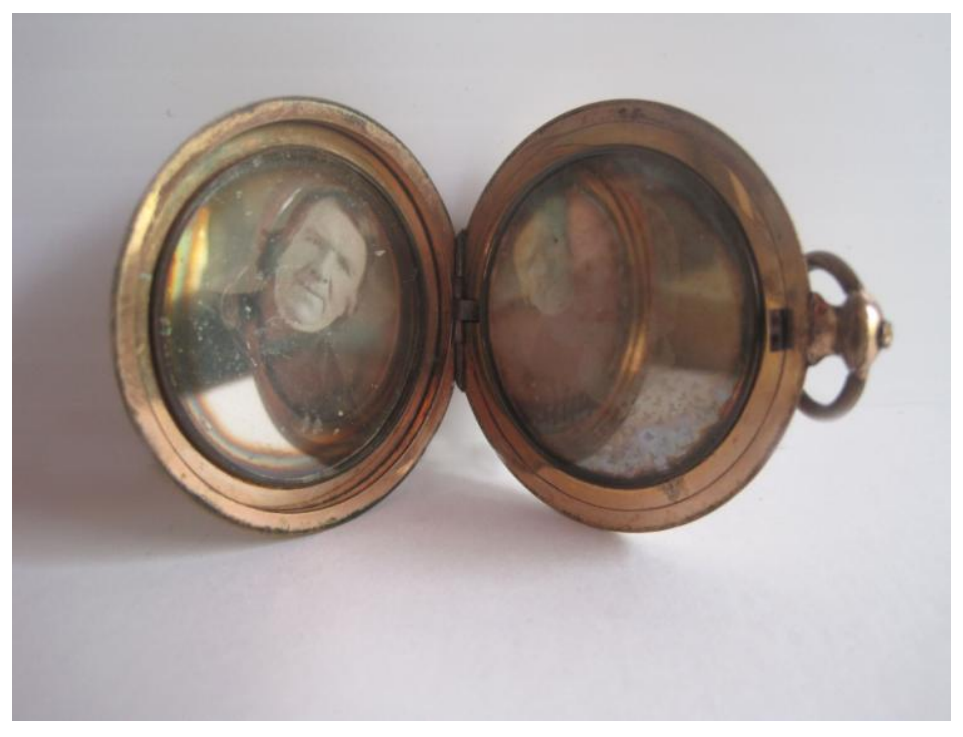

Figure 15c

2001/171; interior 


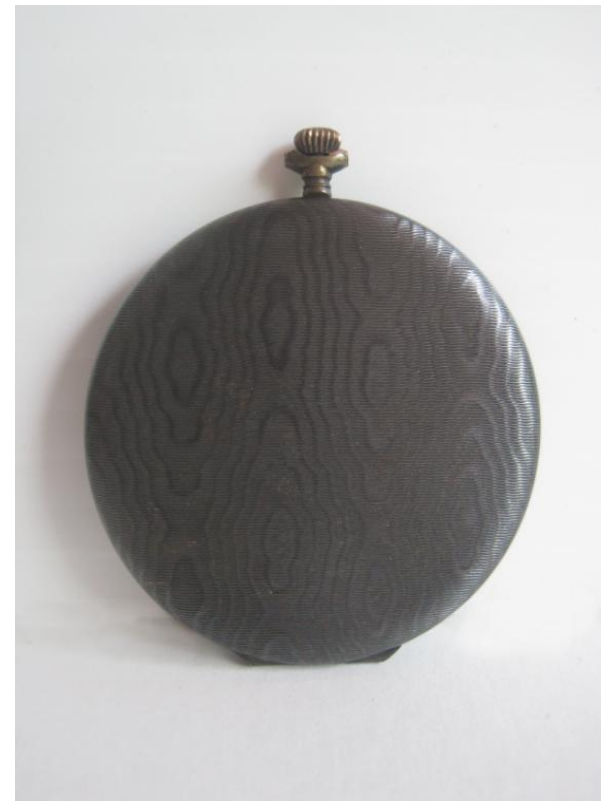

Figure 16a

2001/172; recto

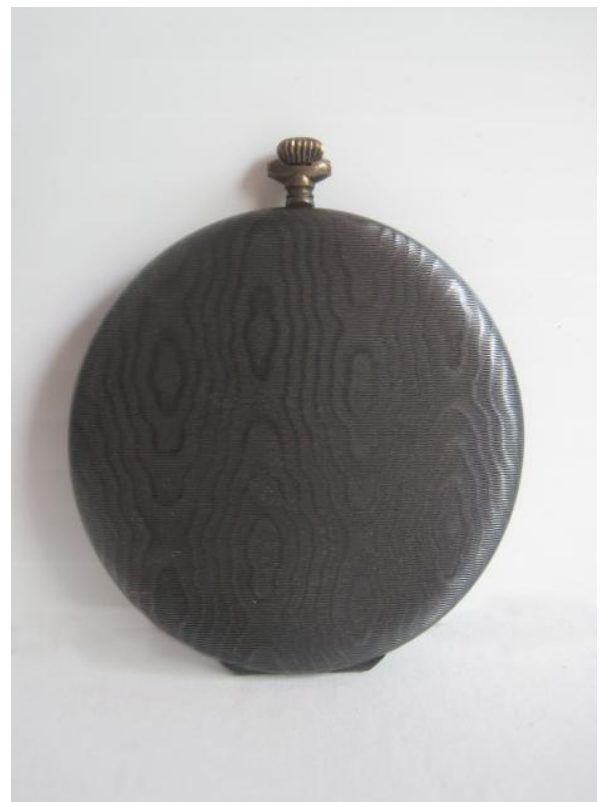

Figure 16b

2001/172; verso

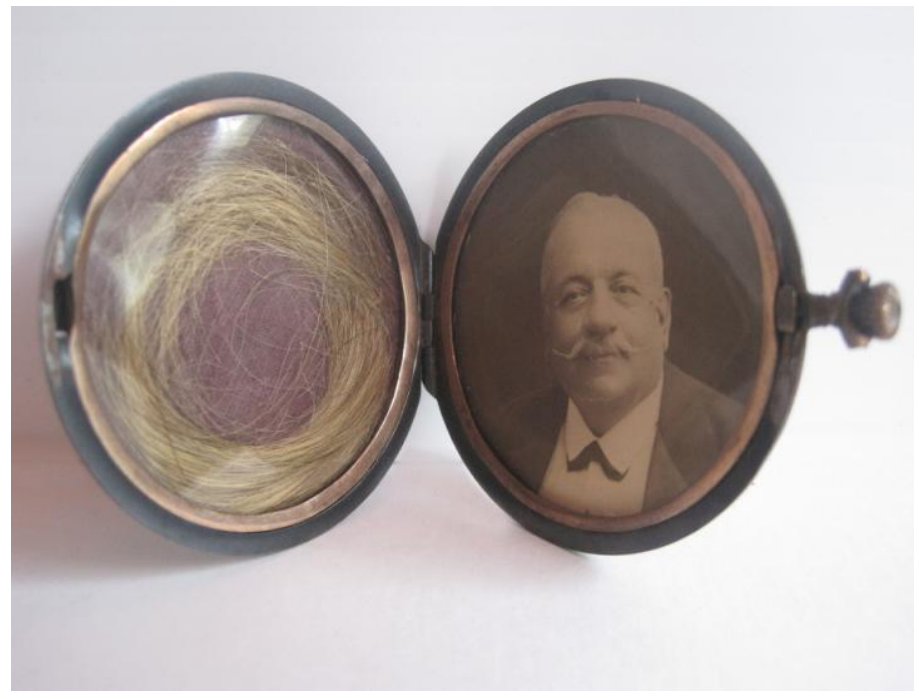

Figure 16c

2001/172; interior 


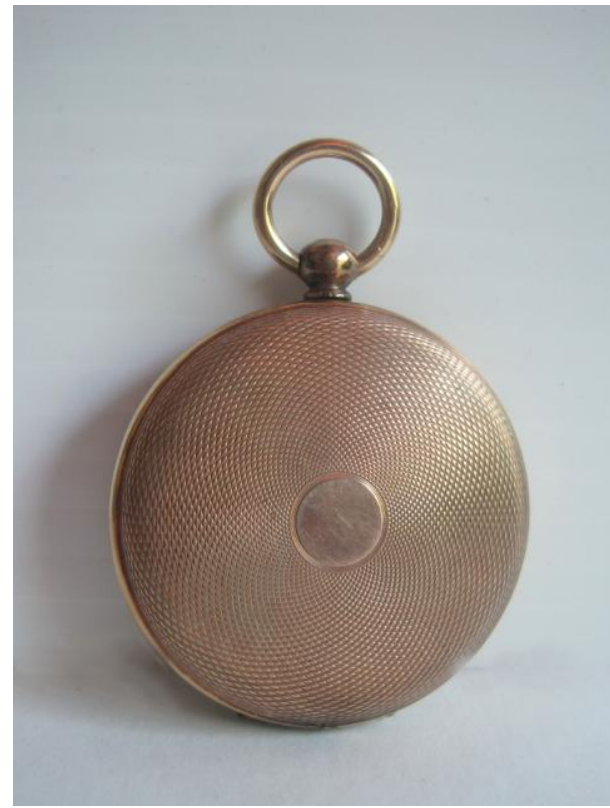

Figure 17a

2002/9421; recto

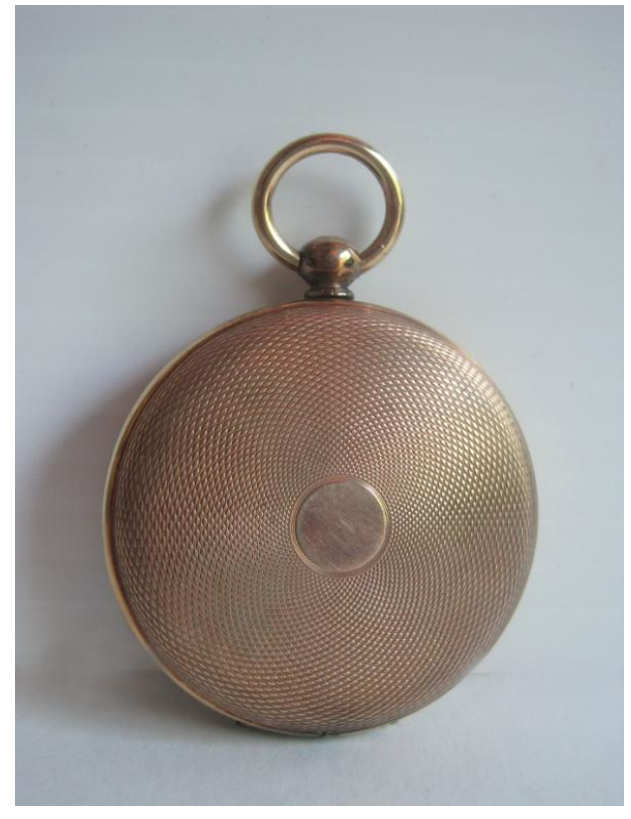

Figure 17b

2002/9421; verso

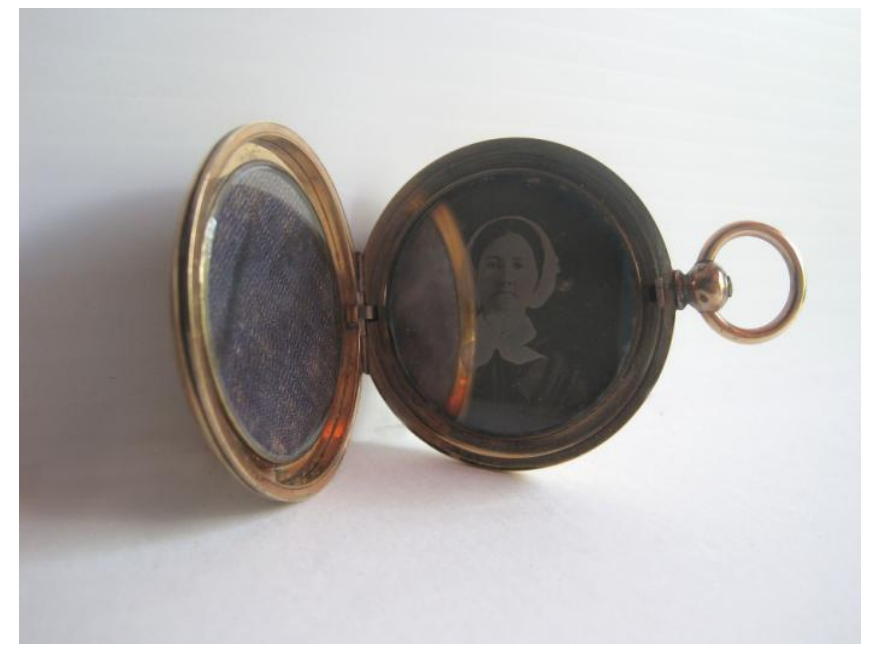

Figure 17c

2002/9421; interior 


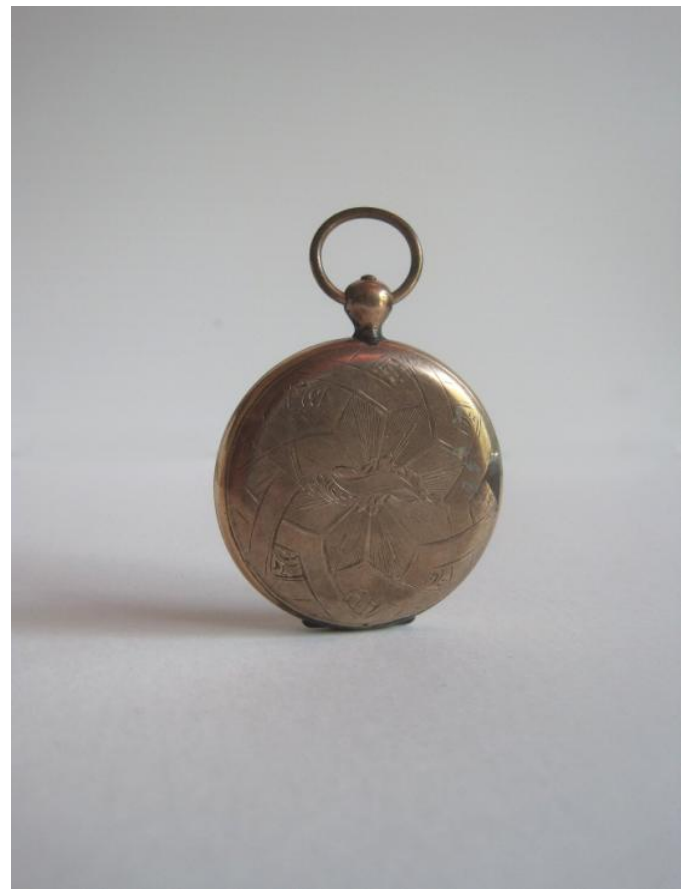

Figure 18a

2002/9422; recto

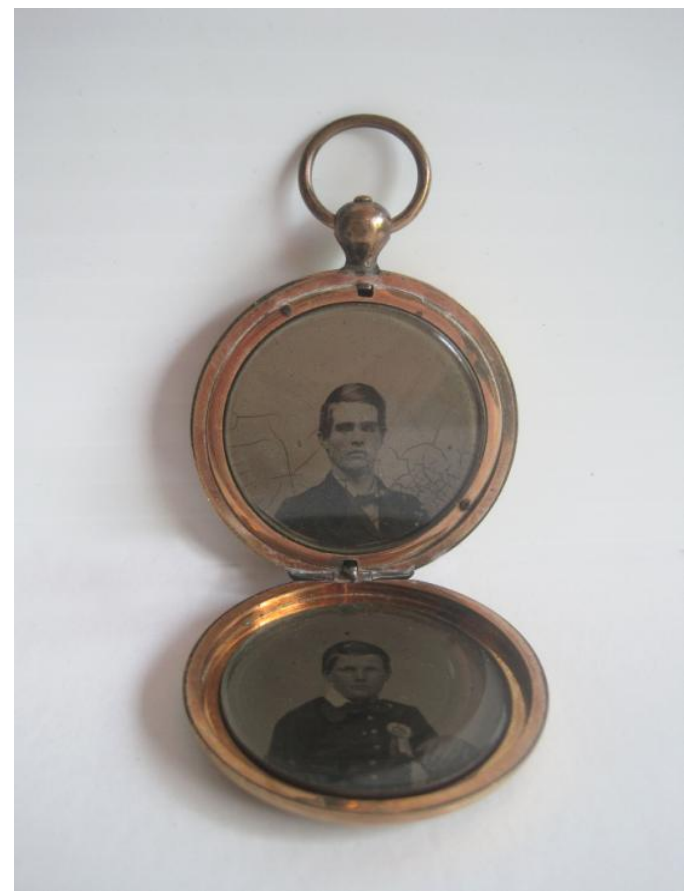

Figure 18b

2002/9422; interior 


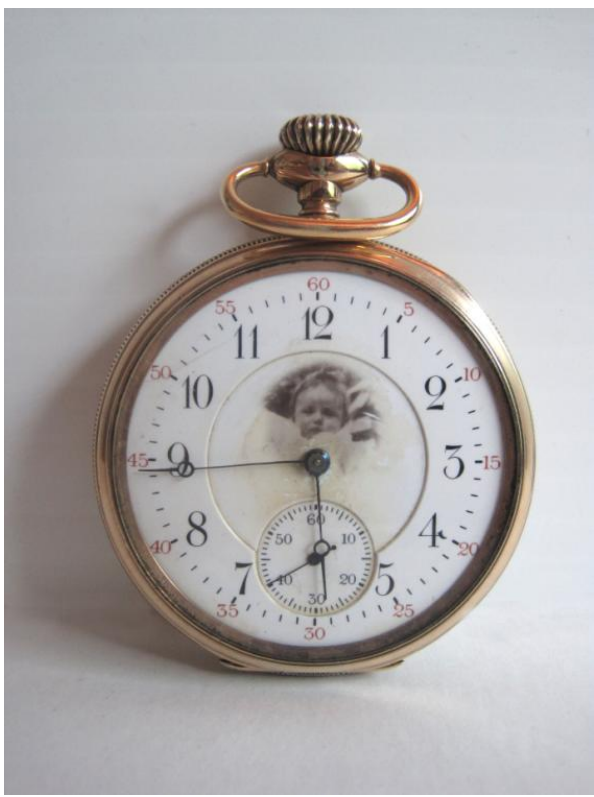

Figure 19a

2004/146; recto

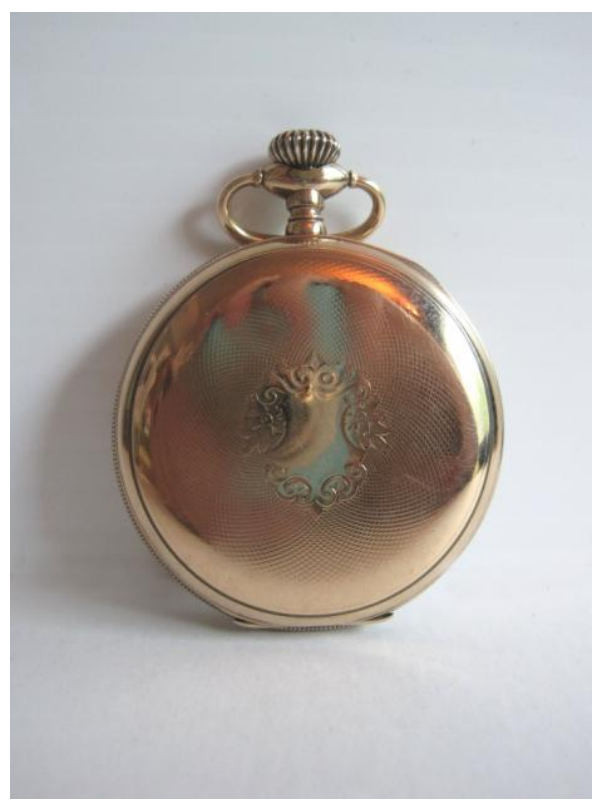

Figure 19b

2004/146; verso

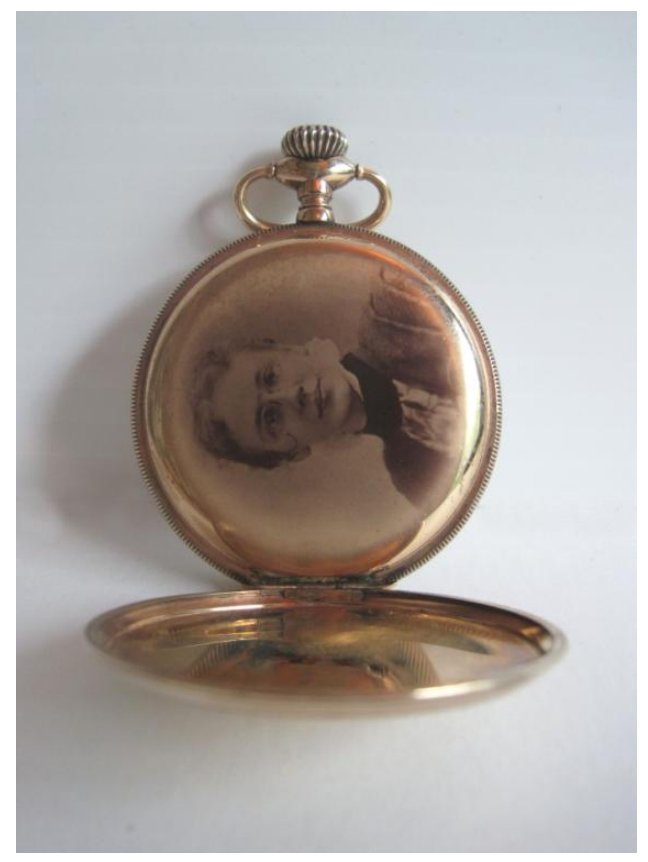

Figure 19c

2004/146; interior 


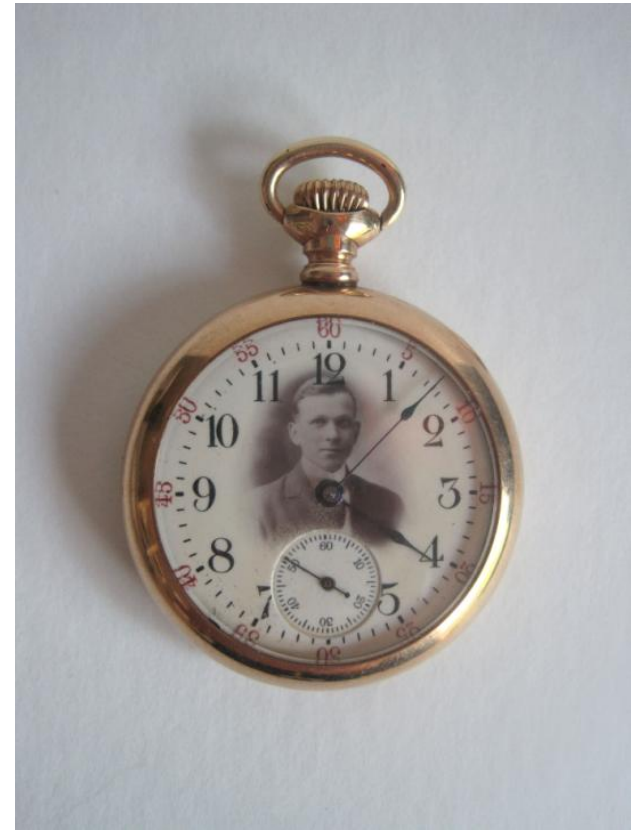

Figure 20a 2004/147; recto

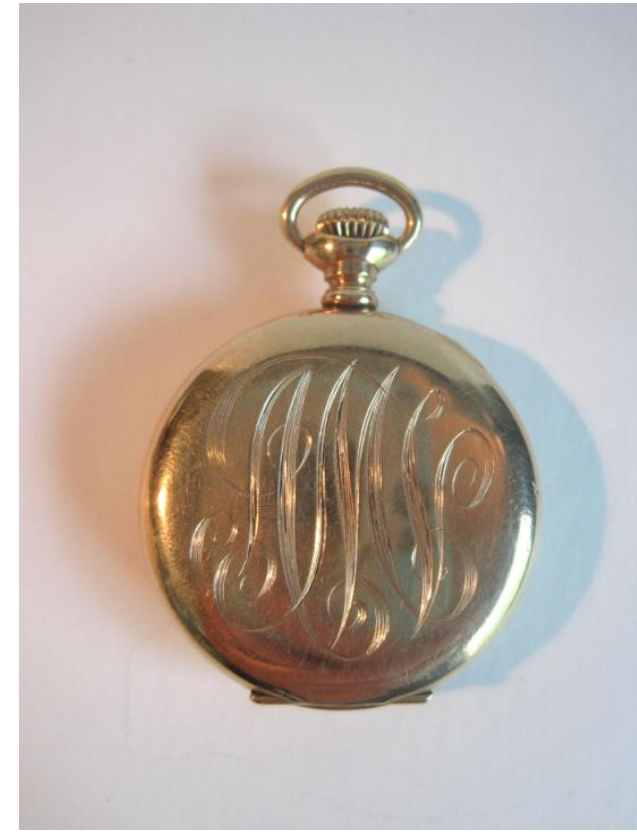

Figure 20b

2004/147; verso

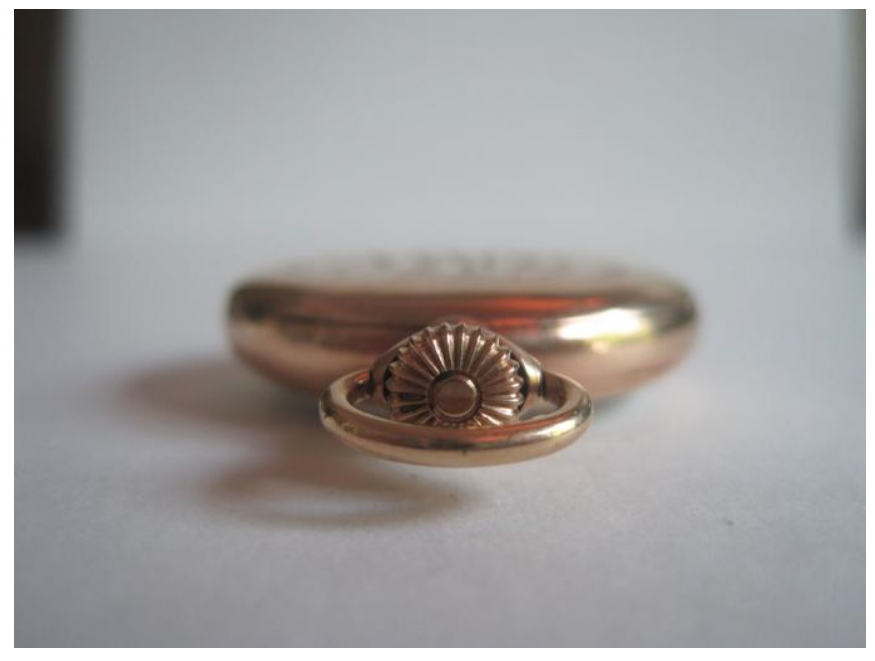

Figure 20c

2004/147; interior 


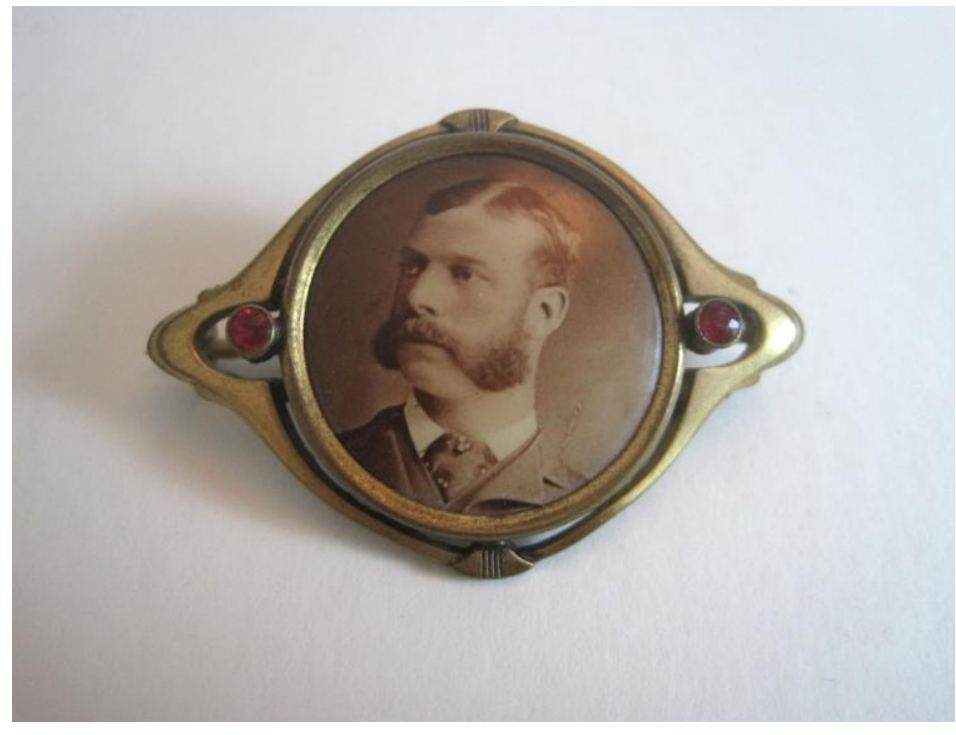

Figure 21a

2004/154; recto

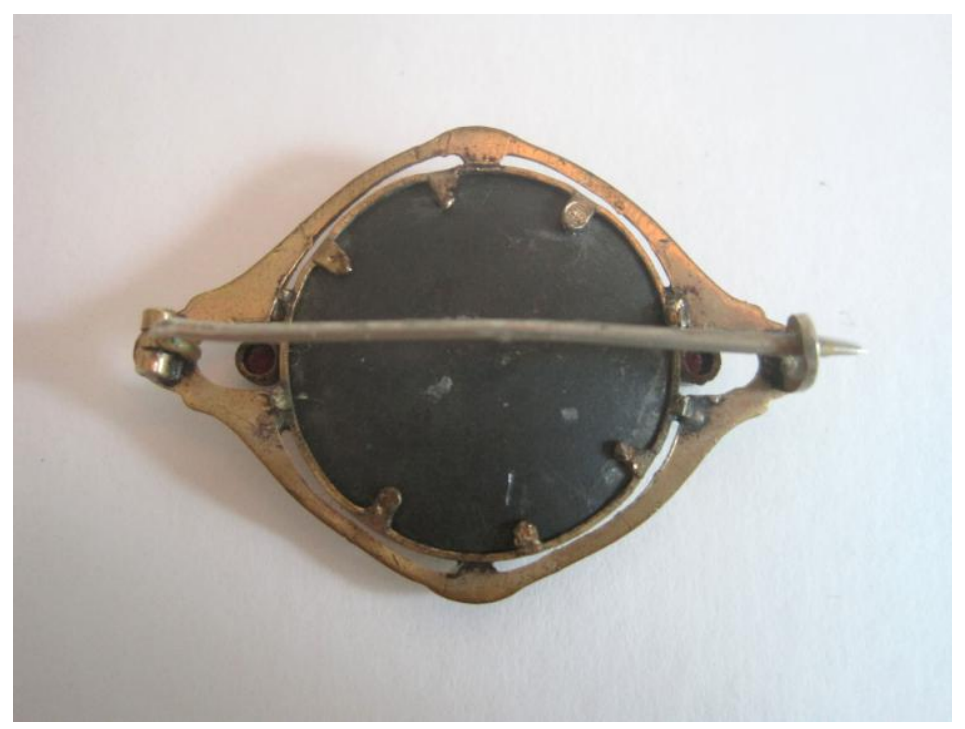

Figure 21b

2004/154; verso 


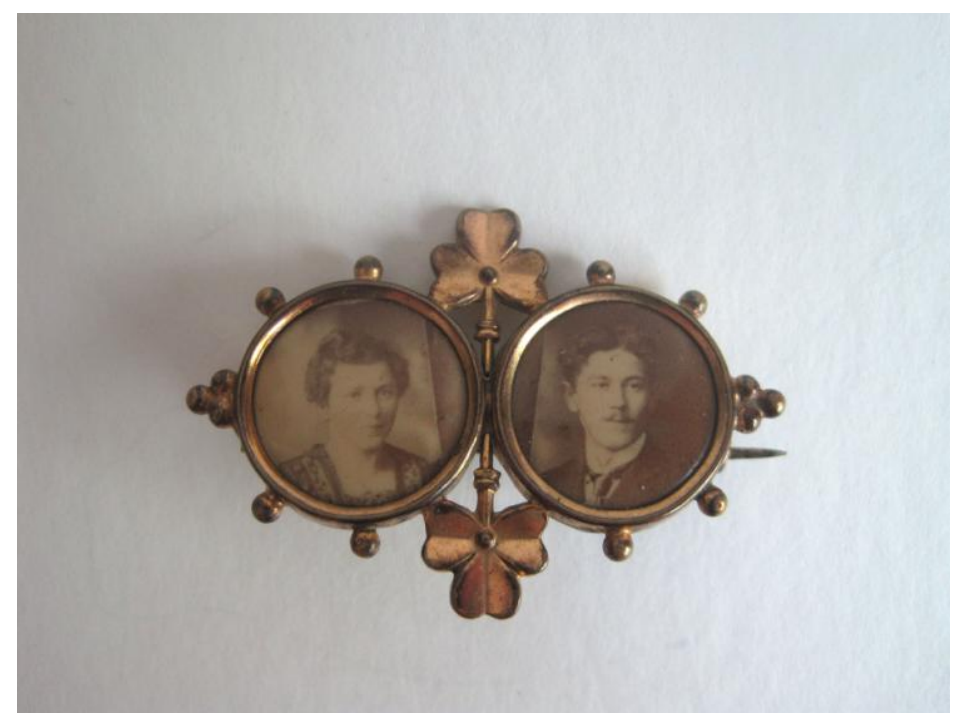

Figure 22a

2006/189; recto

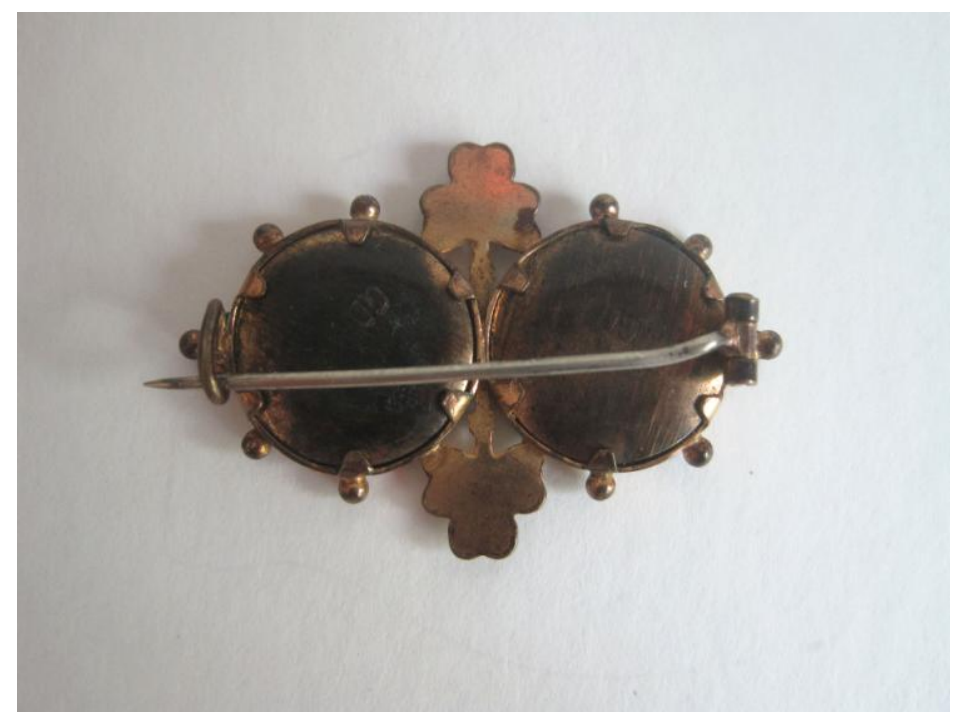

Figure 22b

2006/189; verso 


\section{INTRODUCTION TO CATALOGUING GUIDE \& CONTROLLED VOCABULARY}

The practical component of this thesis was to create a cataloguing guide and controlled vocabulary list that can easily be followed and applied by those wishing to catalogue photographic jewellery. The guide consists of thirty pages that outline the following fields in detail: object count, object level, data fields (artist/creator, object dating, title, medium, and dimensions), handling, accessioning, photographing and digitizing. Extra components exist at the end of the cataloguing guide, such as photographing and properly housing the jewellery, to help ensure each item record is as complete as possible.

It would be ideal to have the guide compatible with every cataloguing system available, however due to time restraints and knowledge restrictions this is not possible. When in doubt about which program to base the guide around, I was advised by private collector, Nicolas Graver, that large database systems with expensive "buy-ins" and annual memberships during all the years of use, add up and that this is not feasible to all institutions and collectors. Therefore, he suggested the guide be set up in an amateur program like FileMakerPro or Excel, and easily convertible to an accessible program so that a wider demographic will be able to use the final product.

As with the cataloguing guide, the controlled vocabulary is a required element in order to maintain consistency among cataloguing records. Vocabulary terms are pre-defined, authorized terms that have been preselected by the designer of the vocabulary that are based on the principles of user 
warrant ${ }^{27}$; these are terms that are projected to be most likely selected by the user. Controlled vocabularies typically also handle the problem of homographs ${ }^{28}$. Although not a very common problem with photographic jewellery, issues with spelling will most definitely occur. As previously mentioned, the word jewellery is spelt several different ways, deriving from its origin. The collection manager who will implement this guide will have to adjust certain word choices according to their country of origin and preference.

There is an extensive vocabulary list of jewellery possibilities, but they typically belong to large groupings: fobs, lockets, necklaces, bracelets, armlets, finger rings, watches, bracelets, buttons, clips, cufflinks, pendants, pins, tie clasps, anklets, toe rings, ear ornaments, hair ornaments, and nose ornaments. Those terms then belong to four larger sections: broad terms (BT), related terms (RT), narrow terms (NT), and specific terms (ST).

The following guide and vocabulary list is adaptable to most cataloguing systems. Many institutions, including the AGO, use The Museum System (TMS). This is the program I have had access to and many illustrations and screen captures illustrate that, but merely as a visual reference.

\footnotetext{
${ }^{27}$ Leise, Fred. "Controlled Vocabularies: An Introduction." The Indexer 26, no.3 (2008): 121-126. ${ }^{28} \mathrm{~A}$ homograph is a word that shares the same written form as another word but has a different meaning.
} 


\section{A Guide for Cataloguing Photographic Jewellery}

Written by Andrea Beiko @2013 


\section{A Guide for Cataloguing Photographic Jewellery}

\section{Table of Contents}

Cataloguing Guide Introduction

Numbering \& Accessioning

Accessioning Objects With More Than One Photograph

Marking the Jewellery

Handling the Jewellery

Photographing/Digitizing

Condition Reports

Photographic Jewellery Condition Report Glossary

Data Fields

Artist/Creator

Dating

Medium

Title

Dimensions

Descriptions

Inscriptions \& Markings

Sources

Controlled Vocabulary Introduction

Controlled Vocabulary List

Photographic Processes

Materials

Definitions A-Z 


\section{A Guide for Cataloguing Photographic Jewellery}

The following is a guide to the accessioning and cataloguing of photographic jewellery within a permanent collection. The examples given throughout this guide will be specific to that of Art Gallery of Ontario (AGO) standards, but can easily be converted to any institutions' standards. The images and screen captures from The Museum System (TMS), but also can be related to most cataloguing system programs.

As defined by Getty's Art \& Architecture Thesaurus, jewellery is an ornament such as a bracelet, necklace, or ring, of precious or semiprecious materials worn or carried on the person for adornment. Photographic Jewellery can be defined as a piece of jewellery containing elements of a photograph. It is a piece of jewellery that contains a photograph of any process affixed on or within the object; it can be worn decoratively or with purpose on the attire or body, and can be classified into the following categories: worn on or around the neck, arms and hands, legs and feet, head, or costume.

NOTE: Be consistent regarding capitalization, punctuation, and syntax. Avoid abbreviations, but when necessary, use standard codes and lists for abbreviations. 


\section{Numbering \& Accessioning}

Whether dealing with a temporary or permanent collection piece, each object must posses an accession number. Accession numbers allow one to differentiate not only separate objects, and permanent collection items from temporary ones, but also to provide documentation. They provide a form of identification that is with that object for its lifespan within a specific institution or collection.

The most common accessioning numbering system is a compound number separated by a forward slash, a period, or a hyphen. A typical set-up is as follows:

The year (YYYY) / forward slash, then the number assigned sequentially within that year.

Example: 2013/1

Sometimes an institution receives a rather large acquisition that contains hundreds, perhaps thousands of objects (this is typical with photographs, but not with photographic jewellery). In this case, the number may be extended; it would be given a group number, another forward slash or period, then a new group number. For example:

The year (YYYY) / forward slash, then the number assigned sequentially within that group / forward slash, then the individual number specific to that object.

Example: 2013/1/1 


\section{Accessioning objects with more than one photograph}

Many photographic jewellery pieces contain more than one photograph. It is preferable that at the time of acquisition, an inventory of components and extensions within the main object is completed. This also applies to jewellery created in a pair; for example, earrings. The earrings as a pair are one object that consists of two components. There would be two records one for each earring - and the records would be linked to one another.

- Count is noted in description field for main object record

- If the piece consists of more than one photograph, both images are given an accession number; the accession number is extended by adding a decimal point

Example 2013/1.1 - .2

The accession number for the jewellery object would be 2013/1 and the accession number for the first photograph would be 2013/1.1 and the accession number for the second photograph would be 2013/1.2

- If the piece consists of more than one photograph, and they are both different mediums, both mediums must be listed within the medium field

- Detachable components, two photographic jewellery pieces attached on one chain, should be noted as unique parts of the object, identified as such by an individual and associated record (parent child relationship established)

- Each object record should have an Object Count value assigned; for each accession number, the object count is based on number of photographs within the object.

Example: If there is only one photograph within the object, the count would then be 1

- Each object record should have an Object Level value assigned

- Records for each of these components will allow for individual condition reports and for proper tracking of individual parts/components for exhibition and 
cataloguing purposes; including exhibition history, light exposure, conservation history, and publication history - Some photographic jewellery pieces consist of not only more than one photograph, but more than one component that also include more than one photograph; each piece would be given a separate object record, and then the photographs within each piece would then be extended with letters 


\section{Marking the jewellery}

Photographic jewellery objects are typically fragile and small in size. Therefore they must be handled with care; with loans, exhibiting, storage/housing, and general handling. When numbering photographic jewellery pieces, after the accession number has been given, acid-free card with reinforced tie holes can be used or a Tyvek@ label (a paper-like material that is near impossible to rip). Most objects can be tied with a $6 \mathrm{~mm}$-wide cotton-tape tie or a cotton string; larger objects may require a 12-mm wide cotton tape tie. The accession number should be written on the tag in Pigma Pen $\odot$, which is archival, acid-free, fade-free, and waterproof. If you cannot find Pigma Pen $@$ or chose not to use it, a softleaded pencil would be best.

Some institutions insist on writing the accession number directly on the object, but a removable tag is preferred. Especially if it is an object that is not handled often, it can be assured that the label will not be lost. If it is an item that is viewed or studied often, a different approach may be necessary to ensure its safety while abiding by institutional guidelines.

Many materials applied directly to the surface of a jewellery piece are either damaging or not durable enough. If you decide writing on the object is best, the following list of items should be avoided:

- Silicone products

- Spray varnishes

- White-out@

- Nail polish

- Nail polish remover

- Ballpoint pen

- Permanent marker

- Chalks

- Metal edged tags

- Nails

- Pins

- Staples

- Other metal fasteners 
When attaching the numbered label, loop the string through the label and tie a knot before attaching the object. This prevents the edge of the label rubbing against the object's surface. The label should always be tied fairly close to the object, so it does not get knotted with any other components. Consider carefully how to attach the label so it won't damage the object or become detached. It can be tied safely through a hole in the objet, or if the object is too small, or if it is round, (with no obvious and safe point for attachment) it can be cross-tied much like a parcel.

When any object is on display, be sure that the tag is either hidden or removed. If the tag is removed from the object while on display, place the tag within the housing container, or in a safe place, and re-attach as soon as the object is no longer on display. 


\section{Handling the Jewellery}

The majority of damage to objects within institutions occurs due to improper handling. Although jewellery is made to be handled and worn, handling of all collections objects should be limited wherever possible. If you are a private collector and you chose to wear the jewellery, treat it with the same care you would your other prized possessions - remove the piece when you are doing any cleaning, laborious jobs, or any other activity in which the piece's care might be in danger.

In comparison to sculptures or large oil paintings, photographic jewellery is very small in size. Therefore, losing or misplacing the jewellery is much more likely than that of a large painting. Always be aware of where you are working; you should be in a clean, well light environment with no food or liquids near the pieces.

It is up to you and/or your institution whether you wear gloves (cotton or latex) while handling the objects. If it is your institutions policy, then you must obey their rules. If dealing with your own private collection, it is up to your discretion. Jewellery was made to endure natural body oils and minimal wear and tear, but as the piece ages it becomes more fragile and direct contact with your hands/body must be limited and observed.

Latex or Nitrile gloves may be preferred over cotton gloves, as cotton is a much thicker material that sometimes inhibits proper handling. Actions such as opening lockets and working with small delicate components will most likely be much more difficult with cotton gloves. 


\section{Photographing/Digitizing}

NOTE: These Guidelines define approaches for creating digital surrogates for facilitating access and reproduction. They are not considered appropriate for preservation reformatting to create surrogates that will replace original records.

Each piece should have a photographic digital file attached to the object file. Preferably, each should consist of a minimum of two images; recto and verso. When more complicated pieces are presented, detailed shots or individual component/extensions can be photographed and attached. Generally, given the high costs and efforts for digitization projects, it is not recommended to digitize anything less than the image parameters provided.

As mentioned, overall images (recto and verso) are required and should also include a colour scale and size scale. Lighting must be adequate, with minimum reflection and shadow; some reflection will mostly likely occur due to many photographic jewellery pieces containing metal, which is inherently reflective. A natural backdrop (preferably white, cream, or black) should be used, and the colour of the backdrop will be dependent on the object being documented.

When many objects are being photographed at once, it is sometimes difficult to keep track of which photograph belongs to which item. Therefore an identification number (catalogue or accession) should be included in the photograph; this also helps in the case of the image being unfortunately separated from its file - it can easily be digitally re-located.

Access Image:

- JPEG file format; medium to high compression, sRGB profile for colour and Gray Gamma 2.2 profile for monochrome

- Images should be 800-3000 pixels/dpi (typically 800-1024 pixels) across long dimension. Adjust accordingly.

- JPEG images should be 8-bit greyscale or 24-bit colour. 
Thumbnail Image:

- JPEG or GIF file format

- Images should fit within a boundary of 150-200 pixels across long dimension (200 pixels preferred)

- JPEG images should be 8-bit greyscale or 24-bit colour. GIF images should be 4-bit greyscale, 8-bit colour.

Master Production Image (optional):

- TIFF file format

- Color and greyscale TIFF files should have ICC colour profiles embedded in the file header, to indicate how the colour and tonal values in the file are to be interpreted.

- TIFF files without embedded profiles will be assumed to be in sRGB colour space if colour, and Gray Gamma 2.2 colour space if monochrome.

(More information about ICC colour profiles can be found on the ICC homepage. The Adobe Photoshop software also includes considerable information about creating, embedding, and using colour profiles.) ; http://www.color.org/index.xalter (ICC)

Thumbnail; Web Browsing:

- JPEG or GIF file format

- Images should be 120 pixels/dpi (minimum of 512 pixels on the long dimension, assuming screen resolution of $600 \times 800$ pixels)

- JPEG file may be compressed 


\section{Condition Reports}

A condition report provides a visual and written description of the location and condition of an objects' state. It can be conducted with two possible intents: the first being for that of intended planning and performing object treatment, and the second is intended for aiding collection management. They are also written before and after a loan has been made or received.

The reports typically include a photograph of the piece(s) in which marks can be made in pencil with either abbreviations or coordinating numbers to describe the condition. Along with the photograph, condition reports include the following general information: accession number, examiner, date examined, artist, title, medium, image size, inscriptions, and any manufacture markings. Check lists for visible defects can also be noted, but that is up to the institution and/or whoever is conducting the report.

Photographic jewellery condition reports would be conducted in the same manner as others within the collection. Institutions typically have a procedure that is followed regarding condition reporting, but if you receive an acquisition that should require more managed attention, more frequent reports may be required.

For private collectors, it is up to you as to how frequent you conduct such reports. They may be conducted annually in order to monitor not only the photographs' condition, but also the state of the jewellery piece (ie. locket hinges, chain links, clasps, etc.).

Please refer to the Photographic Jewellery Condition Report Glossary on the following page for specific terms and their definitions. Other terms may apply to specific pieces, but the following terms will be most common for photographic jewellery. 


\section{Photographic Jewellery Condition Report Glossary}

The following terms and definitions are from Museum Registration Methods $5^{\text {th }}$ Edition (2010) by The AAM Press American Association of Museums: Pages 227-228.
Abrasion: A wearing away of the surface caused by scraping, rubbing, grinding, or friction; often superficial.
Accretion: Any external material deposited on a surface; often results from burial conditions or accidental deposits, such as splashes, drips, flyspecks, etc.

Adhesive residue: May be from glue, paste, or pressure-sensitive tapes.

Bleeding: The suffusion of a colour into adjacent materials; often caused by water or other solvents.

Chip: A defect in a surface characterized by the breaking away of material.

Crack: A surface fracture or fissure across or through a material, either straight-line or branching in form; no loss is implied. A crack may be described as blind when it stops part way, as hairline when it is a tiny fissure, and as open when it is a large fissure.

Crease: A line of crushed of broken fibers, generally made by folding. A dog-ear is a diagonal crease across the corner of a paper, parchment, textile, etc.

Delamination: A separation of layers; splitting.

Dent: A defect in the surface caused by a blow a simple concavity.

Discolouration: A partial or overall change in colour caused by aging, light, or chemical agents. Yellowing and darkening can occur, along with bleaching, the lightening of colour, and fading, a loss of colour or 
a change in hue.

Disjoin: A partial or complete separation of a joint between two members of an object, as distinguished from a crack, tear, check, or split.

Distortion: A warping or misshaping of the original shape; shrinkage may occur.

Embrittlement: A loss of flexibility causing the material (example:, paper, parchment, leather) to break or disintegrate when bent or curled.

Gouge: A defect in the surface where material has been scooped out.

Fold: A turning over of a surface so that it is in contact with itself. The line of flexing may or may not be creased.

Frilling: Separation and lifting of the photographic emulsion from the edges of the support.

Inclusion: Particle accidentally bonded to the surface of an object during manufacture (example: ceramic, plastic, cast metal, paper)

Loss: Missing area or hole.

Missing element: Loss of an integral component of, or an addition or appendage to an object (example: handle, chain)

Mold: Biological in nature, mold or mildew can be in the form of foxing; of coloured, furry or web-like surface excrescences; and/or of musty odor.

Patina: A coloured surface layer, either applied or naturally occurring.

Pest damage: Surface loss, tunneling, holes, fly specks, etc. obviously caused by insects or other pests.

Scratch: Linear surface loss due to abrasion with a sharp point. 
Sheen: A polish produced by handling; often occurs on frequently touched locations.

Silvering: Shiny or mirror-like discolouration in the shadow areas of a photographic image caused by the aging of excessive residual silver compounds.

Soil: A general term denoting any material that dirties, sullies, or smirches an object. Dust is loose soil generally disturbed on surfaces; grime is soil tenaciously held on surfaces; a smear and a fingerprint are types of local grime. A spatter or run is the result of dried droplets or splashes of foreign material.

Stain: A colour change as a result of soiling, adhesives, pest residue, food, oils, etc. a diffuse stain is without a distinct boundary; a discrete stain has a distinct boundary; a liquid stain has a discrete boundary or tideline that is darker than the general area of the stain; a centered stain has a darker or more intensely coloured centre within its general area. In metallic staining, adjacent materials are discoloured as a result of metal corrosion.

Tear: A break in fabric, paper, or other sheet material as a result of tension or torsion.

Wear: Surface erosion, usually at edges, due to repeated handling. 


\section{$\underline{\text { Data Fields }}$}

\section{Artist/Creator}

Definition: The name of the person, institution, agent, or group primarily responsible for the creation of the resource.

Photographic jewellery pieces have a minimum of two artists/creators. It would be extremely rare for the maker of a pocket watch to be the same of the photographer. Jewellery was typically made off site and kept in a stock room within the photography studio.

Both Artist/Creator(s) for Jewellery piece and Artist/Creator(s) for photograph must be included; if unknown for either or both, specify Unknown Artist. If multiple creators, this must be identified via role types for the creator (attributions).

\section{Dating}

Definition: A single date or inclusive dates indicating when the resource was created.

Photographic jewellery cannot always be dated, but the photographic process often helps aid this process. Minor research into jewellery manufactures can also narrow down an estimated time period.

If the exact date is known, then the month-date-year form would be written out.

\section{Example: September $16^{\text {th }} 1987$}

If only an estimated date is known, this must clearly be noted by using either a range of dates, or a circa date form.

\section{Example: 1880-1890 OR c.1885}

- Date for jewellery object will often be different from that of the photograph included; indicate either or both, if known. 
- In either case, list the date for the object first with the word 'object' in brackets, followed by the date for the photograph with the word 'photograph' in brackets.

Example: 1880-1890 (object); 1902 (photograph)

- If neither is known, indicate range of dates or century for the photograph included.

Example: 1845-1885

\section{Medium}

Definition: The substance used within the piece. Must consist of at least one medium.

Photographic jewellery typically consists of two to four mediums.

Traditionally the jewellery base is one medium with the second being the included photograph.

For photographic jewellery with multiple components and photographs, use the following convention for the medium description; include the object name with the medium of the object in brackets, and number of items contained within the object - with the medium included.

\section{Example: Pocket watch (gold electroplated): 2 Photographs within: 1 photographic transfer on enamel, 1 daguerreotype}

\section{Title}

Definition: A concise, identifying name for the resource.

Unlike paintings or photographs created by known artists, photographic jewellery pieces were created by the manufacturers in large quantities, and include photographs taken by unknown photographers. There is no title given to photographic jewellery, therefore institutions and private collectors create their own titles.

The title should be a simple description. Titles can vary from area to area, but it is important to standardise names as much as possible within each 
collection. Using similar words and terms establishes a consistent classification approach to the collection and helps others find what they are after. For example, perhaps begin each title with the type of jewellery.

The type of jewellery should be stated first, followed by a descriptive title enclosed in square brackets. This alerts a researcher that the title has been created by the cataloguer. If by chance a title has been given to a piece of jewellery, the square brackets would then not be used.

Example: Pin [Portrait of young girl holding flowers]

Example: Locket [Portrait of older gentleman in suit]

If the object requires two or more words and consists of a qualifier, it would follow the primary name, being separated by a comma.

Example: Pocket watch with portrait of a baby on clock face, Portrait of Woman wearing glasses (interior of watch)

\section{Dimensions}

Definition: To measure the width, height, and length of an object. Executed numerically, typically either in centimeters or inches depending on country of origin.

Generally, the overall height, length/width, and depth of photographic jewellery should be measured. These measurements should be taken at the point of greatest dimension (ie. at the widest point). Depending on the piece of jewellery, it may be necessary to take a few additional measurements that are specific to the object; this may be important to the identification, display, or use of the piece.

Due to the smaller physical scale of photographic jewellery, measurements should be recorded in centimeters first; some programs will automatically also include the measurements in inches.

NOTE: Once cataloguing an object that is smaller than $1 \mathrm{~cm}$ in width or height, milometers $(\mathrm{mm})$ should then be used in order to achieve 
accurate results.

The width, height, and depth of the jewellery piece should be recorded first, followed by the width and height of the photograph(s); each measurement will be attached to the appropriate accession number. (Please refer to Accessioning $\&$ Numbering on how to properly accession photographic jewellery)

Example: Overall (2013/1/1): $8.4 \mathrm{~cm} X 8.4 \mathrm{~cm} X 2.2 \mathrm{~cm}$

Image (2013/1/1.1): $4.2 \mathrm{~cm} \times 3.0 \mathrm{~cm}$

Image (2013/1/1.2): $1.0 \mathrm{~cm} \times 2.0 \mathrm{~cm}$

\section{Description}

Definition: A brief descriptive statement that characterizes more fully than the title does the scope or content of the resource.

The description is not intended to provide a historical background or personal interpretation of the piece, but rather to do just as it suggests provide a description. The only exception is if there is information that is of extreme interest and/or importance that researchers would be in search of finding. For example, if a piece of photographic jewellery previously belonged to a member of the Royal Family, or included a photograph of someone of importance.

It is useful to begin describing the object from one point to the other - for instance, from top to bottom, or left to right. The sorts of elements to note are shape, colour, materials, texture, ornamentation, method of production, relative size, moving parts, type of photographic processes included in the piece, its components (such as how many photographs the piece contains), and any obvious condition discrepancies (such as a missing half of a locket, or a missing charm from a charm bracelet).

Example: The photograph is set into a two-piece gold-washed brass frame with a loop on the reverse for sewing to a garment. The case design with its simple, raised ornamental border is typical of the gilt-metal buttons mass-produced from 1830 to 1850 
in several New England factories. The button was discovered in the early 1980s in a flea market in Massachusetts.

\section{Inscriptions and Markings}

Definition: A marking, such as the wording on a coin, medal, monument, or seal, that is inscribed on the object.

Some pieces of photographic jewellery include a marking indicating a serial number, signature, text, manufacture, or personal inscription. In some collections it is not mandatory to record these details; however, they can be of some use to researchers. For example, a researcher investigating a specific serial number on a watch would surely be interested to know whether or not the object is still in existence and its current whereabouts. Having this information included in the record, would allow one to search the serial number and bring up the object within your collection.

NOTE: It must be made clear as to whether an inscription was personalized or is the manufacturer marking.

Markings need to be carefully transcribed, and also a placement of the inscription must also be given. If the inscription runs more than one line, a spaced forward slash indicates the line break. Also, any spelling mistakes and capitol letters must also be left in the field.

Example: Engraved on back of watch, centred: To my dearest Mary, / May our love be eternal. / Love always, / John 


\section{$\underline{\text { Sources }}$}

The following sources were used in the creation of the guide.

Buck, Rebecca A., Jean Allman Gilmore, and American Association of Museums. MRM5: Museum Registration Methods 2011. Chicago, Illinois: American Library Association, 2011.

Hughes, Lorna M. Digitizing Collections: Strategic Issues for the Information Manager. London: Facet, 2004.

Whittaker, Beth. Special Collections 2.0: New Technologies for Rare Books, Manuscripts, and Archival Collections. Santa Barbara, California: Libraries Unlimited, 2009. 


\section{Controlled Vocabulary}

A controlled search field is an extremely important component of cataloguing. It provides and maintains consistency among cataloguing records. Vocabulary terms are pre-defined and pre-authorized words which have been preselected by the designer of the vocabulary that are based on the principles of user warrant; these terms are projected to be most likely selected by the user.

No controlled vocabulary selection will be perfect. Researchers will search for terms that will pull no results - but if the collections manager maintains and updates such lists, with time, the controlled vocabulary list can constantly improve.

There is an extensive vocabulary list of jewellery possibilities, but they typically belong to large groupings: fobs, lockets, necklaces, bracelets, armlets, finger rings, watches, bracelets, buttons, clips, cufflinks, pendants, pins, tie clasps, anklets, toe rings, ear ornaments, hair ornaments, and nose ornaments. Those terms then belong to four larger sections: broad terms (BT), related terms (RT), narrow terms (NT), and specific terms (ST). 


\section{Controlled Vocabulary List}

Jewellery $>$ Jewellery by Location

$>$ Jewellery worn around or on the neck

○ Lockets

- Single Locket

- Double Locket

- Locket with more than two components

- Necklaces

- Choker

- Collar

- Lavlieres

○ Enkolpia

$>$ Jewellery worn on arms and hands

○ Armlet

- Bracelets

- Bangles

- Buckle Bracelet

- Charm Bracelet

- Charm

- Identification Bracelet

- Finger Rings

- Charm Ring

- Eternity Ring

- Gimmel Ring

- Mourning Ring

- Poison Ring

- Posy Ring

- Promise Ring

- Signet Ring

- Watches

- Wrist Watch

$$
\begin{array}{ll}
\boldsymbol{D} & =\text { Broad Term }(\mathrm{BT}) \\
\mathrm{O} & =\text { Related Term }(\mathrm{RT}) \\
\mathbf{\square} & =\text { Narrow Term }(\mathrm{NT}) \\
\bullet & =\text { Specific Term }(\mathrm{ST})
\end{array}
$$




\section{$>$ Jewellery worn on costume}

○ Bracelets

- Mourning Bracelet

- Button

- Clip

- Cuff Links

○ Fobs

- Watch Fob

- Key Fob

- Pendants

- Bracteates

- Bullae

- Charm

$\circ$ Pins

- Bar Pin

- Brooch

- Disc Brooch

- Penannular Brooch

- Plaques

- Lapel Pin

- Scatter Pin

- Stickpin

- Tie Clasp

○ Tie Tack

- Watches

- Keywind

- Key-set Movements

- Lever-set Movements

- Pin-set Movements

- Stem-set Movements

- Pocket Watch

- Open-faced Watch

- Hunter-cased Watch

- Watch Locket 


\section{$>$ Jewellery worn on legs and feet \\ - Anklet \\ - Toe Ring}

$>$ Jewellery worn on the head

- Ear Ornaments

- Earrings

- Button Earring

- Ear Clips

- Pendant Earring

- Pierced Earring

- Earspool

- Hair Ornaments

- Hair Pin

- Hair Band

- Nose Ornaments

- Nose Ring

\section{Photographic Processes}

- Albumen Print

- Ambrotype

- Carbon Print

- Celluloid Print

- Daguerreotype

- Gelatin Silver Print

- Mixed Media

- Tintype

$$
\begin{aligned}
& \boldsymbol{D}=\text { Broad Term }(\mathrm{BT}) \\
& \mathrm{O}=\text { Related Term }(\mathrm{RT}) \\
& \mathbf{\square}=\text { Narrow Term }(\mathrm{NT}) \\
& \bullet=\text { Specific Term }(\mathrm{ST})
\end{aligned}
$$




\section{$>$ Materials}

- Bakelite (Plastic); First produced in 1909, Bakelite is a phenolformaldehyde resin made in opaque colours and/or a clear transparent form which can be dyed. Bakelite has been used to replicate amber and to produce imitation faceted stones. It is typically easy to identify because, unlike metal, it is very light, warm to the touch, and can be scratched with a knife blade. It has the disadvantage of yellowing with age. (Mason, Anita, Diane Packer. An Illustrated Dictionary of Jewellery. Reading, Berkshire: Osprey Publishing Limited, 1973. Pages 289-290)

- Bronze; An alloy of approximately 8 parts copper to 1 part tin, sometimes also containing small amounts of lead and zinc. Since the merging of barbarian and classical styles of jewellery at the beginning of the Middle Ages bronze has had very little place in jewellery. A variety of base metals, cheaper and sometimes more attractive than bronze, became available. (Mason, Anita, Diane Packer. An Illustrated Dictionary of Jewellery. Reading, Berkshire: Osprey Publishing Limited, 1973. Page 45)

- Gems; Typically possessing no function, other than decorative, an array of gems can be incorporated in any jewellery piece including photographic jewellery. Typically gems are seen as the centrepiece within a brooch or necklace - with photographic jewellery, gems would be used as decorative elements.

- Glass; A non-crystalline substance produced by a fusion of oxides (or one acidic oxide) at a high temperature/ Numerous materials may be used in making glass, but a major constituent of nearly all glass is silica. It can be coloured and can immolate stones and gems for a fraction of the cost. With photographic jewellery, it is often a component of a watch, or locket. It is also used for protecting daguerreotypes. (Mason, Anita, Diane Packer. An Illustrated Dictionary of Jewellery. Reading, Berkshire: Osprey Publishing Limited, 1973. Page 161) 
- Gold; in many ways gold is the ideal metal for jewellery, and its advantages have been recognized since very early times. It is sometimes the main component in manufactures' pocket watches, and in rings. Most kinds of jewellery can be made from gold; others can be coated in gold. Cheaper metals would be coated with gold to give the illusion of being of higher quality.

- Hair; Human and animal hair has been incorporated in jewellery since the seventeenth century. The hair is typically woven to create decorative elements for the piece; either a background, plaited into a bracelet, or incorporated in a locket. (Mason, Anita, Diane Packer. An Illustrated Dictionary of Jewellery. Reading, Berkshire: Osprey Publishing Limited, 1973. Pages 176-177)

- Ivory; A material used ornamentally from very early times on account of its mellow appearance, elasticity and the ease with which it can be fashioned and carved. There are many different kinds of ivory (elephant ivory, fossil ivory, hippopotamus ivory, walrus ivory, vegetable ivory) that are all used to create either the base for a jewellery piece, or as an added element on a pendant, brooch, or ring. The material most commonly used to imitate ivory is celluloid, which can be given a convincing colour and weight. (Mason, Anita, Diane Packer. An Illustrated Dictionary of Jewellery. Reading, Berkshire: Osprey Publishing Limited, 1973. Pages 199200)

- Pearl; Pearls are among the most precious, and were probably one of the earliest materials used in jewellery. Pearls are available in a wide range of sizes and colours. With photographic jewellery, they would be incorporated as an added, decorative element within a piece.

- Silver; The most common of the precious metals, silver has working qualities almost as good as those of gold. The advantage is that silver is much cheaper. Many photographic lockets and 
rings were made of silver. Silver is also used in many photographic processes as the base component. 
The following definitions were gathered from numerous resources. If a reliable definition could not be found, they were written by myself. The letters in brackets following the definition indicate which source it is derived from. The legend for the sources is as follows:

GAT (Getty Art \& Architecture Thesaurus; website http://www.getty.edu)

GEMA (Gem Affair; website http://www.gemaffair.com)

DOJ (An Illustrated Dictionary of Jewellery by Anita Mason and Diane Packer.

Reading, Berkshire: Osprey Publishing Limited, 1973)

Anklet; Ornamental bands, rings, or chains worn around the ankle. (GAT)

Armlet; Ornamental bands or circlets worn on the upper arm. (GAT)

Bangles; Nonflexible bracelets that slip over the hand or which are hinged and closed by a clasp. (GAT)

Bar Pin; Long, narrow ornamental pins. (GAT)

Bauble; A small, showy ornament of little value; a trinket. (GEMA)

Bracelet; Ornamental bands or circlets worn on the lower arm. Use "armlets" for similar articles worn on the upper arm. (GAT)

Bracteates; Pendants in the form of discs of thin, beaten gold or silver with stamped decoration based on Roman coin or medallion prototypes or with runic inscriptions. Suspended by means of a circular attachment and intended to be worn on a thong or other support around the neck. (GAT)

Brooch; Ornamental jewelry made in a variety of forms fastened by a pin. For decorative items, similar in appearance to a brooch, but attached to a garment with a spring fastening, use "clips (jewelry)." (GAT)

Buckle Bracelet; A bracelet that features a buckle closure as opposed to a more traditional clasp like a toggle, lobster, or fishhook clasp. These bracelets are commonly made of leather or finely woven metal fibers. (GEMA)

Bullae; Small pendants, usually of gold but sometimes of leather, designed as containers for amulets; use especially for those of Etruscan origin. (GAT)

Button; Buttons are seldom elaborate enough to be considered as articles of jewellery, but they can include a photograph as the face of the button. They were worn very large; sometimes enamel surrounded by marcasite, and garnet surrounded by pearls, cut steel, 
and often flower shaped. (DOJ)

Button Earring; An earring that has no movable parts. (GEMA)

Charms; Small pendants worn for luck or decoration. (GAT)

Charm Bracelet; Bracelets of metal links, to which are attached charms or trinkets, often acquired as souvenirs or mementos. (GAT)

Charm Ring; A ring that features a dangling charm from the top. (GEMA)

Choker; Short, narrow necklaces worn close to the throat. For wide ornamental bands worn tightly around the neck, use "dog collars." (GAT)

Clip; Decorative items, similar in appearance to a brooch, but attached to a garment with a spring fastening. For jewelry made in a variety of forms fastened by a pin, uses "brooches." (GAT)

Collar; Worn during the sixteenth century, but were never an important feature of dress until the late Victorian period, when they became indispensable for fashionable women. In 1885 they consisted of broad bands of velvet - worn plain or decorated with beads for those of modest means, covered with previous stones for the wealthy. (DOJ)

Cuff Link; Linked ornamental buttons or button like devices for fastening a shirt cuff. (GAT)

Disc Broche; Brooches made in the form of a flat disc, to the back of which is attached a fastening pin. (GAT)

Double Locket; A locket containing two photographs. Typically facing each other, when the locket is closed, this piece of jewellery is very common within photographic jewellery.

Ear Clips; Earrings with clip fasteners. (GAT)

Ear Ornaments; Decorative items worn in, on, or about the ear. (GAT)

Earspool; Spool-shaped ear ornaments worn through an enlarged hole in the earlobe. (GAT)

Earrings; Ear ornaments worn suspended from a bent wire or a thin loop passed through a hole pierced in the lobe of the ear or clipped or screwed to the lobe. (GAT) 
Enkolpia; (cross - religion) Pectoral medallions, suspended from the neck, bearing a sacred picture; worn by bishops of the Orthodox Eastern Church. (GAT)

Eternity Ring; Rings in the form of a circular band set with a continuous row of gemstones, usually diamonds, of the same size and cut. (GAT)

Finger Ring; Small circular bands worn on the finger; typically circlets of real or simulated precious metal, and frequently set with precious stones or imitations of these, intended for wearing upon the finger either as an ornament or as a token. (GAT)

Fobs; Small ornaments or medallions suspended from a watch; sometimes includes a short chain, mesh like band, or ribbon. (GAT)

Gimmel Ring; A ring formed of two or more linked hoops that fit together. The loops were often surmounted by hands, which would clasp when the ring was put together. Used for both betrothal and wedding rings, and in some cases they were made so that they could be taken apart and be worn separately by the couple, then symbolically joined together at the wedding. (DOJ)

Hair Ornament; Worn in the hair purely for decoration; can vary in size from rather small and unnoticeable, to a main focus piece of a costume.

Hair Pin; A thin cylindrical strip of metal or other material bent in the shape of a long $U$, used to secure a hair style or headdress.

Hair Band; Bands worn around the head, made of cloth, leather, metal, or various other materials, typically worn to keep the hair in place, for decorative purposes, or as a sign of status or rank. (GAT)

Hunter-cased Watch; A hunter-case pocket watch ("hunter") contains a spring-hinged circular metal lid or cover, that closes over the watch-dial and crystal, protecting them from dust, scratches and other damage or debris. The majority of antique and vintage hunter-case watches have the lid-hinges at the 9 o'clock position and the stem, crown and bow of the watch at the 3 o'clock position. Modern hunter-case pocket watches usually have the hinges for the lid at the 6 o'clock position and the stem, crown and bow at the 12 o'clock position, as with open-face watches. In both styles of watch-cases, the sub-seconds dial was always at the 6 o' clock position. (DOJ)

Identification Bracelet; Bracelets generally of metal chain interlinked with a plain metal strip bearing a name or other identification. (GAT)

Key-set Movements (Keywind); The very first pocket watches, since their creation in the 16th century, up until the third quarter of the 19th century, had key-wind and key- 
set movements. A watch key was necessary to wind the watch and to set the time. This was usually done by opening the caseback and putting the key over the winding-arbor (which was set over the watch's winding-wheel, to wind the mainspring) or by putting the key onto the setting-arbor, which was connected with the minute-wheel and turned the hands. (DOJ)

Lavlieres; Popular name for small, delicate pendants which are suspended from a chain to form a necklace. (GAT)

Lever-set Movements (Stem-Wind); Mandatory for all railroad watches after roughly 1908 , this kind of pocket watch was set by opening the crystal and bezel and pulling out the setting-lever (some hunter cases have levers accessible without removing the crystal or bezel), which was generally found at either the 10 or 2 o'clock positions on open-faced watches, and at 5:00 on hunting cased watches. Once the lever was pulled out, the crown could be turned to set the time. The lever was then pushed back in and the crystal and bezel were closed over the dial again. This method of time setting on pocket watches was preferred by American and Canadian railroads, as lever setting watches make accidental time changes impossible. After 1908, lever setting was generally required for new watches entering service on American railroads. (DOJ)

Locket; Small decorative cases, opening to reveal a portrait or memento, generally worn suspended from a chain around the neck. (GAT)

Mourning Ring; Finger rings made in memory of a deceased person, often distributed at funerals, generally gold with black or of blue or white enamel, bearing the name of the deceased and birth and death dates, sometimes incorporating a lock of hair, portraits, or sentimental scenes. (GAT)

Necklace; Ornaments worn around the neck, usually in the form of chains or strands of beads, pearls, stones, or decorative or precious materials, and often including a suspended ornamental pendant. Use "chokers" for short, narrow necklaces worn close to the throat. Use "dog collars (necklaces)" for wide ornamental bands worn tightly around the neck. (GAT)

Nose Ornament; Decorative items worn in, on, or about the nose. (GAT)

Nose Ring; Ring-shaped ornaments worn in the nose. (GAT)

Open-faced Watch; An open-faced watch is one in which the case lacks a metal cover to protect the crystal. It is typical for an open-faced watch to have the pendant located at 12:00 and the sub-second dial located at 6:00. After 1908, watches approved for railroad service were required to be cased in open-faced cases with the winding stem at 12:00. (DOJ) 
Penannular Brooch; (Celtic brooch) Discontinuous, ring-shaped brooches with two terminals which are often flattened and highly decorative. (GAT)

Pendant; Hanging articles of jewelry, usually suspended from a necklace, brooch, or earrings, but also includes Renaissance examples fastened to the sleeve often worn as decorative ornaments; can also be an article of devotional, magical, or mourning jewelry which then may sometimes be concealed under clothing. (GAT)

Pendant Earrings; Earrings that incorporate additional dangling ornamental elements in their design. (GAT)

Pierced Earrings; Earrings attached through a hole in the lobe of the ear. (GAT)

Pin-set Movements (Stem-Wind); Much like the lever-set movements, these pocket watches had a small pin or knob next to the watch-stem that had to be depressed before turning the crown to set the time and releasing the pin when the correct time had been set. This style of watch is occasionally referred to as "nail set", as the set button must be pressed using a finger nail. (DOJ)

Pin; Ornaments consisting essentially or partly of a pointed penetrating wire or shaft. (GAT)

Plaques; Plate-like usually rectangular brooches; may be ornamental or badges of honorary orders. (GAT)

Pocket Watch; Watches meant to be carried in pockets, as opposed, for example to be worn on the wrist or carried on chains. (GAT)

Poison Ring; A ring with a hidden hinged compartment that could conceivably contain poison. (GEMA)

Posy Ring; Finger rings that are engraved with a posy, a brief, sentimental expression. From the 17th century, often an engagement ring or wedding ring. (GAT)

Promise Ring; A ring given to another or worn by the purchaser that symbolizes a promise or vow. Commonly worn by couples, friends or those who take a vow to remain pure. The latter are also called purity rings. (GEMA)

Scatter Pin; Small pins intended to be worn in clusters, often in the shape of insects. (GAT) 
Signet Ring; Finger rings made with a signet or seal and used from the earliest times for the utilitarian purpose of authenticating a document by impressing the seal, or later for ornamental wear. (GAT)

Single Locket; A locket containing one photograph. The facing side could remain empty, have an inscription, or contain a lock of hair.

Stem-set Movements (Stem-Wind); The first stem-wind and stem-set pocket watches were sold during the Great Exhibition in London in 1851 and the first owners of these new kinds of watches were Queen Victoria and Prince Albert. Stem-wind, stem-set movements are the most common type of watch-movement found in both vintage and modern pocket watches. The mainstream transition to the use of Stem-wind, stem-set watches occurred at around the same time as the end of the manufacture and use of the fusee watch. (DOJ)

Stickpin; Long, straight pins with a decorative head and sometimes a sheath for encasing the point. (GAT)

Tie Clasp; Ornamental metal clasps that secure by tension the two ends of a necktie to a shirt front. (GAT)

Tie Tack; Ornamental pins, made with a wide variety of decorative heads, whose point pierces and holds a necktie to a shirt and fits into a receiving snap or button on the underside. (GAT)

Toe Ring; Rings worn on one of the toes. (GAT)

Watch; A functional piece which can be found in many different sizes. Timepieces small and convenient enough to be carried about on a person. (GAT)

Watch Locket; A watch that is contained within a locket. Typically suspended from a chain or necklace. To be worn around the neck.

Wrist Watch; Watches attached to bands or straps and worn about the wrist. (GAT) 
FULL AGO PHOTOGRAPHIC JEWELLERY CATALOGUE 


\section{Photographer Unknown \\ Manufacturer Unknown}

Locket [Portrait of a Woman, Portrait of a Woman with Collar]

c. 1860

locket; silver plated; 2 photographs within: 1 daguerreotype (left), 1 ambrotype (right)

Image (left): $3.5 \times 3.5 \mathrm{~cm}(13 / 8 \times 13 / 8 \mathrm{in}$.)

Image (right): $3.5 \times 3.5 \mathrm{~cm}(13 / 8 \times 13 / 8 \mathrm{in}$. $)$

Overall diameter (jewellery): $4.5 \times 4.5 \mathrm{~cm}(13 / 4 \times 13 / 4 \mathrm{in}$.)

This double portrait locket contains two daguerreotypes that reside within a gold plated locket. The exterior of the locket is very ornate; the recto contains a depiction of a landscape surrounded by a decorative border. The verso has the same decorative border and a simple line design. A loop resides at the top of the locket suggesting it was intended to be worn on a chain.

Anonymous Gift, 2001

$2001 / 170$
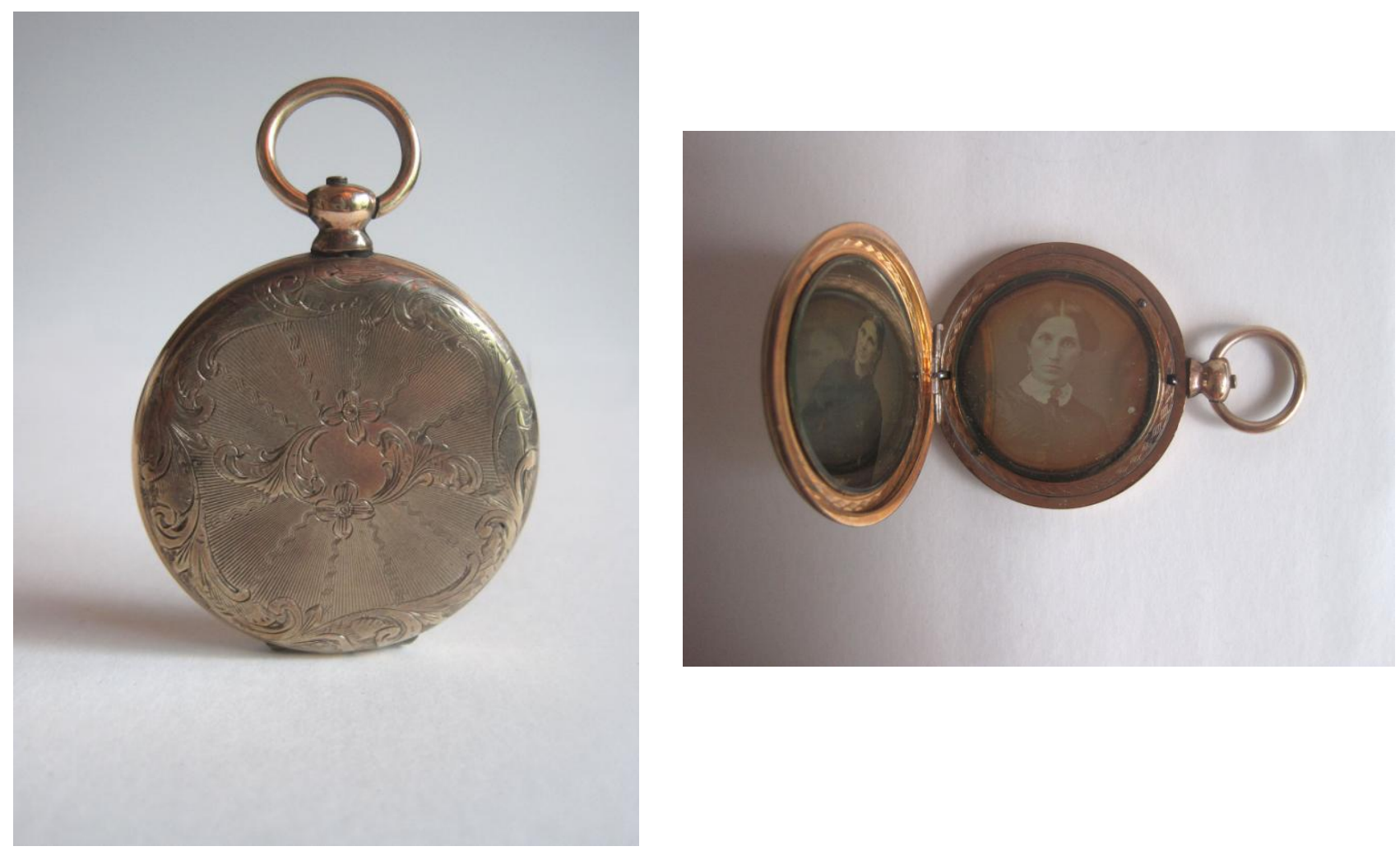


\section{Photographer Unknown}

\section{Manufacturer Unknown}

\section{Locket [Portrait of an Elderly Man, Portrait of an Elderly Woman]}

c. 1860

locket; silver plated; 2 photographs within: 2 daguerreotypes (left and right)

Overall diameter (jewellery): $4.5 \times 4.5 \mathrm{~cm}(13 / 4 \times 13 / 4$ in.)

Image (left): $3.5 \times 3.5 \mathrm{~cm}(13 / 8 \times 13 / 8 \mathrm{in}$.)

Image (right): $3.5 \times 3.5 \mathrm{~cm}(13 / 8 \times 13 / 8$ in. $)$

A simply designed silver plated locket containing two portrait daguerreotypes. The design on the exterior of the locket is identical on both the recto and verso a very simple pattern. The two portraits within are of an elderly man and an elderly woman. The portraits would face each other when the locket is closed which makes one presume this double portrait locket reflects a married couple. Anonymous Gift, 2001 $2001 / 171$
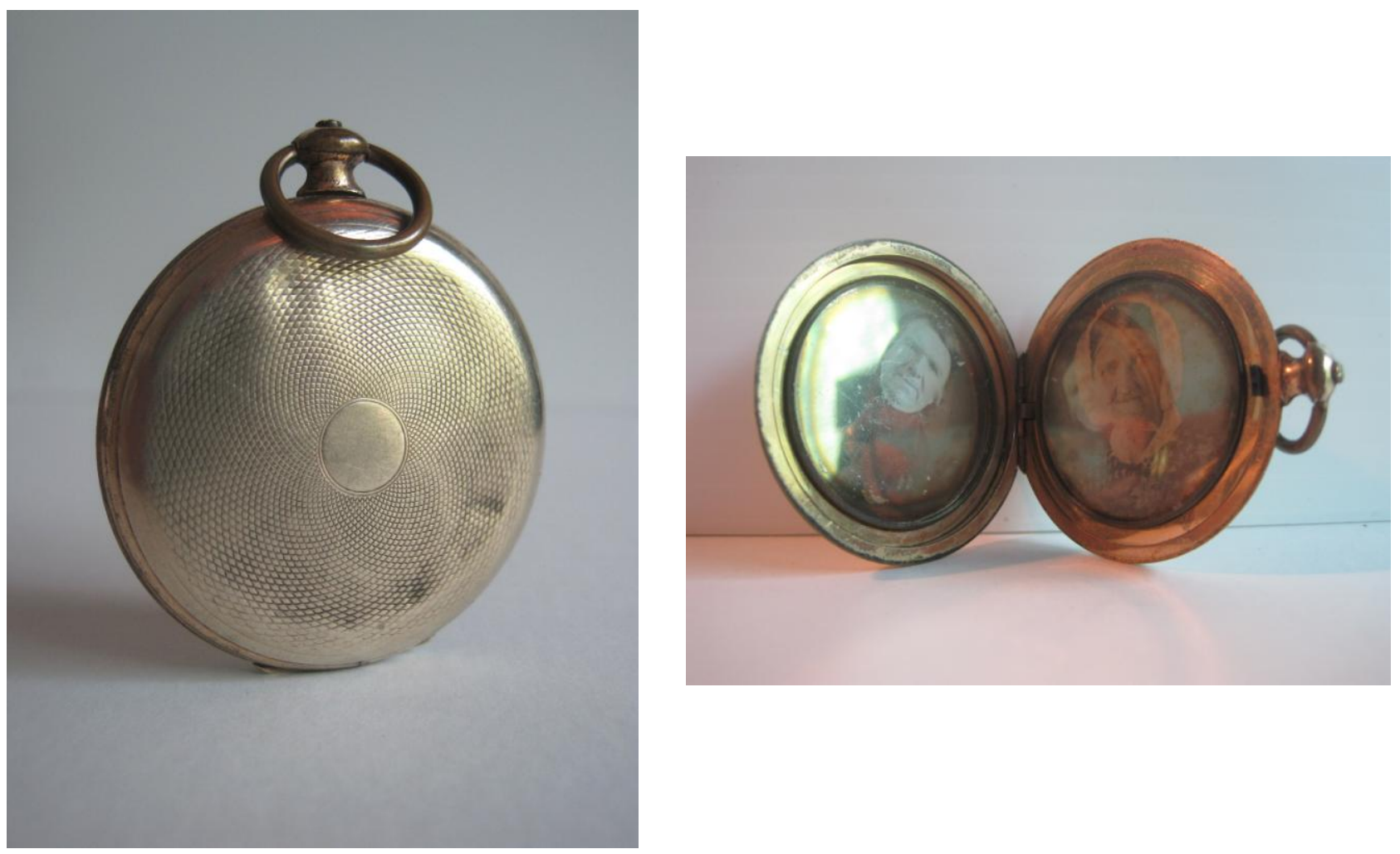


\section{Photographer Unknown \\ Manufacturer Unknown}

Locket [Portrait of man with mustache, lock of hair]

c. 1900

locket; black metal case; 1 bromide toned print, hair

Overall diameter (jewellery): $5 \mathrm{~cm}, 5 \mathrm{lb} .(115 / 16 \mathrm{in} ., 2.3 \mathrm{~kg})$

Image: $4.2 \times 4.2 \mathrm{~cm}(15 / 8 \times 15 / 8 \mathrm{in}$.)

A portrait of a man with a mustache resides within a case covered in black material. This case also possesses a lock of hair; to whom the hair belonged to, remains unknown. The locket's exterior design is quite simple; the recto and verso covered in the same dark material. There is no top loop for a chain, therefore this would have most likely been a pocket piece, or a displayed piece of jewellery within a home.

Anonymous Gift, 2001

2001/172
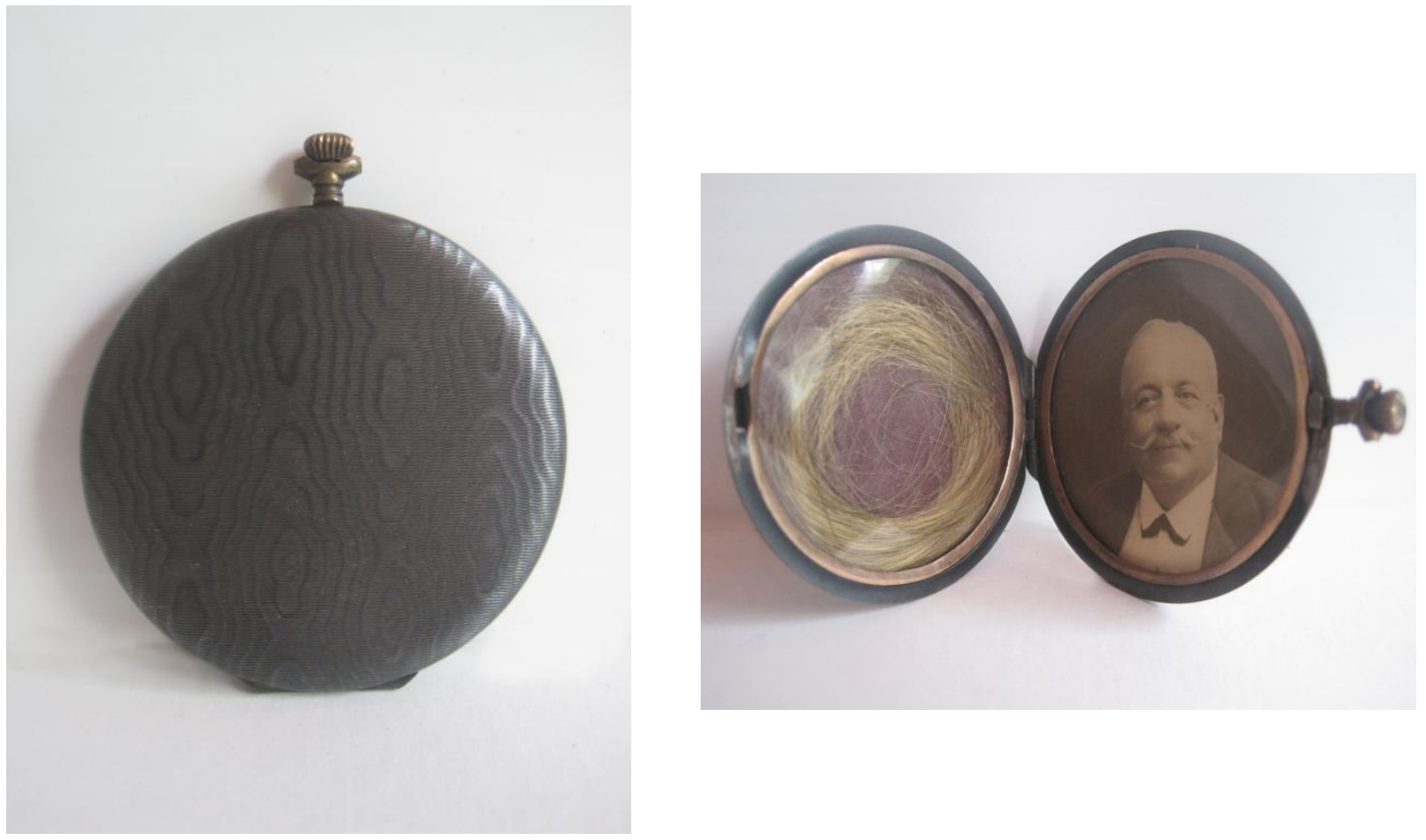


\section{Photographer Unknown \\ Manufacturer Unknown}

Locket [Portrait of a woman wearing a bonnet]

1850s

locket; gold plated; 1 daguerreotype

Image: $3.6 \times 3.6 \mathrm{~cm}(17 / 16 \times 17 / 16$ in. $)$

Overall diameter (jewellery): $4.7 \times 4.7 \mathrm{~cm}(17 / 8 \times 17 / 8 \mathrm{in}$.)

This single portrait locket is of a middle-aged woman wearing a bonnet. Her portrait is on the right interior of the locket, and on the left interior is a dark material being glass. The exterior of the gold plated locket is extremely simple in its design; the recto and verso design is identical.

Anonymous Gift, 2002

2002/9421
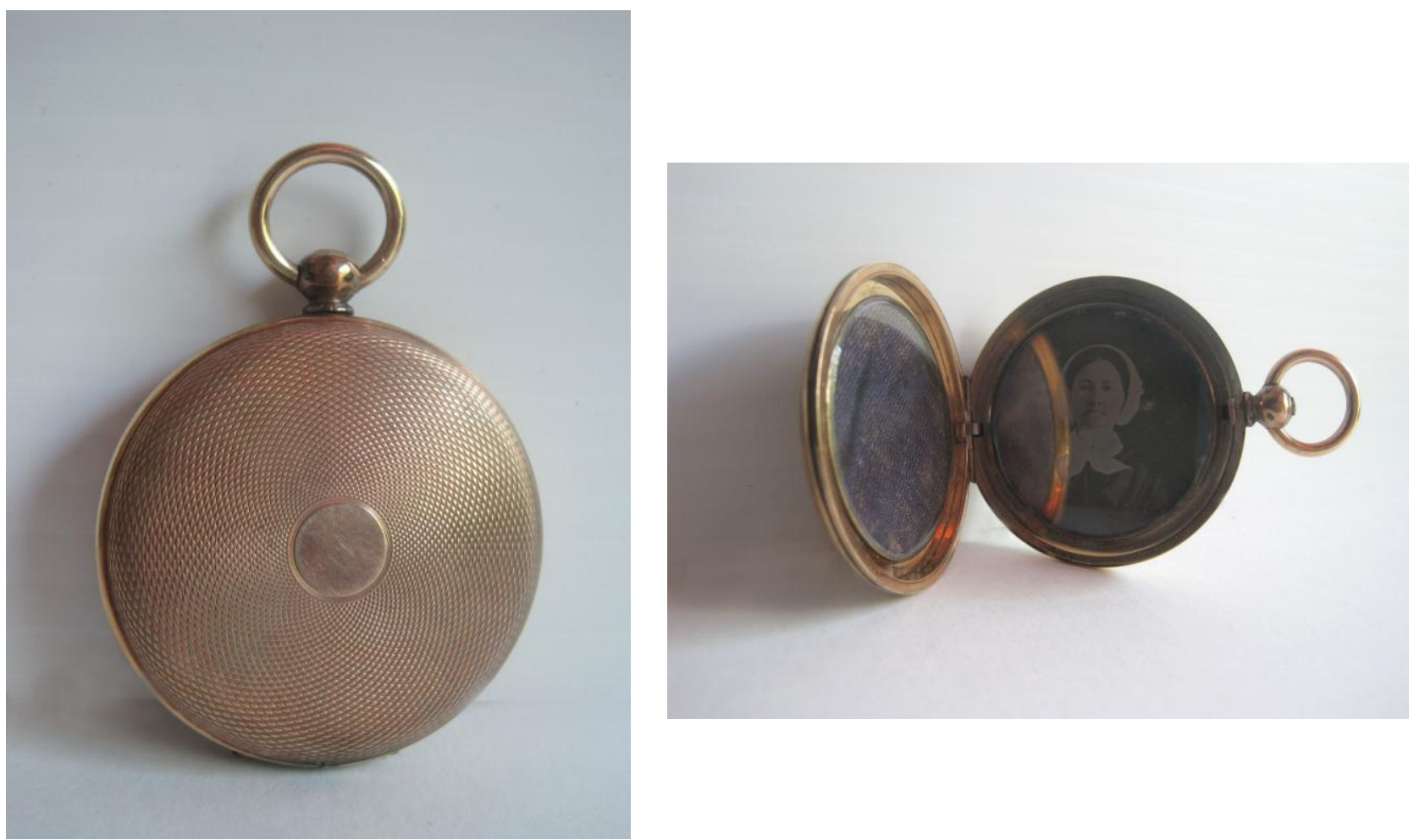


\section{Photographer Unknown \\ Manufacturer Unknown}

\section{Locket [Portrait of a boy, Portrait of a young man]}

1870s

locket; gold plated; 2 photographs within: 2 tintypes

Overall diameter (jewellery): $4.3 \times 4.3 \mathrm{~cm}(111 / 16 \times 111 / 16 \mathrm{in}$.)

Image (top): $3.3 \times 3.3 \mathrm{~cm}(15 / 16 \times 15 / 16$ in.)

Image (bottom): $4.3 \times 4.3 \mathrm{~cm}(111 / 16 \times 111 / 16 \mathrm{in}$.)

The exterior of this double tintype portrait locket is gold plated and contains a detailed design. The recto includes a border design with a landscape depicted within the border. The verso has a detailed decorative design. The two portraits are of young men; one younger than the other.

Anonymous Gift, 2002

2002/9422
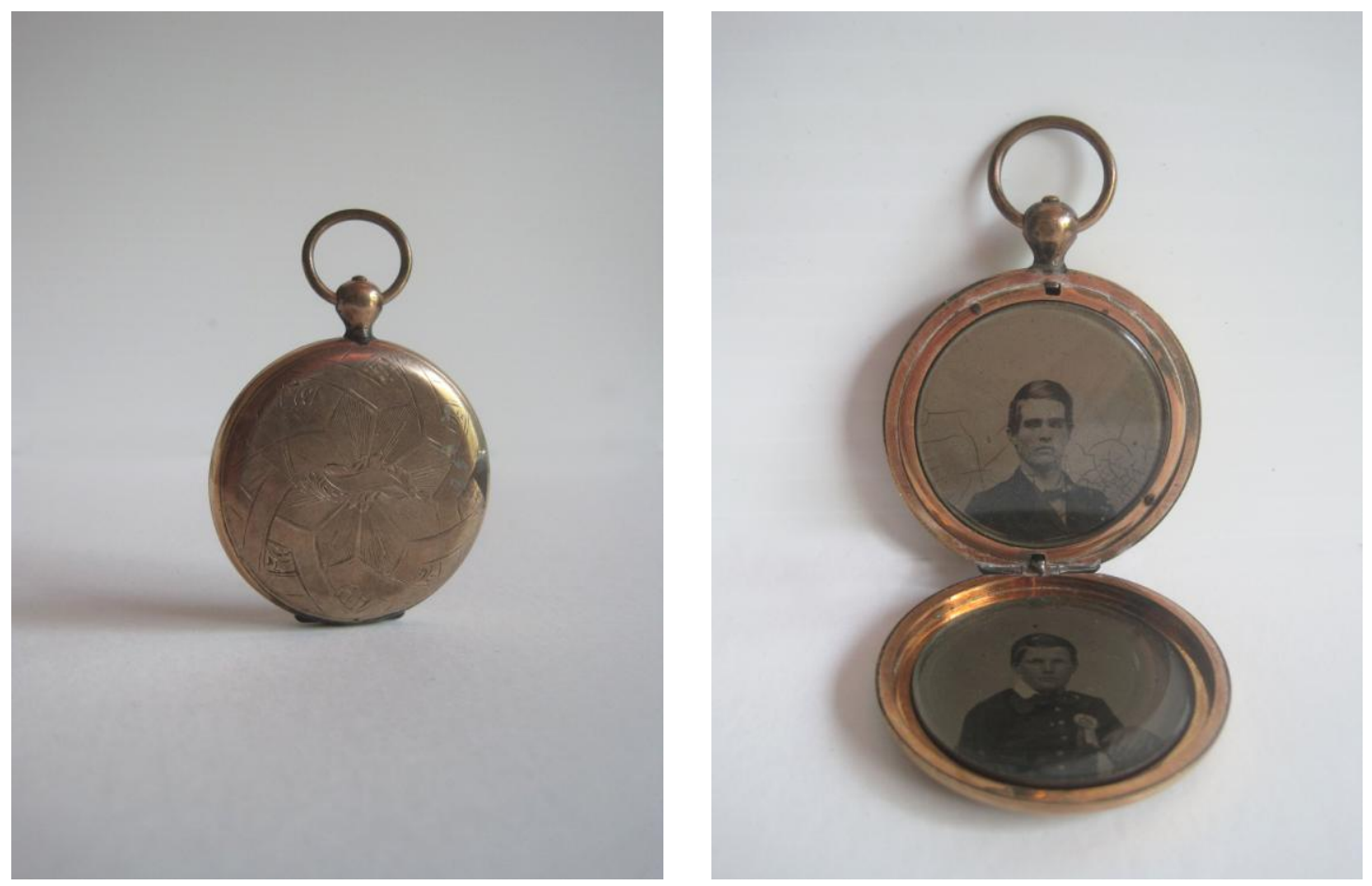


\section{Photographer Unknown}

\section{Keystone Watch Co., American}

Pocket watch [Portrait of a baby on clock face, Portrait of woman wearing

glasses in interior of verso]

c. 1892

Pocket watch; gold plated; 1 transfer on enamel

Overall diameter (jewellery): $5 \times 5 \mathrm{~cm}(115 / 16 \times 115 / 16 \mathrm{in}$.)

Image (on clock face): $2 \times 2 \mathrm{~cm}(13 / 16 \times 13 / 16 \mathrm{in}$.)

Image (within hinge - verso): $4.7 \times 4.7 \mathrm{~cm}(17 / 8 \times 17 / 8$ in.)

Inscribed, centre: $11367 \mathrm{No} ; 83952$

This is an example of a large pocket watch with a unique way to display two photographs. The first photograph is on the clock face; a young child's portrait is incorporated onto the recto of the watch. The verso contains a hinged back where the second portrait can be found within; the portrait of a woman wearing glasses. The watch is from Keystone Watch Case Company. The E. Howard Watch Co. ceased to make watches and in 1903 they sold to the Keystone Watch Case Co. Keystone then purchased the old US Watch Co. Factory in Waltham, Massachusetts where production took place.

Anonymous Gift, 2004

$2004 / 146$
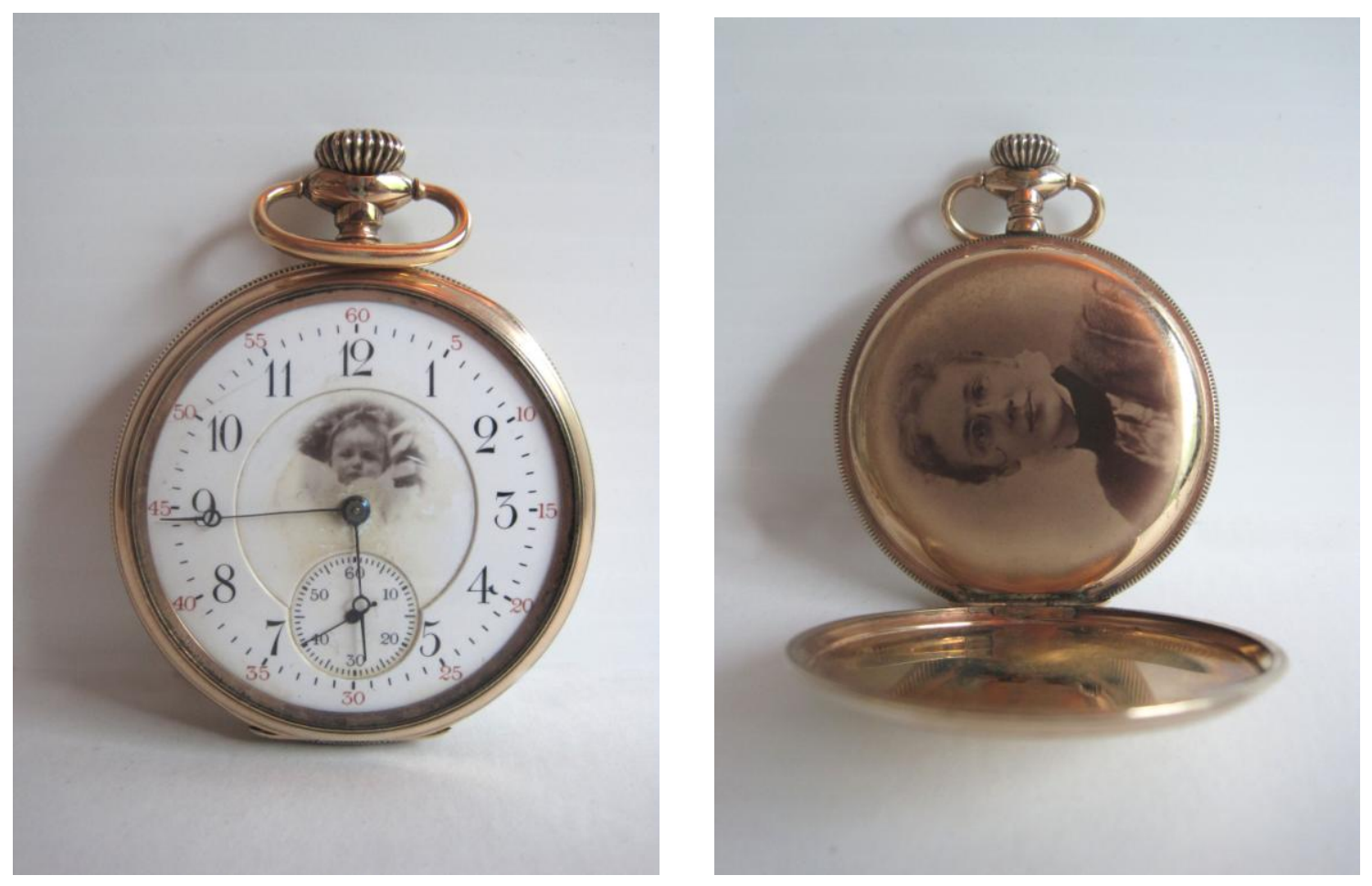


\section{Photographer Unknown}

\section{C.W.C. Co. Planet Watch, American}

\section{Pocket watch [Portrait of young man on clock face]}

\section{c. 1910}

Pocket watch; gold plated; 1 photographic image on enamel

Overall diameter (jewellery): $3.5 \times 3.5 \mathrm{~cm}(13 / 8 \times 13 / 8$ in.)

Image: $1.8 \times 1.5 \mathrm{~cm}(11 / 16 \times 9 / 16 \mathrm{in}$.)

Inscribed within interior of hinged backing, top: $21844 \mathrm{~W}$

A twentieth-century example of a pocket watch with a single portrait on the clock face. The portrait of a young man is incorporated into the clock face (recto) which uses natural numbers. The back inside of case marked with Patented C.W.C. Co (Crescent Watch Case Co), PLANET (guaranteed to be made of two plates of Solid Gold), Crescent Moon, and Star (meaning that it is gold filled 10KT, guaranteed for 20 Years).

Anonymous Gift, 2004 2004/147
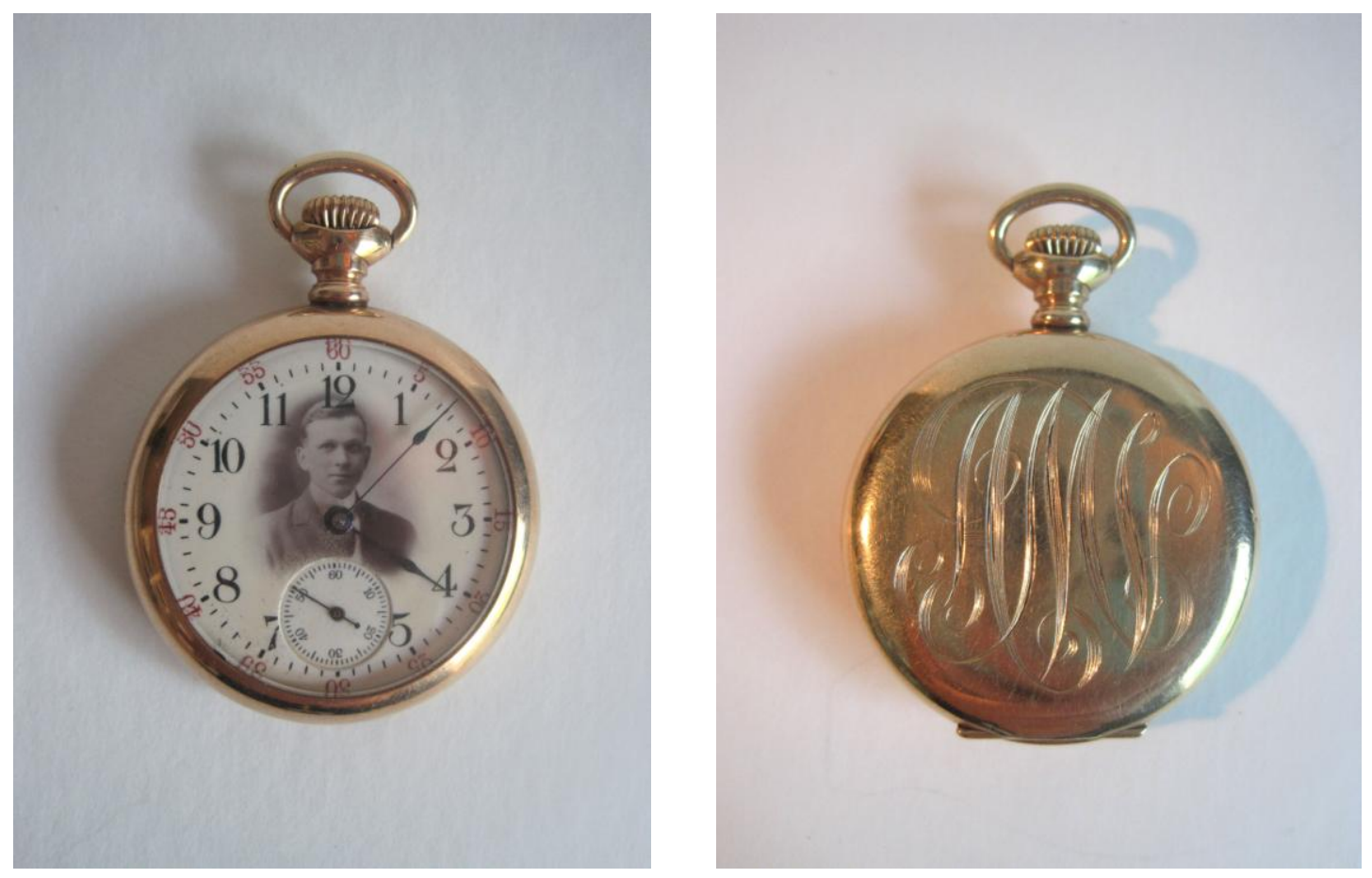


\section{Photographer Unknown \\ Manufacturer Unknown}

Pin [Portrait of a man with muttonchops]

c. 1900

Pin; brass; 1 gelatin silver print, red stones

Overall diameter (jewellery): $3 \times 4.2 \mathrm{~cm} \mathrm{(13/16 \times 15/8} \mathrm{in.)}$

Image: $2.2 \times 2.2 \mathrm{~cm}(7 / 8 \times 7 / 8$ in. $)$

This is an example of a small single portrait pin consisting of two red stones to the left and right of the photograph. The photograph is of a man with muttonchops looking off to his right. The pin has a simple brooch pin backing. Anonymous Gift, 2004

$2004 / 154$
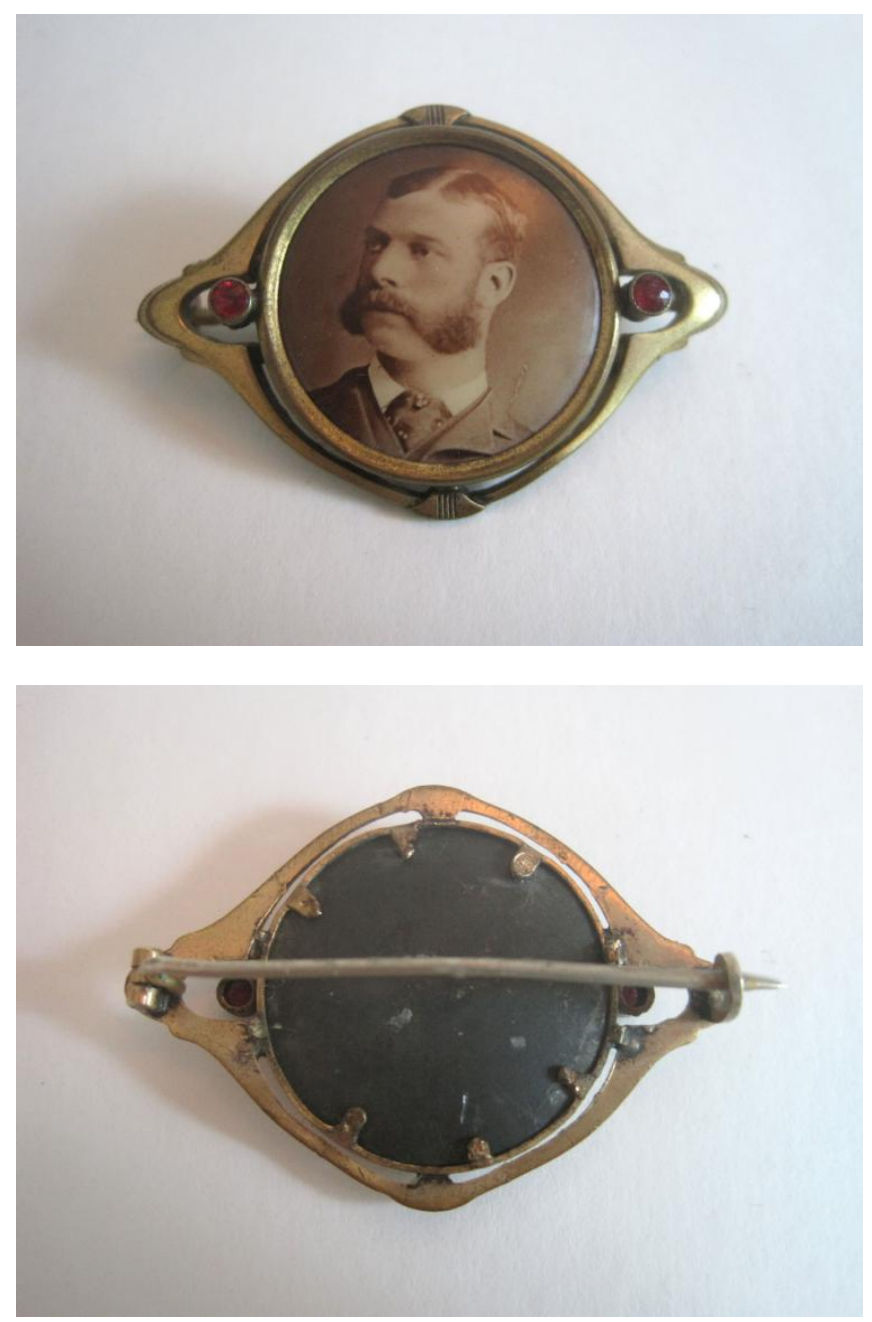


\section{Photographer Unknown}

\section{Manufacturer Unknown}

Pin [Portrait of a man, Portrait of a woman]

1890s

Pin; gold plated; 2 photographs attached: 2 bromide prints

Overall diameter (jewellery): $2.5 \times 3.8 \mathrm{~cm}(1 \times 11 / 2 \mathrm{in}$.)

Image (left): $1.4 \times 1.4 \mathrm{~cm}(9 / 16 \times 9 / 16 \mathrm{in}$.)

Image (right): $1.4 \times 1.4 \mathrm{~cm}(9 / 16 \times 9 / 16 \mathrm{in}$.)

This object displays a small double portrait within a gold plated simple brooch pin back setting. The pin has two bromide prints mounted side by side in a gold plated clover-leaf motif. One portrait is that of a man, and the other of a woman. Anonymous Gift, 2006 2006/189
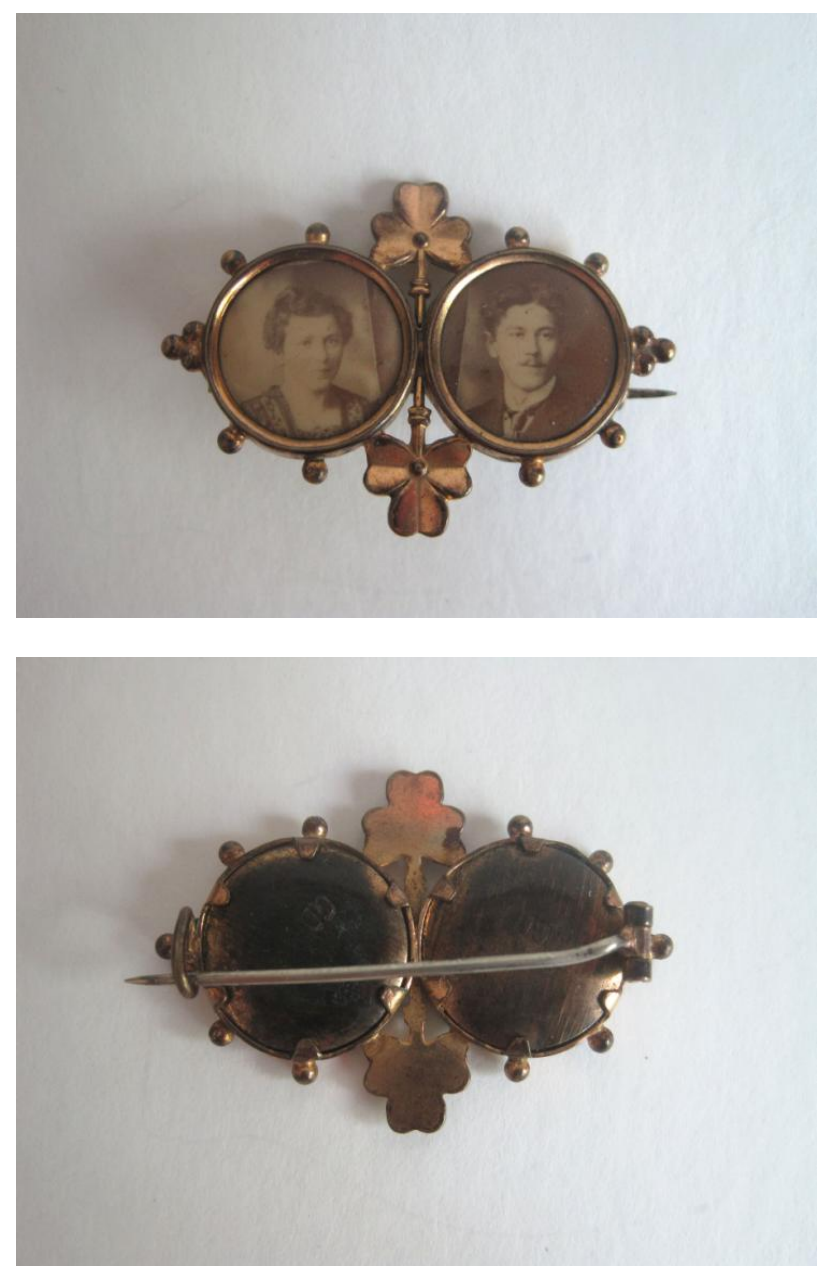


\section{CONCLUSION}

Photographic jewellery is a part of costume, photographic, visual, vernacular, and jewellery histories. They are mostly one-of-a-kind novelty and precious keepsakes that were made to display the affections for a loved one. Most institutions acquire their jewellery collection slowly over time, as family legacies end and personal property are abandoned or discarded. They are a part of a visual history that is treasured within museums and private collectors' care.

The intent of this practical thesis was to create a completed guide for cataloguing photographic jewellery within a collection. The structure of this report was to illustrate the issues that cataloguers are facing and the solutions that I have developed. This thesis will give future cataloguers and researchers in photographic jewellery a modern resource guide and vocabulary with which to catalogue. While every type of jewellery cannot be addressed, I have attempted to tackle the most common photographic processes and forms of jewellery.

Although further research can always be done within a topic, I am confident that this paper has provided a broad understanding of photographic jewellery to those who are interested. The guide will be of aid to anybody who desires to catalogue their collection, or use the guide to complete already existing records.

After completion of the cataloguing records at the Art Gallery of Ontario, I am certain that the guide and accompanying controlled vocabulary are complete and can be applied affectively. I will be sending out the complete guide and vocabulary to the institutions that responded to my institutional inquiry letter ${ }^{29}$

\footnotetext{
${ }^{29}$ Figure 12 which is available in the METHODOLOGY section.
} 
in hopes that they can implement it as a standard reference. The guide will be available for public use, accessible to any institution, collector, or individual with photographic jewellery.

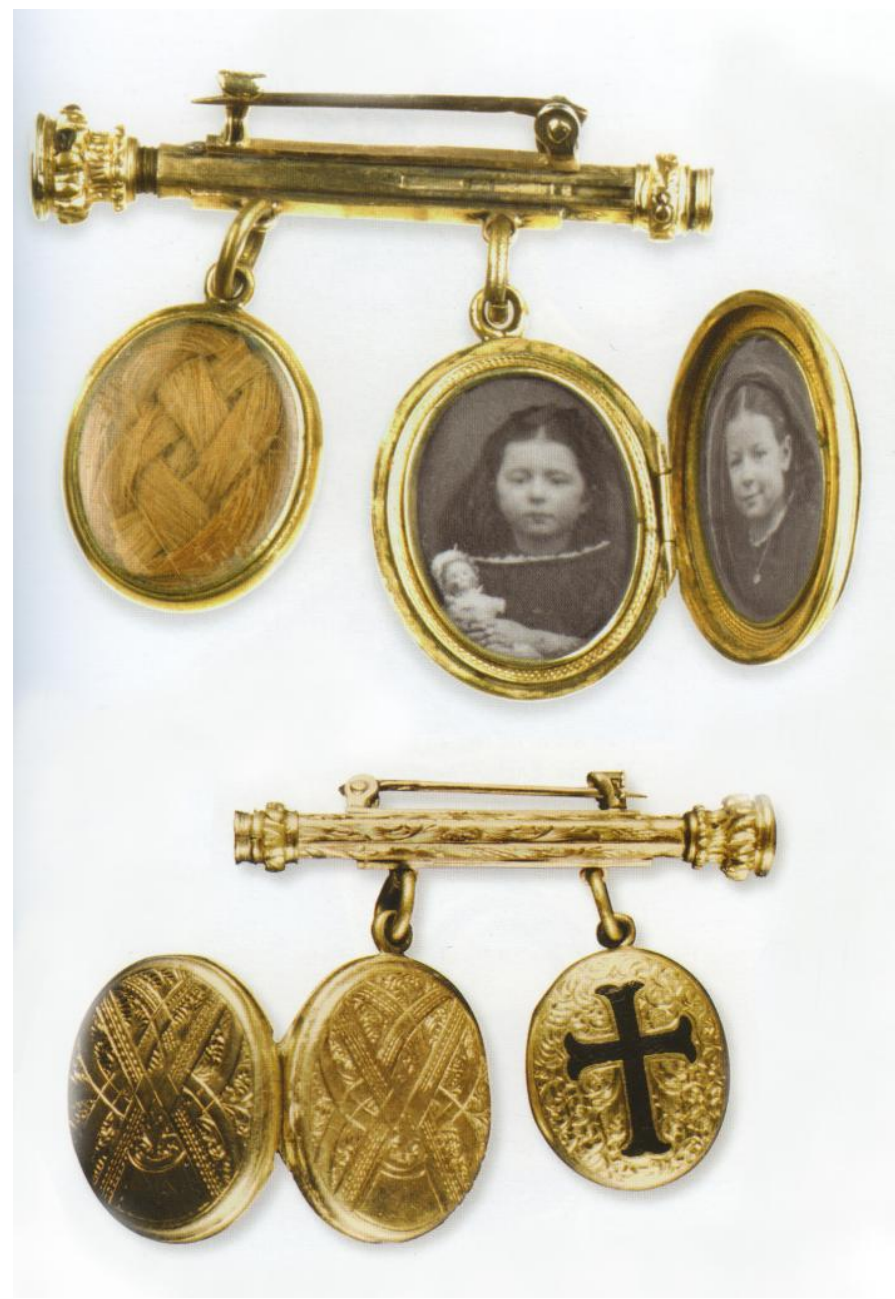

Figure 23

Source: Larry J. West's Antique Photographic Jewelry: Tokens of Affection and Regard, 2005 


\section{BIBLIOGRAPHY}

Abbott, Patricia, and Larry J. West. Antique Photographic Jewelry: Tokens of Affection and Regard. New York: West Companies, 2005.

Anonymous. Fashions in Jewelry Forty Years Ago, from "Jewelers Circular and Horological Review." February 3, 1892.

Banta, Melissa. A Curious \& Ingenious Art: Reflections on Daguerreotypes at Harvard. Massachusetts: Harvard University Press, 2000.

Batchen, Geoffrey. Each Wild Idea: Writing, Photography, History. Cambridge, Massachusetts: MIT Press, 2001.

- Forget me not: photography \& remembrance. New York: Princeton Architectural Press, 2004.

---------. "Ere the Substance Fade: Photography and Hair Jewellery." In Photographs Objects Histories: On the Materiality of Images, edited by Elizabeth Edwards and Janice Hart, 32-46. Florence, Kentucky: Routledge, 2004.

Bercaw, Nancy Dunlap. "Solid Objects/Mutable Meanings: Fancywork and the Construction of Bourgeois Culture, 1840-1880." Winterthur Portfolio 26, no. 4 (1991): 231-247.

Buck, Rebecca A., Jean Allman Gilmore, and American Association of Museums. MRM5: Museum Registration Methods 2011. Chicago, Illinois: American Library Association, 2011.

Evans, Joan. History of Jewellery, 1100-1870. Boston, Massachusetts: Boston Book and Art, 1970.

Falk, Patricia. Cataloguing outside the box: a practical guide to cataloguing special collections materials. Oxford: Chandos Publishing, 2010.

Frank, Robin Jaffee. Love and loss: American portrait and mourning miniatures. New Haven, Connecticut: Yale University Art Gallery, 2000. 
Goodwin, Sarah and Bronfen, Elisabeth. Death and Representation. Baltimore: Johns Hopkins University Press, 1993.

Gurney, Jeremiah. "Photography and the Law"' The American Journal of Photography 1, November 1, 1858.

Harping, Patricia. Introduction to Controlled Vocabularies: Terminology for Art, Architecture, and Other Cultural Works. Los Angeles, California: Getty Research Institute, 2010.

Henisch, Bridget and Heinz. The Photographic Experience 1839-1914. Pennsylvania: State University Press, 1994.

Hirsch, Robert. Seizing the Light: A History of Photography. New York: McGraw Hill, 2000.

Hughes, Lorna M. Digitizing Collections: Strategic Issues for the Information Manager. London: Facet, 2004.

Kaplan, Daile. Pop Photographica: photography's objects in everyday life, 1842-1969. Toronto: Art Gallery of Ontario, 2003.

Knapp, Bettina L. Perspectives on World Literature - - Death and Representation Edited by Sarah Webster Goodwin and Elisabeth Bronfed. Vol. 68. Norman: University of Oklahoma, 1994.

Kwint, Mraius, Christopher Breward, and Jeremy Aynsley. Material Memories. New York: Berg, 1999.

Leise, Fred. "Controlled Vocabularies: An Introduction." The Indexer 26, no.3 (2008): 121-126.

Lutek, Tasha Ann. "The Specimens Box: A Case Study in Cataloguing at George Eastman House" Master's thesis, Ryerson University, 2010.

Marilyn Gaull. "Things Forever Speaking" and "Objects of all Thought." The Wordsworth Circle 39, no. 1/2 (2008): 52.

McInturff, Jennifer. “Celluloid Buttons: Cataloguing Unusual Photographic 
Objects." Master's thesis, Ryerson University, 2009.

Newman, Harold. An Illustrated Dictionary of Jewelry. London: Thames and Hudson, 1981.

Ogden, Jack. The Intelligent Laymans Book of Golden Jewellery. New York: Il Pub, 2008.

Phillips, Clare, Vivienne Becker, Tiffany and Company, and Gilbert Collection. Bejeweled by Tiffany, 1837-1987. New Haven, Connecticut: Yale University Press, 2006.

Phillips, Clare. Jewels and Jewelry. New York: Watson-Guptill Publications, 2000.

Reibel, Daniel B. Registration Methods for the Small Museum. Toronto: AltaMira Press, 2008.

Tait, Hugh. 7000 Years of Jewelry. Richmond Hill, Ontario: Firefly Books, 2008.

Whittaker, Beth. Special Collections 2.0: New Technologies for Rare Books, Manuscripts, and Archival Collections. Santa Barbara, California: Libraries Unlimited, 2009.

Williams, Sarah Hue. Christie's Guide to Jewellery. New York: Assouline, 2001.

Wythe, Deborah.ed. Museum Archives: An Introduction. Chicago: The Society of American Archivists, 2004. 


\section{ILLUSTRATION CREDITS}

All figures in the Introduction, A Brief History of Photographic Jewellery, Photographic Jewellery Processes and Materials, Methodology, and Conclusion are all courtesy of Larry West and are available in his publication Antique Photographic Jewelry: Tokens of Affection and Regard (2005).

Figure 7 was taken by Grant Romer and is also available in Larry J. West's Antique Photographic Jewelry: Tokens of Affection and Regard (2005).

All figures within the AGO cataloguing records and Current AGO Photographic Jewellery Collection were digitized by myself within the Ryerson Hub.

All italicized descriptions used in the List of Illustrations were taken from Larry West's Antique Photographic Jewelry: Tokens of Affection and Regard (2005), as these objects are from his collection. 